\title{
Cooperative Photoredox- and Nickel-Catalyzed Alkylative Cyclization Reactions of Alkynes with 4-Alkyl-1,4-dihydropyridines
}

Yulin Zhang, Yoshiaki Tanabe, Shogo Kuriyama, and Yoshiaki Nishibayashi*

Department of Applied Chemistry, School of Engineering, The University of Tokyo, Tokyo 113-8656, Japan; E-mail: ynishiba@g.ecc.u-tokyo.ac.jp

\section{Table of Contents}

S1. X-ray crystallographic study

S2. Reaction in the presence of TEMPO

S3. Determination of quantum yields 
S1. X-ray crystallography study. Diffraction data for a crystal of (E)-1-(2-(2,2-dimethylcyclopentylidene)ethyl)naphthalene $((E)-3 i i)$ were collected for the $2 \theta$ range of $5.2^{\circ}$ to $62.6^{\circ}$ at $-180{ }^{\circ} \mathrm{C}$ on a Rigaku XtaLAB Synergy-S diffractometer equipped with a HyPix-6000HE Hybrid Photon Counting (HPC) detector and VariMax optics using multi-layer mirror monochromated Mo-K $\alpha(\lambda=$ $0.71073 \AA$ ) radiation, and VariMax optics. Intensity data were corrected for Lorentz and polarization effect and for empirical absorptions (CrysAlisPro), ${ }^{\mathrm{S} 1}$ while structure solutions and refinements were carried out by using CrystalStructure package. ${ }^{\mathrm{S} 2}$ Positions of non-hydrogen atoms were determined by direct methods (SHELXS Version 2013/1), ${ }^{\text {S3 }}$ and subsequent Fourier syntheses (SHELXL Version 2016/6), ${ }^{\text {S4 }}$ and were refined on $F_{\mathrm{o}}{ }^{2}$ with all the unique reflections by full-matrix least squares with anisotropic thermal parameters. All the hydrogen atoms were placed at the calculated positions with fixed isotropic parameters. Anomalous dispersion effects were included in $F_{\mathrm{c}}$, 5 and mass attenuation coefficients, values for $\Delta f^{\prime}$ and $\Delta f^{\prime \prime}$, and neutral atom scattering factors were taken from references. ${ }^{\text {S6-S8 }}$ Details of the crystal and data collection parameters of $(E)$-3ii are summarized in Table S1. ORTEP drawing of $(E)-3 i i$ is shown in Figure $\mathrm{S} 1$.

Table S1. Crystallographic Data for $(E)-3$ ii.

\begin{tabular}{|c|c|}
\hline compound & $(E)-3 i i$ \\
\hline chemical formula & $\mathrm{C}_{19} \mathrm{H}_{22}$ \\
\hline CCDC number & 2061338 \\
\hline formula weight & 250.38 \\
\hline crystal size, $\mathrm{mm}^{3}$ & $0.123 \times 0.056 \times 0.040$ \\
\hline crystal color, habit & colorless, block \\
\hline temperature, ${ }^{\circ} \mathrm{C}$ & -180 \\
\hline crystal system & monoclinic \\
\hline space group & $P 2_{1} / c($ no. 14$)$ \\
\hline$a, \AA$ & $6.9419(4)$ \\
\hline$b, \AA$ & $15.5787(8)$ \\
\hline$c, \AA$ & $13.4022(8)$ \\
\hline$\alpha, \operatorname{deg}$ & 90 \\
\hline$\beta, \operatorname{deg}$ & $91.814(6)$ \\
\hline$\gamma, \operatorname{deg}$ & 90 \\
\hline$V, \AA^{3}$ & $1448.66(14)$ \\
\hline$Z$ & 4 \\
\hline$d_{\text {calcd }}, \mathrm{g}, \mathrm{cm}^{-3}$ & 1.148 \\
\hline$F(000)$ & 544 \\
\hline$\mu, \mathrm{cm}^{-1}$ & 6.41 \\
\hline transmission factors range & $0.163-0.997$ \\
\hline number of measured reflections & 13165 \\
\hline number of unique reflections & 3920 \\
\hline number of refined parameters & 174 \\
\hline$R_{\text {int }}$ & 0.01192 \\
\hline$R 1(I>2 \sigma(I))^{a}$ & 0.0636 \\
\hline$w R 2$ (all data) ${ }^{b}$ & 0.1183 \\
\hline $\mathrm{GOF}^{c}$ & 1.000 \\
\hline maximum residual peak / hole, e $\AA^{-3}$ & $+0.18 /-0.19$ \\
\hline
\end{tabular}




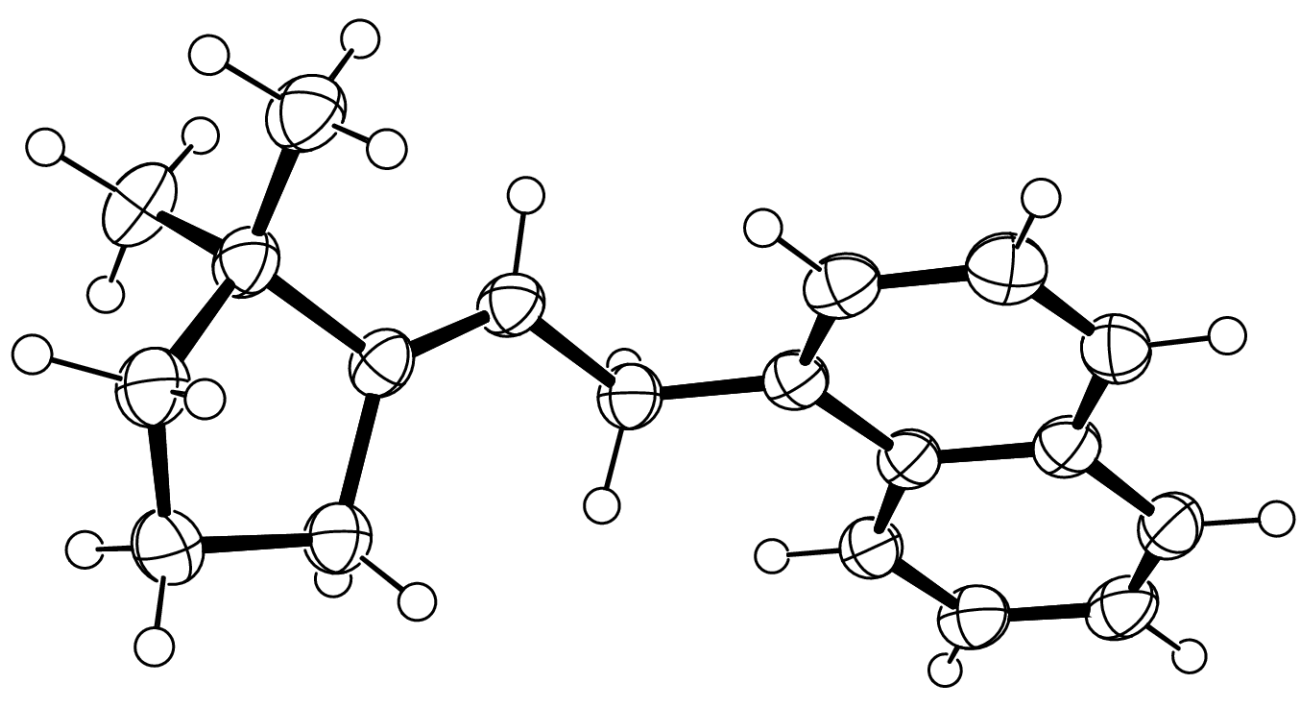

Figure S1. ORTEP drawing of $(E)$-3ii. Thermal ellipsoids of carbon atoms are drawn at the $50 \%$ probability level.

S2. Reaction of 1 a with $2 \mathrm{a}$ in the presence of TEMPO. In a $20 \mathrm{~mL}$ Schlenk flask were placed 6-iodohex-1-yne (1a) $\quad(50.3 \quad \mathrm{mg}$. $0.242 \mathrm{mmol})$, diethyl 4-benzyl-2,6-dimethyl-1,4-dihydropyridine-3,5-dicarboxylate (2a) (257 mg, 0.749 mmol), (2,2,6,6-tetramethylpiperidin-1-yl)oxyl (TEMPO) (117 mg, $0.748 \mathrm{mmol}$ ), fac-[Ir(ppy) 3$]$ (ppy = 2-(2-pyridyl)phenyl) $(3.4 \mathrm{mg}, 0.0052 \mathrm{mmol})$, anhydrous $\mathrm{NiCl}_{2}$ (3.4 mg, $0.026 \mathrm{mmol}$ ), dMeObpy (dMeObpy = 4,4'-dimethoxyl-2,2'-bipyridine) (8.2 $\mathrm{mg}, 0.038 \mathrm{mmol})$ and $\mathrm{Cs}_{2} \mathrm{CO}_{3}(122 \mathrm{mg}, 0.374 \mathrm{mmol})$ under $\mathrm{N}_{2}$, where 1,4-dioxane $(2.5 \mathrm{~mL})$ was added at room temperature. The reaction flask was placed in an As One LTB-125 constant low temperature water bath set at $25{ }^{\circ} \mathrm{C}$, and was illuminated from the bottom of the bath with an Aitech System TMN100×120-22WD 12 W white LED lamp (400 $\mathrm{nm}$ to $750 \mathrm{~nm}$ ) at a distance of approximately $2 \mathrm{~cm}$ from the light source for $24 \mathrm{~h}$. The volatiles were removed in vacuo, and the crude yield of 1-(benzyloxy)-2,2,6,6-tetramethylpiperidine (6a) (0.167 mmol, 69\% NMR yield based on the amount of 1a) was determined by ${ }^{1} \mathrm{H} \mathrm{NMR}$ in $\mathrm{CDCl}_{3}$, where 1,1,2,2-tetrachloroethane $(42.1 \mathrm{mg}, 0.251 \mathrm{mmol})$ was added as an internal standard (Scheme S1).

\section{Scheme S1}

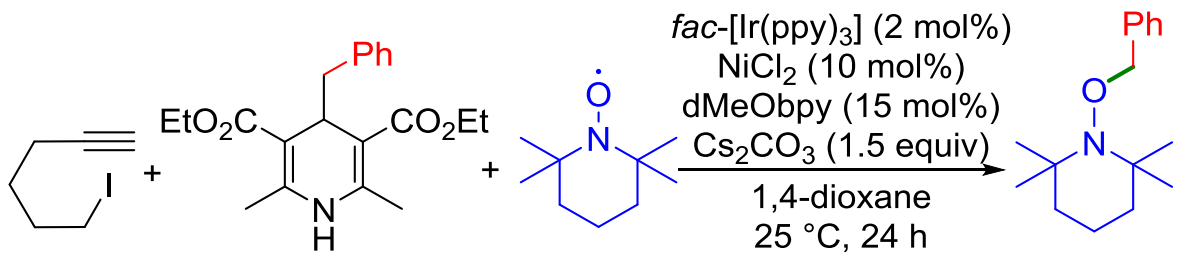

$1 \mathbf{a}$

2a (3 equiv) TEMPO ( 3 equiv)

visible light

$6 a, 69 \%$ 
S3. Determination of quantum yields. In a $20 \mathrm{~mL}$ Schlenk flask were placed 6-iodohex-1-yne (1a) $\quad(50.1 \quad \mathrm{mg} . \quad 0.241 \quad \mathrm{mmol}), \quad$ diethyl 4-benzyl-2,6-dimethyl-1,4-dihydropyridine-3,5-dicarboxylate (2a) (257 mg, 0.749 $\mathrm{mmol}), f a c$-[ $\left.\operatorname{Ir}(\mathrm{ppy})_{3}\right]$ (ppy = 2-(2-pyridyl)phenyl) $(3.4 \mathrm{mg}, 0.0052 \mathrm{mmol})$, anhydrous $\mathrm{NiCl}_{2}$ (3.4 mg, $0.026 \mathrm{mmol}$ ), dMeObpy (dMeObpy = 4,4'-dimethoxyl-2,2'-bipyridine) (8.1 mg, $0.037 \mathrm{mmol})$ and $\mathrm{Cs}_{2} \mathrm{CO}_{3}(120 \mathrm{mg}, 0.370 \mathrm{mmol})$ under $\mathrm{N}_{2}$, where 1,4-dioxane $(2.5 \mathrm{~mL})$ was added at room temperature. The reaction flask was illuminated from the side with an Ushio SX-U1251HQ ultrahigh pressure $250 \mathrm{~W} \mathrm{Hg}$ lamp equipped with a 440-nm band pass filter (Kenko B440) at a distance of approximately $0 \mathrm{~cm}$ from the light source for $1.5 \mathrm{~h}$. The volatiles were removed in vacuo, and the crude yield of (2-cyclopentylideneethyl)benzene (3aa) $(0.0475 \mathrm{mmol}$, $20 \%$ NMR yield based on the amount of 1a) was determined by ${ }^{1} \mathrm{H} \mathrm{NMR} \mathrm{in} \mathrm{CDCl}_{3}$, where 1,1,2,2-tetrachloroethane $(42.0 \mathrm{mg}, 0.250 \mathrm{mmol}$ ) was added as an internal standard. Independently, the yields of 3aa were determined by terminating the reactions at 0.5 and $1.0 \mathrm{~h}$, which clarified a zero-order reaction rate at $(8.89 \pm 0.20) \times$ $10^{-9} \mathrm{~mol} \mathrm{~s}^{-1}$ (Figure S2). The irradiated light intensity to a $2.5 \mathrm{~mL}$ solution in $50-\mathrm{mL}$ Schlenk was estimated to be $1.41 \times 10^{-7} \mathrm{E} \mathrm{s}^{-1}$ at $440 \mathrm{~nm}$ by using $\mathrm{K}_{3}\left[\mathrm{Fe}\left(\mathrm{C}_{2} \mathrm{O}_{4}\right)_{3}\right]$ as a chemical actinometer. ${ }^{\text {S9 }}$ Thus, the quantum yield of the photoredox- and nickel-catalyzed reaction of 1a with 2a to afford 3aa is given as $\Phi=0.0630 \pm 0.0014$.

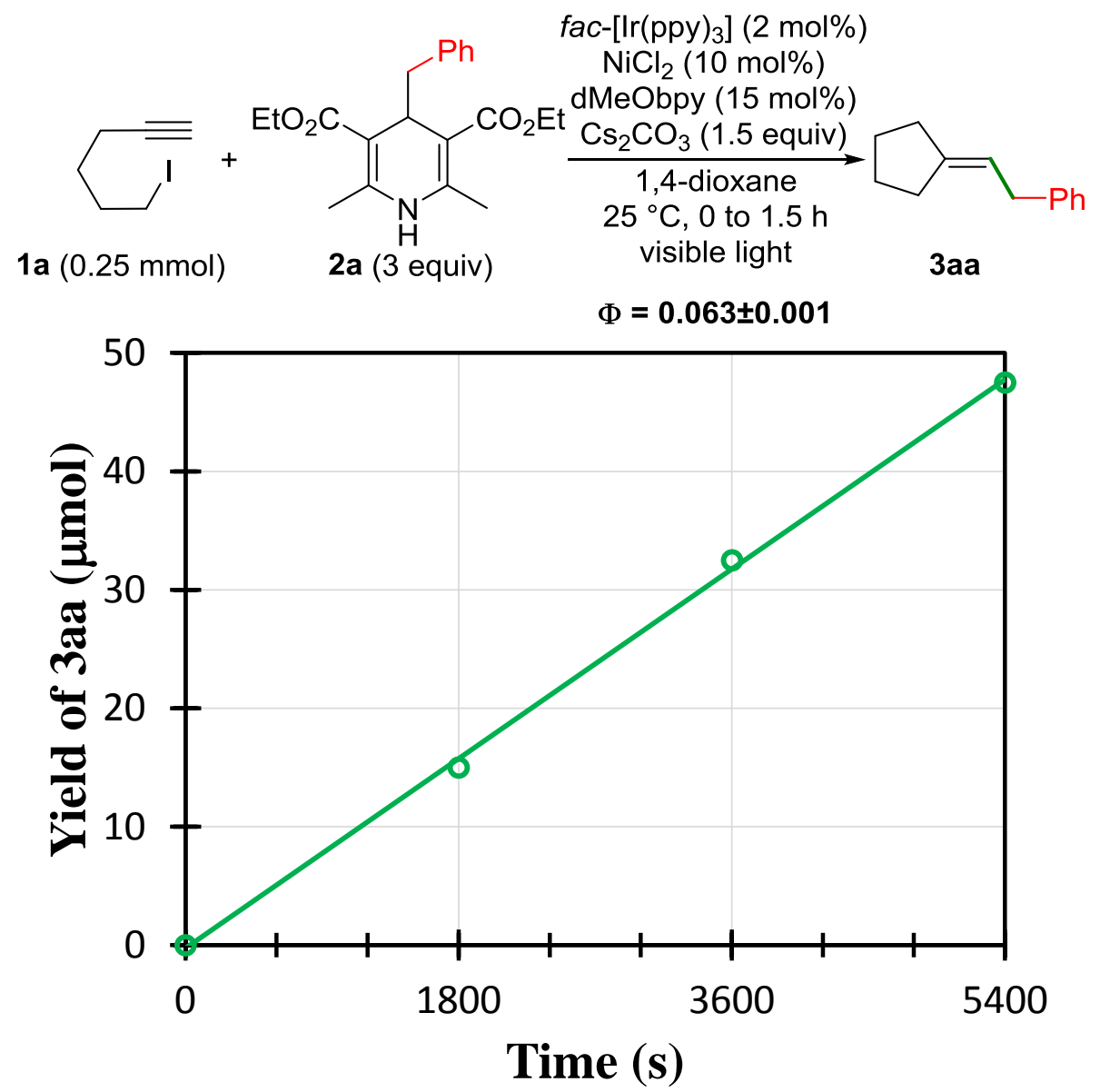

Figure S2. Time-dependent yields of 3aa. 
Similarly, quantum yields of other reactions shown in Scheme S2 were determined by quantitative measurements of gas chromatography-mass spectroscopy (GC-MS) recorded on a Shimadzu GCMS-QP2010 PLUS instrument, where 1,1,2,2-tetrachloroethane was added as an internal standard.

\section{Scheme S2}

A)

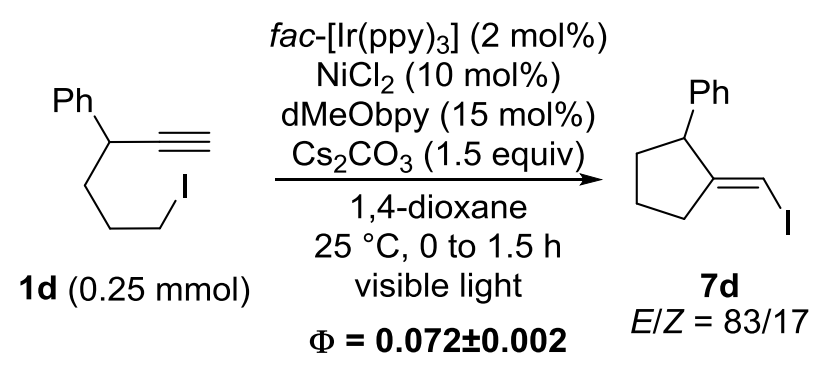

B)

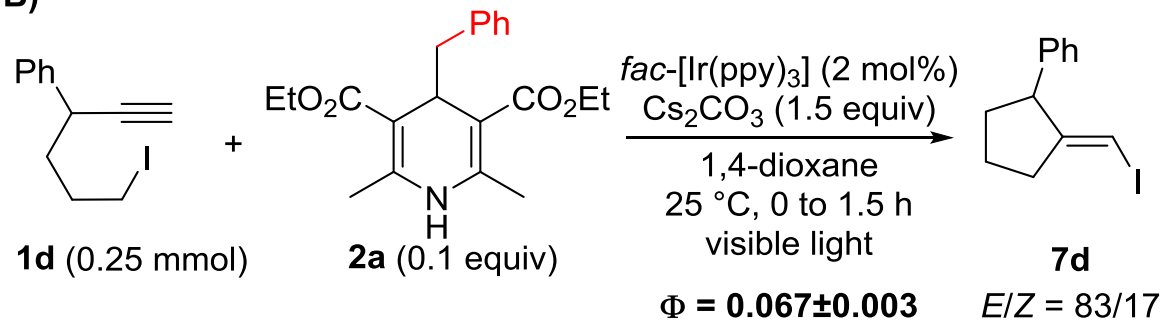

C)

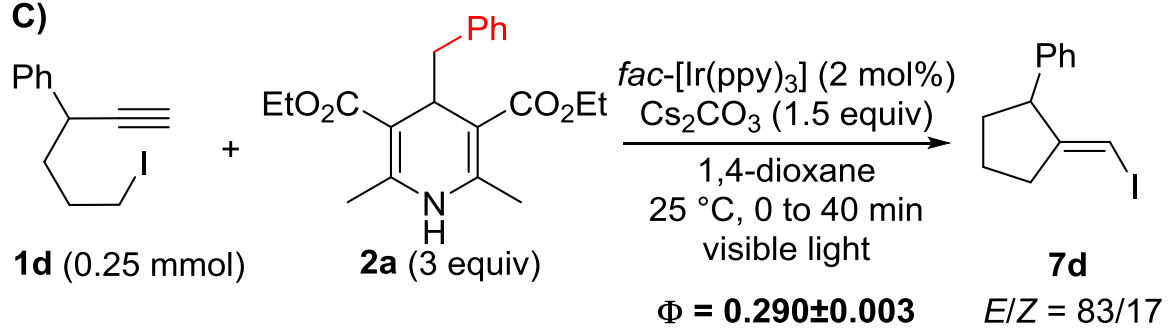

D)<smiles>[R]C(Cc1ccccc1)=C1CCCC1[R]</smiles>
$(0.25 \mathrm{mmol})$ $\Phi=0.028 \pm 0.001$ 
S4. Stern-Volmer analysis. Luminescence quenching experiments for the 1,4-dioxane solution of $f a c$-[Ir(ppy $\left.)_{3}\right](2.0 \mu \mathrm{mol} / \mathrm{L}$, prepared by stepwise dilutions of fac-[Ir(ppy) $\left.)_{3}\right](1.3 \mathrm{mg}, 2.0 \mu \mathrm{mol})$ with 1,4-dioxane) with 1a, (iodohex-1-yl)benzene (1d), or 2a in selected concentrations were performed on a Shimadzu RF-5300PC spectrophotometer, where the solutions containing $f a c-\left[\operatorname{Ir}(\mathrm{ppy})_{3}\right]$ and 1a, 1d, or 2a were excited at $\lambda_{\max }=440 \mathrm{~nm}$, and emissions were measured at $\lambda=494 \mathrm{~nm}$.

From the slopes $(28.9 \pm 2.9$ for $\mathbf{1 a}, 27.5 \pm 2.9$ for $\mathbf{1 d}$, and $138 \pm 14$ for $\mathbf{2 a})$ obtained by the plot and the excited-state lifetime of $f a c-\left[\operatorname{Ir}(\mathrm{ppy})_{3}\right](\tau=1.90 \mu \mathrm{s}),{ }^{\mathrm{S} 10}$ the rate constants for the reduction of $\mathbf{1 a}$ or $\mathbf{1 d}$, and the oxidation of $\mathbf{2 a}$ were calculated to be at $k=(1.5 \pm 0.2) \times 10^{7} \mathrm{M}^{-1} \mathrm{~s}^{-1}$ (1a), $k=(1.4 \pm 0.2) \times 10^{7} \mathrm{M}^{-1} \mathrm{~s}^{-1}(\mathbf{1 d})$, and $k=(7.3 \pm 0.7)$ $\times 10^{7} \mathrm{M}^{-1} \mathrm{~s}^{-1}(\mathbf{2 a})$, respectively (Figure S3).

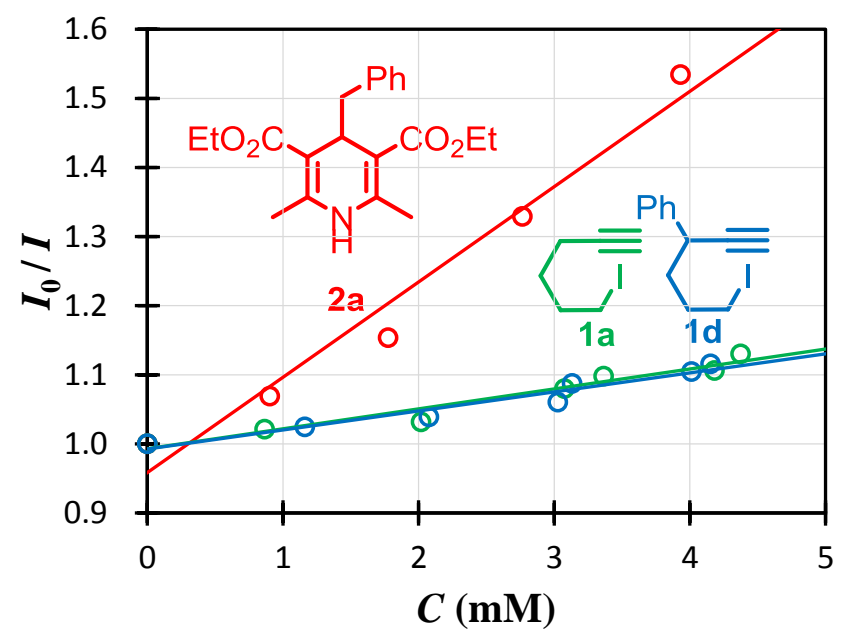

Figure S3. Stern-Volmer plot for the emission quenching of $f a c$-[ $\left.\operatorname{Ir}(\mathrm{ppy})_{3}\right]$. 
S5. Light on/off experiment. In a $20 \mathrm{~mL}$ Schlenk flask were placed 6-iodohex-1-yne $(52.0$ mg. 0.250 mmol), diethyl 4-benzyl-2,6-dimethyl-1,4-dihydropyridine-3,5-dicarboxylate (2a) (257 mg, 0.749 $\mathrm{mmol}), f a c$-[ $\left.\operatorname{Ir}(\mathrm{ppy})_{3}\right]$ (ppy = 2-(2-pyridyl)phenyl) $(3.4 \mathrm{mg}, 0.0052 \mathrm{mmol})$, anhydrous $\mathrm{NiCl}_{2}$ (3.4 mg, $0.026 \mathrm{mmol}$ ), dMeObpy (dMeObpy = 4,4'-dimethoxyl-2,2'-bipyridine) (8.2 mg, $0.038 \mathrm{mmol}), \mathrm{Cs}_{2} \mathrm{CO}_{3}(123 \mathrm{mg}, 0.378 \mathrm{mmol}$ ), and octane (28.5 mg, 0.249 mmol, added as an internal standard) under $\mathrm{N}_{2}$, where 1,4-dioxane $(2.5 \mathrm{~mL})$ was added at room temperature. The reaction flask was placed in an As One LTB-125 constant low temperature water bath set at $25{ }^{\circ} \mathrm{C}$. The reaction was conducted for 8 $\mathrm{h}$ under alternating periods of (1) irradiation from the bottom of the bath with an Aitech System TMN100×120-22WD $12 \mathrm{~W}$ white LED lamp (400 nm to $750 \mathrm{~nm}$ ) at a distance of approximately $2 \mathrm{~cm}$ from the light source, and (2) darkness with the reaction vessel wrapped with aluminum foil, where yields of 3aa were determined every hour by quantitative measurements of gas chromatography-mass spectroscopy (GC-MS) recorded on a Shimadzu GCMS-QP2010 PLUS instrument (Figure S4).

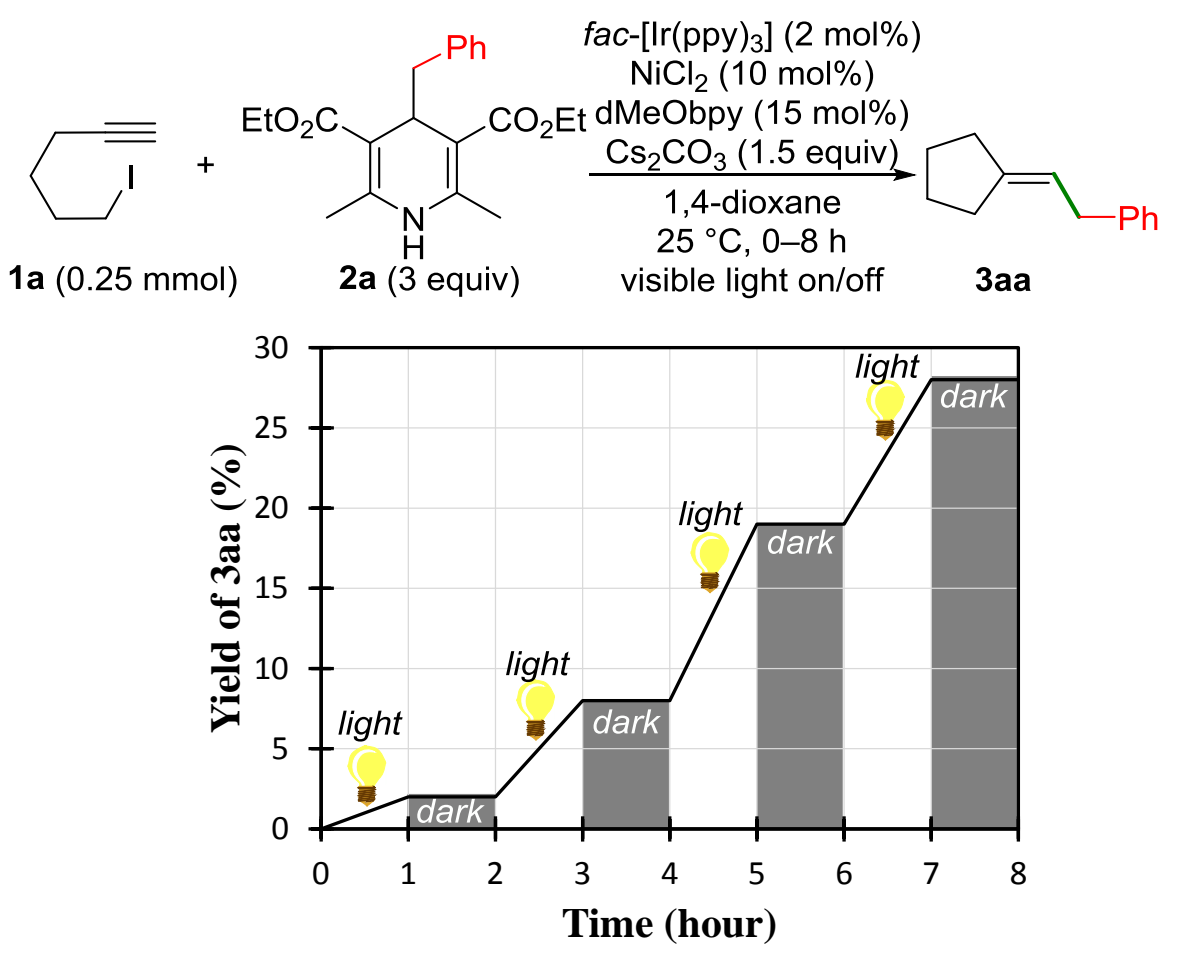

Figure S4. Time profile for the formation of 3aa with and without visible light irradiation. 
S6. Time profile experiment. In a $20 \mathrm{~mL}$ Schlenk flask were placed (6-iodohex-1-yl)benzene (1d) (71.1 mg. $0.250 \mathrm{mmol}), 2 \mathrm{a}$ (256 mg, $0.746 \mathrm{mmol})$, fac-[Ir(ppy) $)_{3}$ (3.4 mg, $\left.0.00532 \mathrm{mmol}\right)$, anhydrous $\mathrm{NiCl}_{2}(3.3 \mathrm{mg}, 0.025 \mathrm{mmol})$, dMeObpy (8.3 mg, $0.038 \mathrm{mmol}), \mathrm{Cs}_{2} \mathrm{CO}_{3}(122 \mathrm{mg}, 0.375 \mathrm{mmol}$ ), and methyl 4-methoxybenzoate (41.5 mg, $0.250 \mathrm{mmol}$, added as an internal standard), under $\mathrm{N}_{2}$, where 1,4-dioxane $(2.5 \mathrm{~mL})$ was added at room temperature. The reaction flask was placed in an As One LTB-125 constant low temperature water bath set at $25{ }^{\circ} \mathrm{C}$, and was illuminated from the bottom of the bath with an Aitech System TMN100 $\times 120$ 22WD $12 \mathrm{~W}$ white LED lamp (400 $\mathrm{nm}$ to $750 \mathrm{~nm}$ ) at a distance of approximately 2 $\mathrm{cm}$ from the light source. Yields of (2-(2-phenylcyclopentylidene)ethyl)benzene (3da) as well as ((2-(iodomethylene)cyclopentyl)benzene) (7d) at selected times $(0.5$, $1,2,4,8,12$, and $24 \mathrm{~h}$ ) were determined by quantitative measurements of GC-MS (Figure S5).

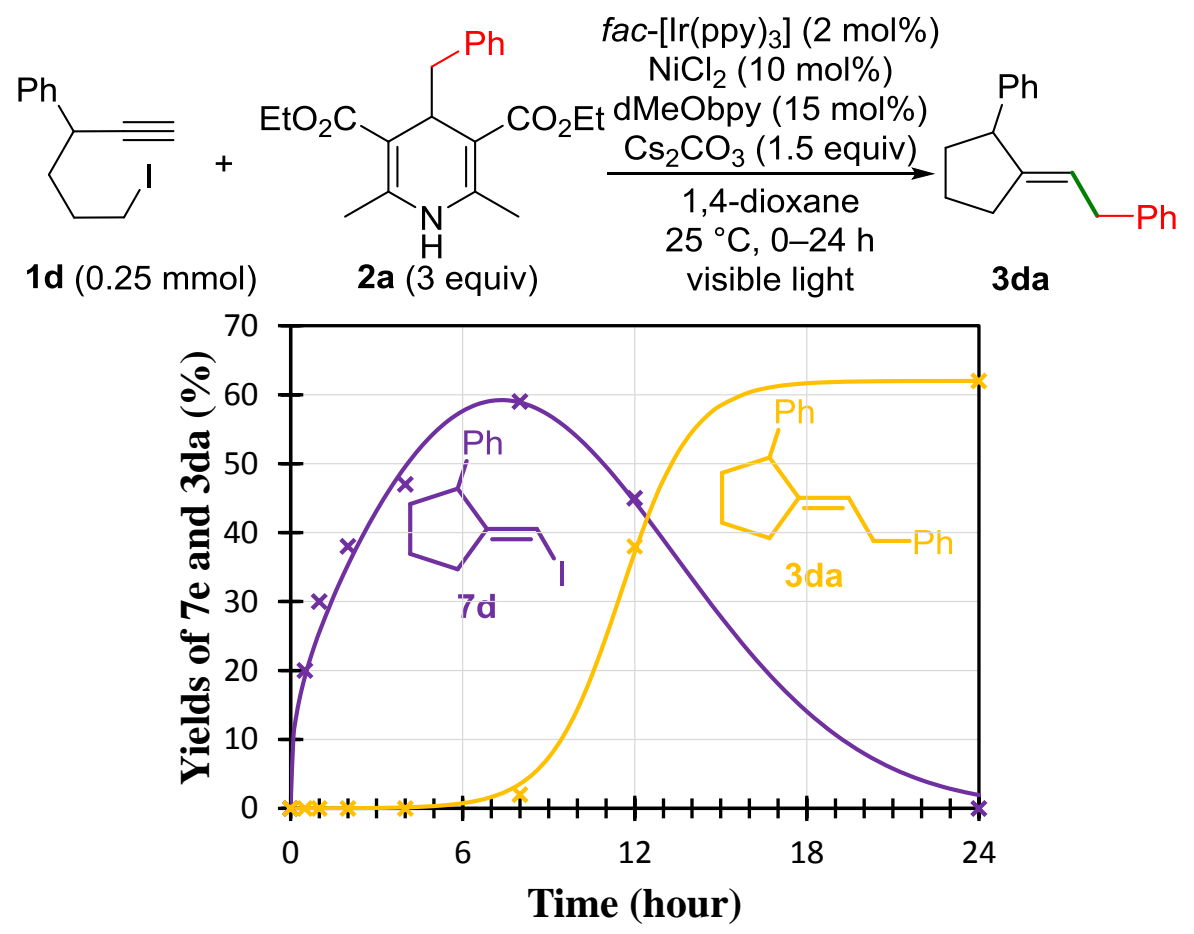

Figure S5. Time profile for the formation of $\mathbf{3 d a}$ with the formation of $\mathbf{7 d}$ as a reactive intermediate. 
S7. Transformation reaction of a mixture of $(\boldsymbol{E})$ - and $(\boldsymbol{Z})$-isomers. In a $20 \mathrm{~mL}$ Schlenk flask were placed 3da $(Z / E=84 / 16,24.8 \mathrm{mg}, 0.100 \mathrm{mmol}), 2 a(103 \mathrm{mg}$, $0.299 \mathrm{mmol})$, fac- $\operatorname{Ir}(\mathrm{ppy})_{3}(1.4 \mathrm{mg}, 0.0021 \mathrm{mmol})$, anhydrous $\mathrm{NiCl}_{2}(1.4 \mathrm{mg}, 0.011$ $\mathrm{mmol}$ ), dMeObpy (3.3 mg, $0.015 \mathrm{mmol}$ ), and $\mathrm{Cs}_{2} \mathrm{CO}_{3}$ (49.1 mg, $0.151 \mathrm{mmol}$ ) under $\mathrm{N}_{2}$, where 1,4-dioxane $(1.0 \mathrm{~mL})$ was added at room temperature. The reaction flask was placed in an As One LTB-125 constant low temperature water bath set at $25{ }^{\circ} \mathrm{C}$, and was illuminated from the bottom of the bath with an Aitech System TMN100 $\times 120-22 \mathrm{WD} 12 \mathrm{~W}$ white LED lamp $(400 \mathrm{~nm}$ to $750 \mathrm{~nm})$ at a distance of approximately $2 \mathrm{~cm}$ from the light source for $24 \mathrm{~h}$. After the reaction, the $Z / E$ ratio of $4 \mathbf{a}$ was determined to be $84 / 16$ by quantitative measurements of GC-MS, by adding methyl 4-methoxybenzoate $(41.5 \mathrm{mg}, 0.250 \mathrm{mmol})$ to the reaction mixture as an internal standard (Scheme S3).

\section{Scheme S3}

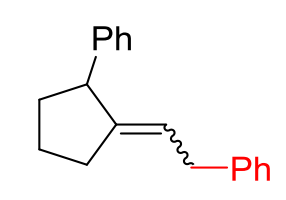

$1 d(0.10 \mathrm{mmol})$

$Z / E=84 / 16$

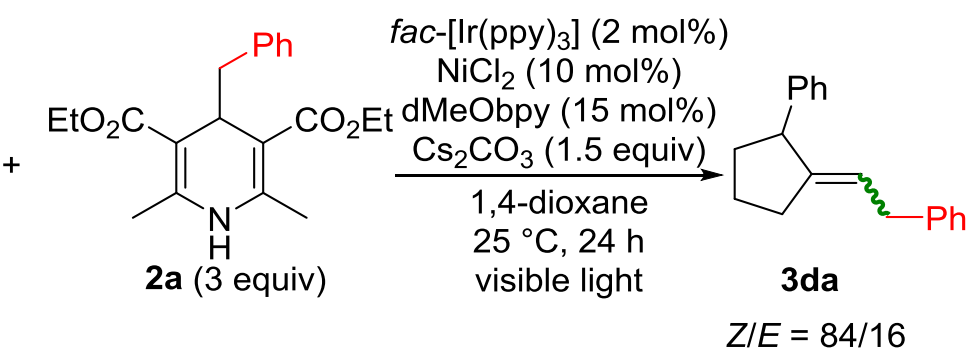


S8. Plausible reaction pathways for the conversion of $1 \mathrm{~d}$ into $\mathbf{7 d}$. A mixture of 7d $(Z / E=84 / 16)$ was obtained from the cyclization reaction of 1d: (A) in the presence of a catalytic amount of $\mathbf{2 a}$ but in the absence of $\mathrm{NiCl}_{2} / \mathrm{dMeObpy}$ or (B) in the absence of 2a but in the presence of a catalytic amount of $\mathrm{NiCl}_{2} / \mathrm{dMeObpy}$. In both cases, conversion of 1a into 7a completely or almost did not take place in the absence of $f a c$-[ $\left.\operatorname{Ir}(\mathrm{ppy})_{3}\right]$, demonstrating that the iridium photoredox catalyst always play a key role. Thus, the initial cyclization reaction can proceed via following possible three pathways.

A: In the presence of photoredox and 4-alkyl-1,4-dihydropyridine catalysts, where propagation cycle is initiated by the photoredox catalyst (Scheme S4). Cyclization of alkyl iodide has been known to proceed by several radical initiators ${ }^{\mathrm{S} 11}$ or photoredox catalysts. ${ }^{\mathrm{S} 12, \mathrm{~S} 13}$ The reaction pathway depicted here follows the one reported by Martin and co-workers. ${ }^{\text {S12 }}$ However in contrast to their proposals, possibility of the formation of exciplex complex with 1d is rather excluded, because $f a c-\left[\operatorname{Ir}(\text { ppy })_{3}\right]$ is the only photosensitizer that can absorb visible light in this reaction. At the same time, quenching of propagation cycle should frequently occur by the termination with the photoredox catalyst or with alkyl radicals based on the observation of a low quantum yield.

\section{Scheme S4}

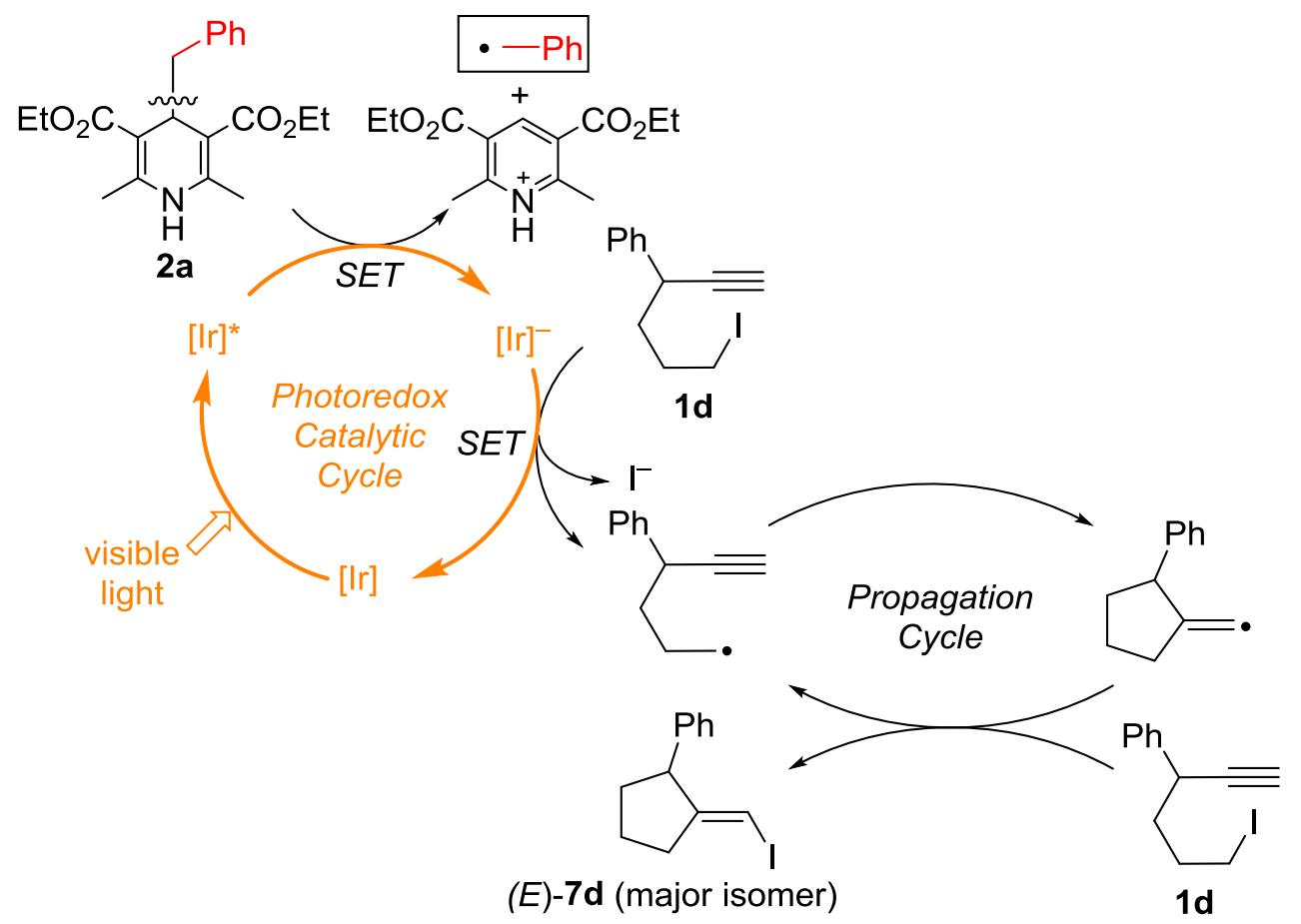

B.1: In the presence of photoredox and nickel catalysts, where propagation cycle is initiated by the photoredox catalyst (Scheme S5). This also depicted based on the proposals by Martin and co-workers, ${ }^{\mathrm{S} 12}$ where possibility of the formation of exciplex complex with $\mathbf{2 a}$ or benzyl radical-initiated propagation cycle are excluded, because 2a did not work as a photosensitizer, nor formation of benzyl iodide was observed for the crude mixtures. At the same time, quenching of chain propagation should 
frequently occur by the termination with the photoredox catalyst or alkyl radicals based on the observation of a low quantum yield.

\section{Scheme S5}

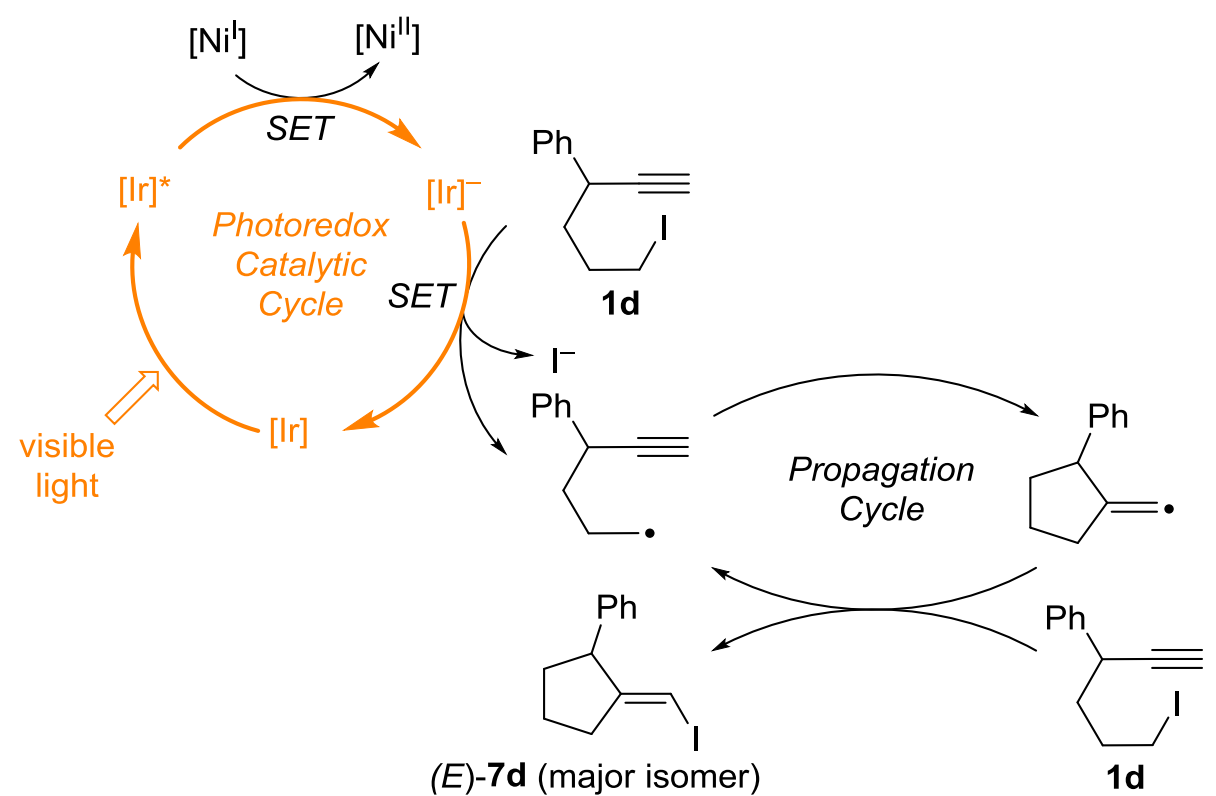

B.2: In the presence of photoredox and nickel catalysts, where both catalysts participate in the cyclization reaction (Scheme S6). Here the oxidative addition of 1d and reductive elimination of $\mathbf{7 d}$ are shown at the $\mathrm{Ni}(\mathrm{I}) / \mathrm{Ni}(\mathrm{III})$ cycle based on the recent work by Nocera and co-workers for the iridium photoredox and $\mathrm{NiCl}_{2}(\mathrm{dtbbpy})$ catalytic systems, ${ }^{\mathrm{S} 14}$ whereas $\mathrm{Ni}(0) / \mathrm{Ni}(\mathrm{II})$ cycle can be also possible.

\section{Scheme S6}

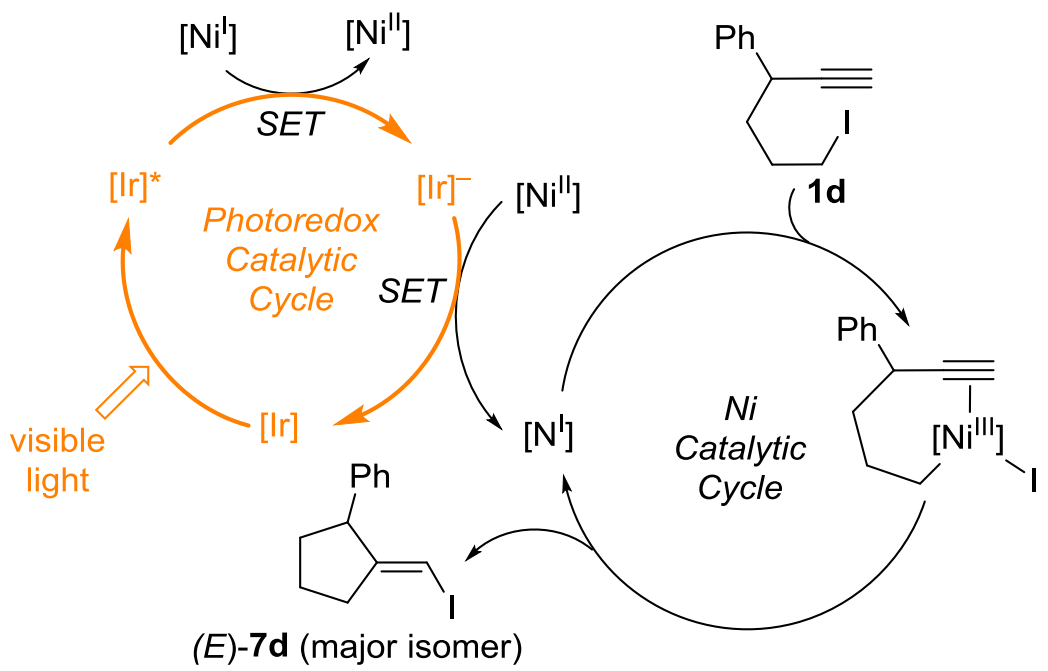




\section{S9. References}

S1 CrysAlisPro, Data Collection and Processing Software; Rigaku Corporation: Tokyo, Japan, 2015.

S2 CrystalStructure, version 4.3; Crystal Structure Analysis Package; Rigaku Corporation: Tokyo, Japan, 2015.

S3 Sheldrick, G. M. A short history of SHELX. Acta Crystallogr., Sect. A: Found. Crystallogr. 2008, A64, 112-122.

S4 Sheldrick, G. M. Crystal structure refinement wish SHELXL. Acta Crystallogr., Sect. C: Struct. Chem. 2015, C71, 3-8.

S5 Ibers, J. A.; Hamilton, W. C. Dispersion corrections and crystal structure refinements. Acta Crystallogr. 1964, 17, 781-782.

S6 Creagh D. C.; Hubbell, J. H. Table 4.2.4.3. Mass attenuation coefficients $\left(\mathrm{cm}^{2} \mathrm{~g}^{-1}\right)$. In International Tables for Crystallography, Wilson, A. J. C., Ed.; Kluwer Academic Publishers: Dordrecht, The Netherlands, 1992; vol. C, pp. 200-206.

S7 Creagh, D. C.; McAuley, W. J. Table 4.2.6.8. Dispersion corrections for forward scattering. In International Tables for Crystallography, Wilson, A. J. C., Ed.; Kluwer Academic Publishers: Dordrecht, The Netherlands, 1992; vol. C, pp. 219222.

S8 Maslen, E. N.; Fox, A. G.; O’Keefe, M. A. Table 6.1.1.4. Coefficients for analytical approximation to the scattering factors of Tables 6.1.1.1 and 6.1.1.3. In International Tables for Crystallography, Wilson, A. J. C., Ed.; Kluwer Academic Publishers: Dordrecht, The Netherlands, 1992; vol. C, pp. 500-503.

S9 Hatchard, C. G.; Parker, C. A. A new sensitive chemical actinometer II. Potassium ferrioxalate as a standard chemical actinometer. Proc. R. Soc. London, Ser. A 1956, $235,518-536$.

S10 Dixon, I. M.; Collin, J.-P.; Sauvage, J.-P.; Flamigni, L.; Encinas, S.; Barigelletti, F. A family of luminescent coordination compounds: iridium(III) polyimine complexes. Chem. Soc. Rev. 2000, 29, 385-391.

S11 Curran, D. P.; Chen, M.-H.; Kim, D. Atom Transfer Cyclization Reactions of Hex-5-ynyl Iodides: Synthetic and Mechanistic Studies. J. Am. Chem. Soc. 1989, $111,6265-6276$.

S12 Shen, Y.; Cornella, J.; Juliá-Hernández, F.; Martin, R. Visible-Light-Promoted Atom Transfer Radical Cyclization of Unactivated Alkyl Iodides. ACS Catal. 2017, 7, 409-412.

S13 Weng, W.-Z.; Liang, H.; Liu, R.-Z.; Ji, Y.-X.; Zhang, B. Visible-Light-Promoted Manganese-Catalyzed Atom Transfer Radical Cyclization of Unactivated Alkyl Iodides. Org. Lett. 2019, 21, 5586-5590.

S14 Qin, Y.; Sun, R.; Gianoulis, N. P.; Nocera, D. G. Photoredox Nickel-Catalyzed C-S Cross-Coupling: Mechanism, Kinetics, and Generalization. J. Am. Chem. Soc. 2021, 143, 2005-2015. 
S10. ${ }^{1} \mathrm{H}$ and ${ }^{13} \mathrm{C}\left\{{ }^{1} \mathrm{H}\right\}$ NMR spectra for each compound.

${ }^{1} \mathrm{H}\left(400 \mathrm{MHz}, \mathrm{CDCl}_{3}\right.$, upper) and ${ }^{13} \mathrm{C}\left\{{ }^{1} \mathrm{H}\right\}$ (100 $\mathrm{MHz}, \mathrm{CDCl}_{3}$, lower) NMR spectra of (6-iodohex-1-yn-3-yl)benzene (1d)
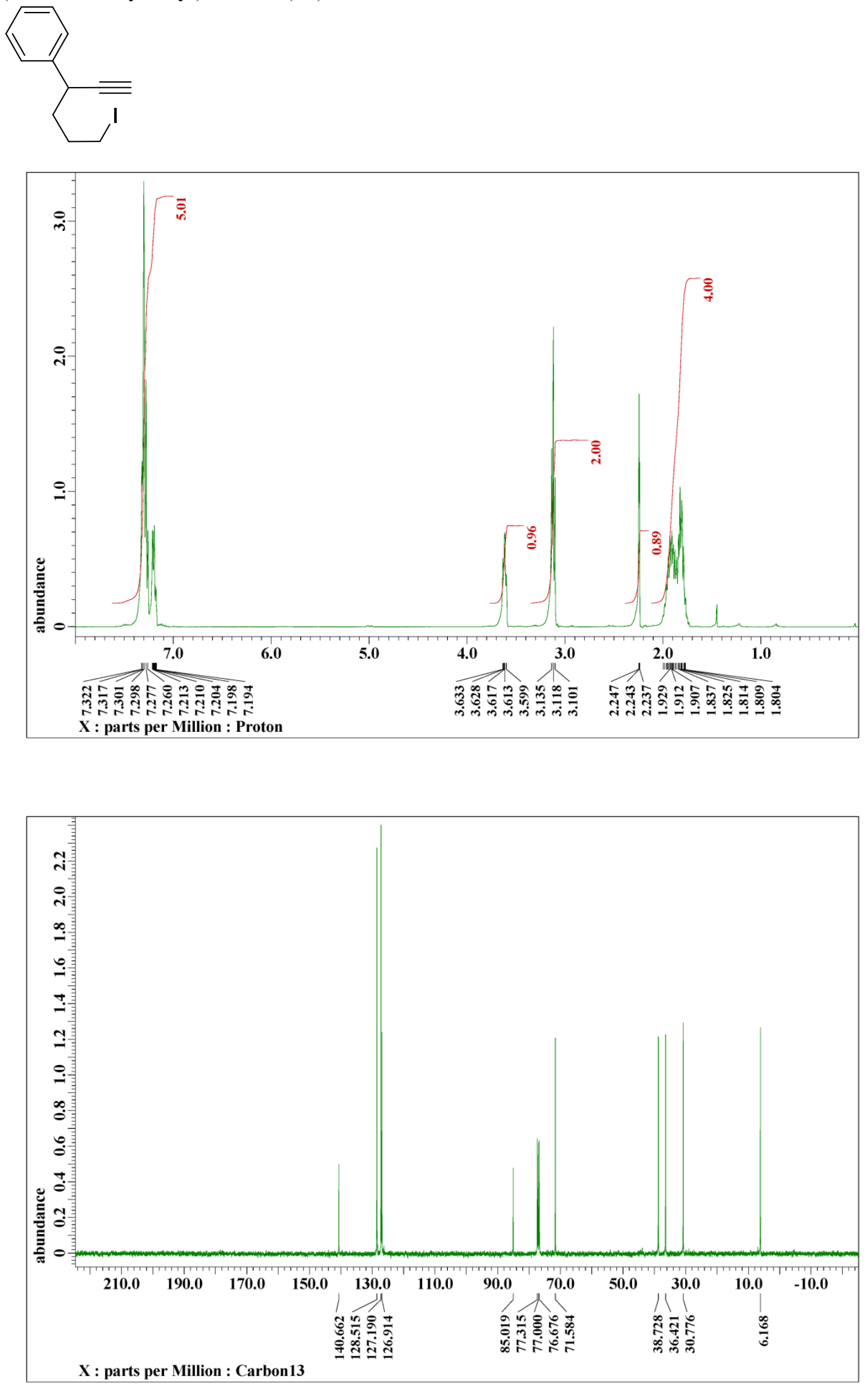
${ }^{1} \mathrm{H}\left(400 \mathrm{MHz}, \mathrm{CDCl}_{3}\right.$, upper) and ${ }^{13} \mathrm{C}\left\{{ }^{1} \mathrm{H}\right\} \quad\left(100 \mathrm{MHz}, \mathrm{CDCl}_{3}\right.$, lower) NMR spectra of 3-ethyl-6-iodohex-1-yne (1e)
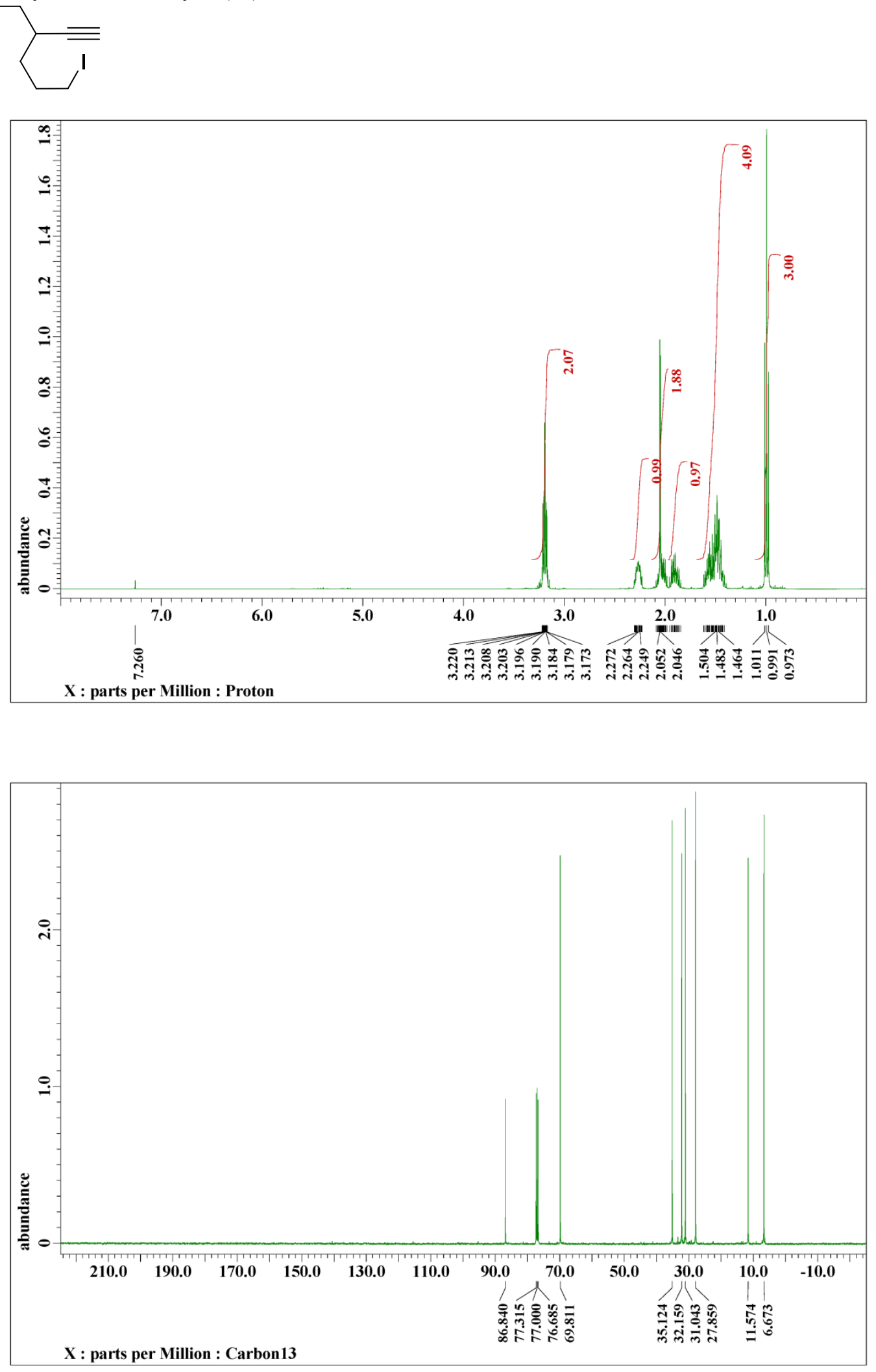
${ }^{1} \mathrm{H}\left(400 \mathrm{MHz}, \mathrm{CDCl}_{3}\right.$, upper) and ${ }^{13} \mathrm{C}\left\{{ }^{1} \mathrm{H}\right\} \quad\left(100 \mathrm{MHz}, \mathrm{CDCl}_{3}\right.$, lower) NMR spectra of 4-ethynyl-1-iodooctane (1f)
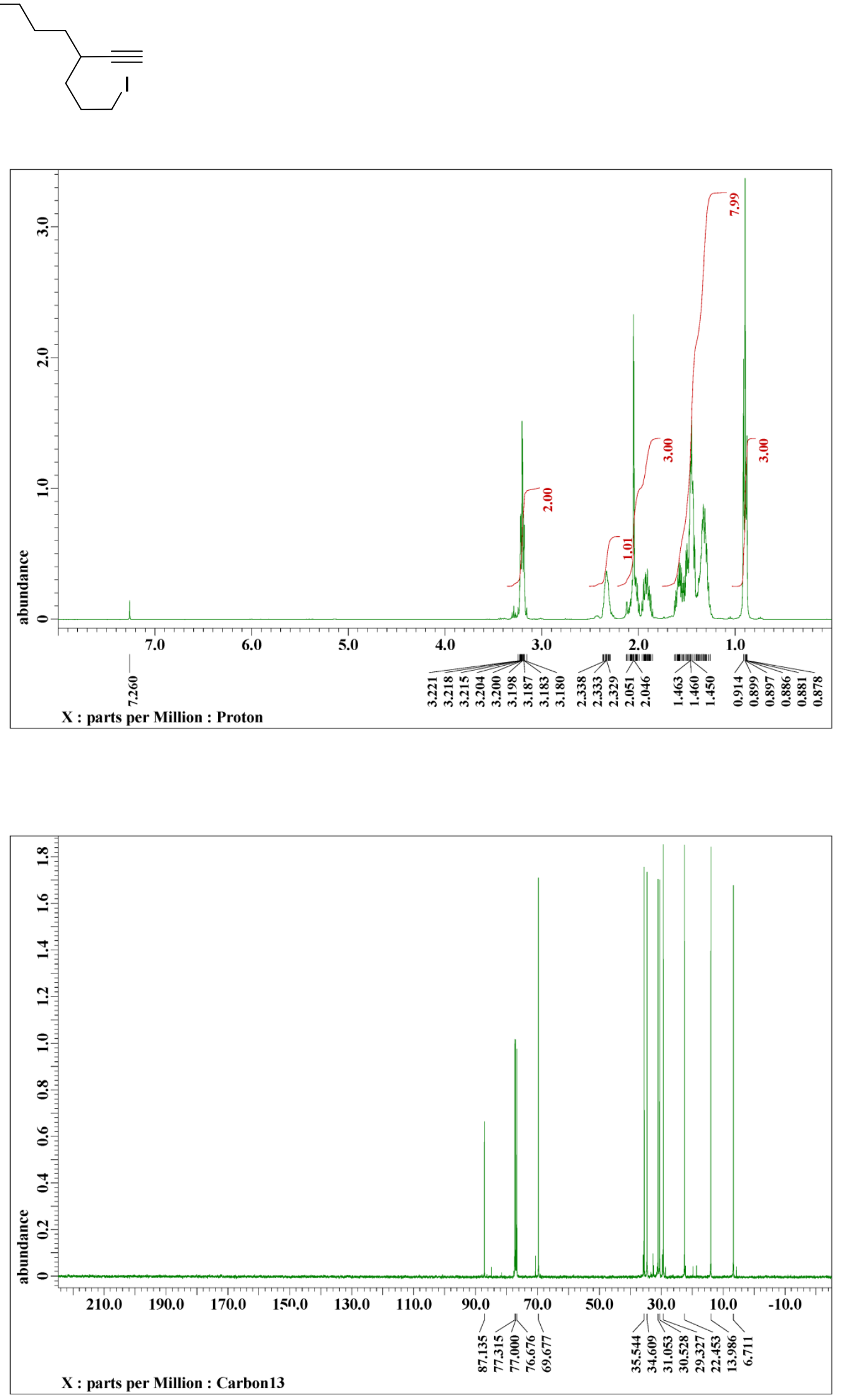
${ }^{1} \mathrm{H}\left(400 \mathrm{MHz}, \mathrm{CDCl}_{3}\right.$, upper) and ${ }^{13} \mathrm{C}\left\{{ }^{1} \mathrm{H}\right\} \quad\left(100 \mathrm{MHz}, \mathrm{CDCl}_{3}\right.$, lower) NMR spectra of 4-ethynyl-1-iodoundecane (1g)
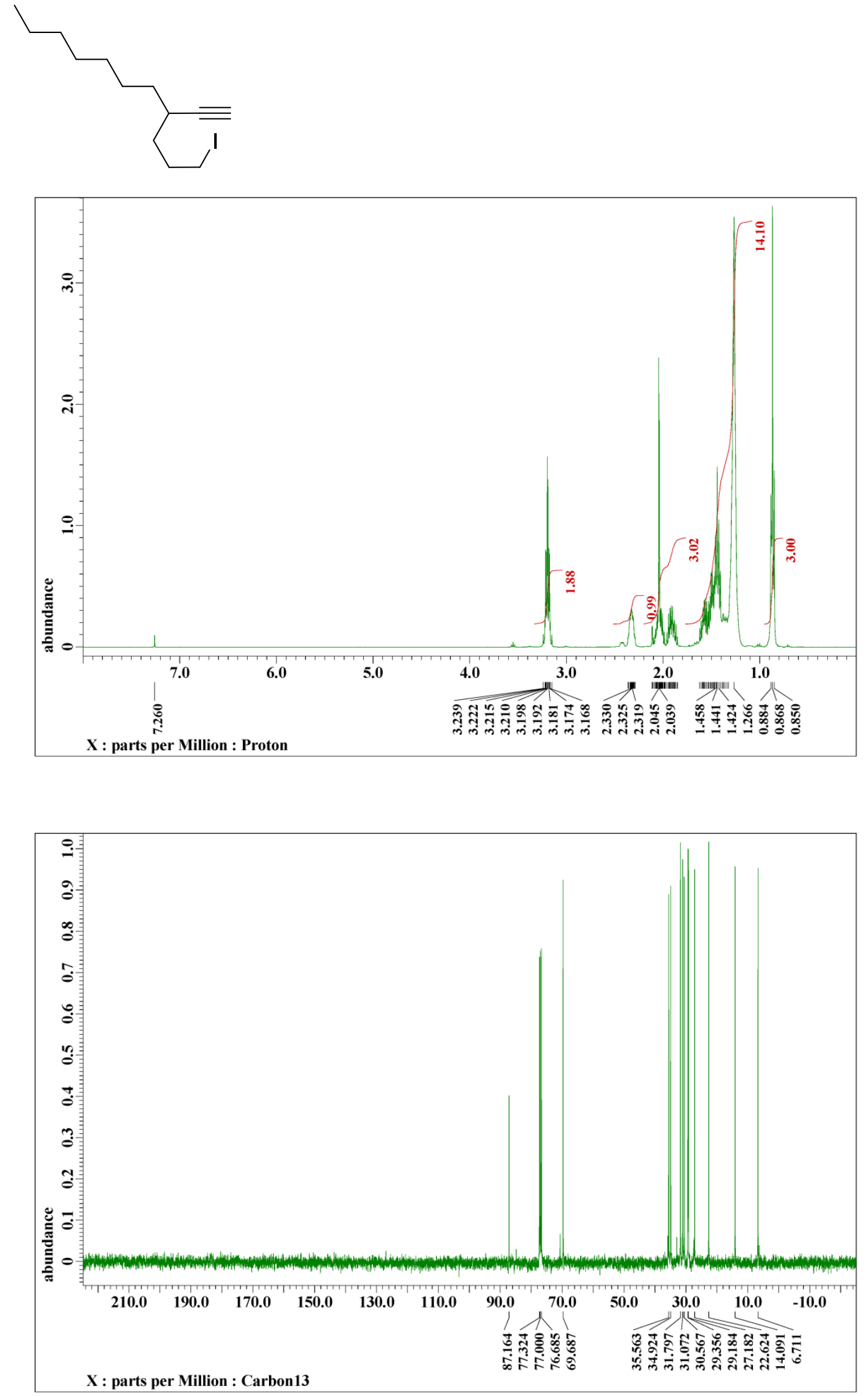
${ }^{1} \mathrm{H}\left(400 \mathrm{MHz}, \mathrm{CDCl}_{3}\right.$, upper) and ${ }^{13} \mathrm{C}\left\{{ }^{1} \mathrm{H}\right\} \quad\left(100 \mathrm{MHz}, \mathrm{CDCl}_{3}\right.$, lower) NMR spectra of (6-iodohex-1-yn-3-yl)cyclohexane (1h)
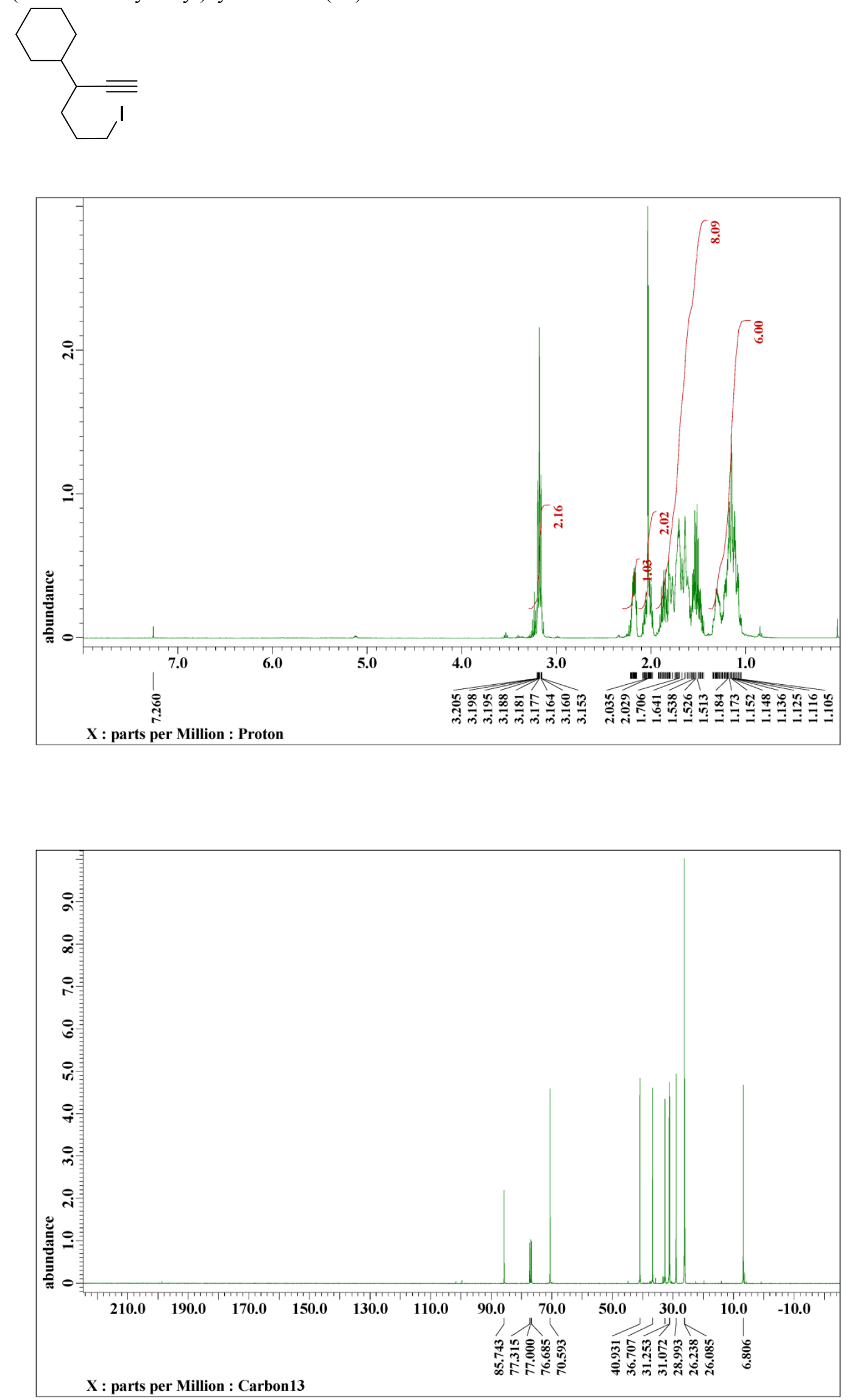
${ }^{1} \mathrm{H}\left(400 \mathrm{MHz}, \mathrm{CDCl}_{3}\right.$, upper) and ${ }^{13} \mathrm{C}\left\{{ }^{1} \mathrm{H}\right\}\left(100 \mathrm{MHz}, \mathrm{CDCl}_{3}\right.$, lower) NMR spectra of (7-iodohept-2-yn-4-yl)benzene (1j)
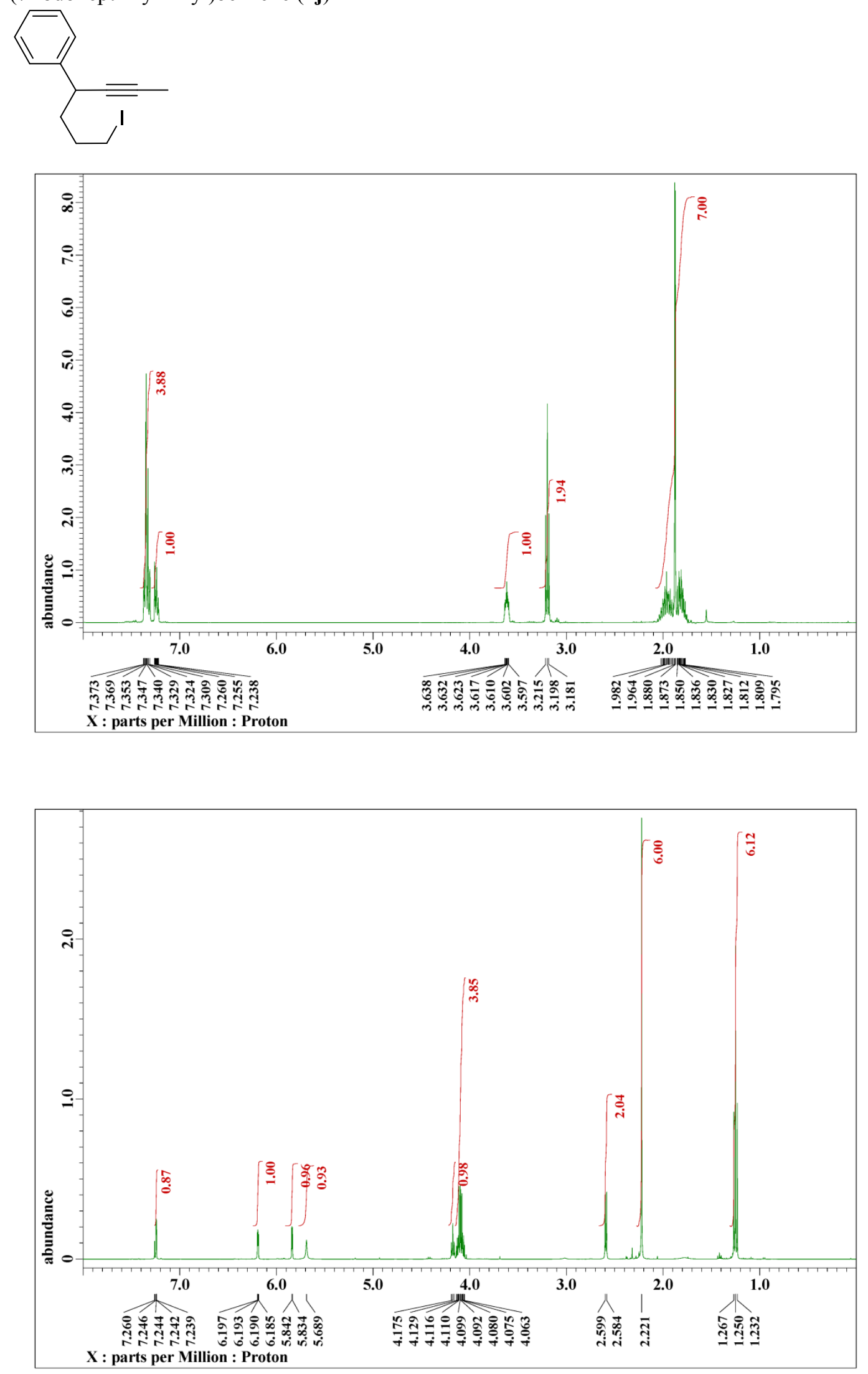
${ }^{1} \mathrm{H}\left(400 \mathrm{MHz}, \mathrm{CDCl}_{3}\right.$, upper) and ${ }^{13} \mathrm{C}\left\{{ }^{1} \mathrm{H}\right\}\left(100 \mathrm{MHz}, \mathrm{CDCl}_{3}\right.$, lower) NMR spectra of diethyl 4-(4-cyanobenzyl)-2,6-dimethyl-1,4-dihydropyridine-3,5-dicarboxylate (2f)<smiles>CCOC(=O)C1=C(C)NC(C)=C(C(=O)OCC)C1Cc1ccc(C#N)cc1</smiles>
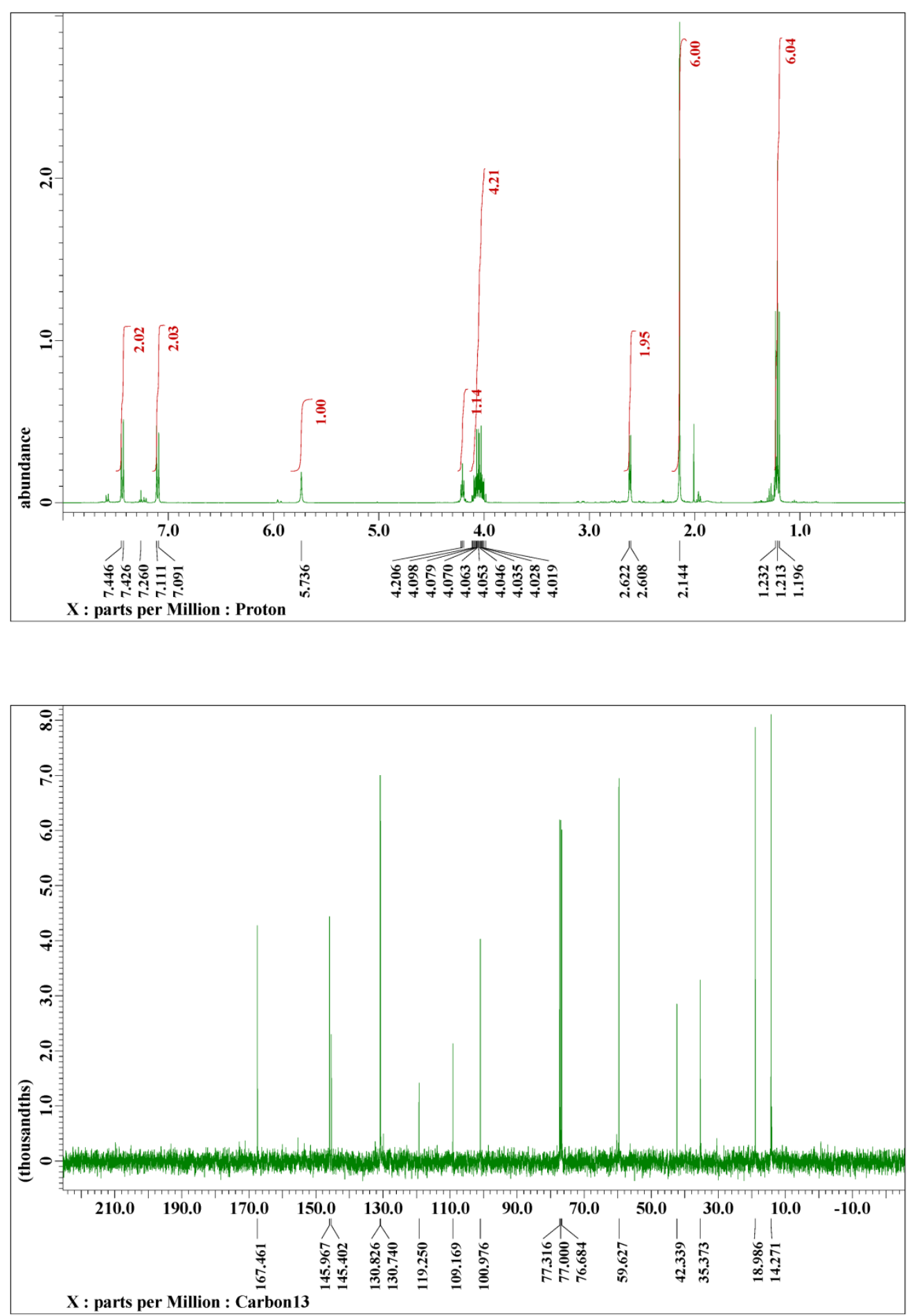
${ }^{1} \mathrm{H}\left(400 \mathrm{MHz}, \mathrm{CDCl}_{3}\right.$, upper) and ${ }^{13} \mathrm{C}\left\{{ }^{1} \mathrm{H}\right\}\left(100 \mathrm{MHz}, \mathrm{CDCl}_{3}\right.$, lower) NMR spectra of diethyl 4-(furan-2-ylmethyl)-2,6-dimethyl-1,4-dihydropyridine-3,5-dicarboxylate (2q)<smiles>CCOC(=O)C1=C(C)NC(C)=C(C(=O)OCC)C1Cc1ccco1</smiles>
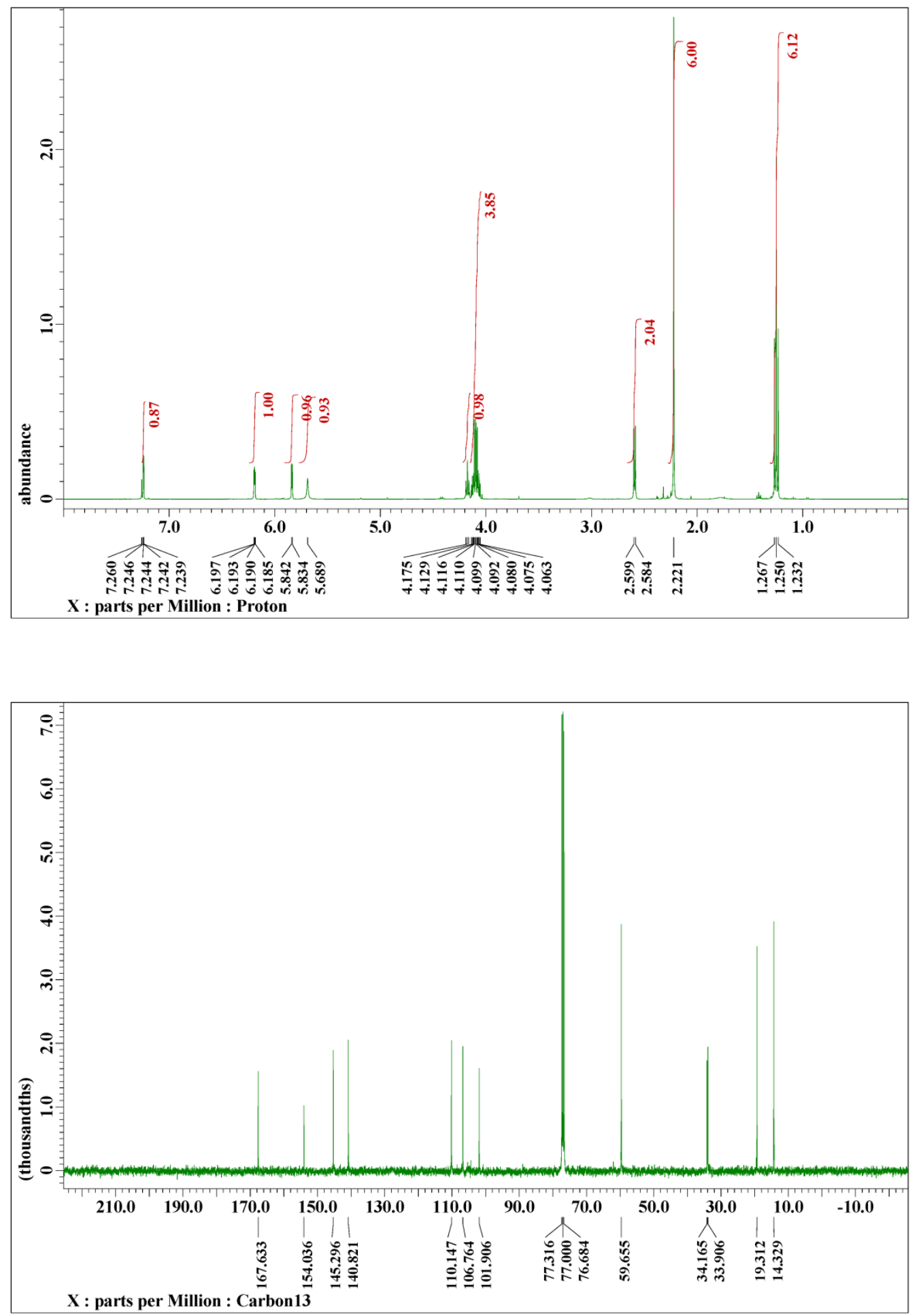
${ }^{1} \mathrm{H}\left(400 \mathrm{MHz}, \mathrm{CDCl}_{3}\right.$, upper) and ${ }^{13} \mathrm{C}\left\{{ }^{1} \mathrm{H}\right\} \quad\left(100 \mathrm{MHz}, \mathrm{CDCl}_{3}\right.$, lower) NMR spectra of (2-cyclopentylideneethyl)benzene (3aa)
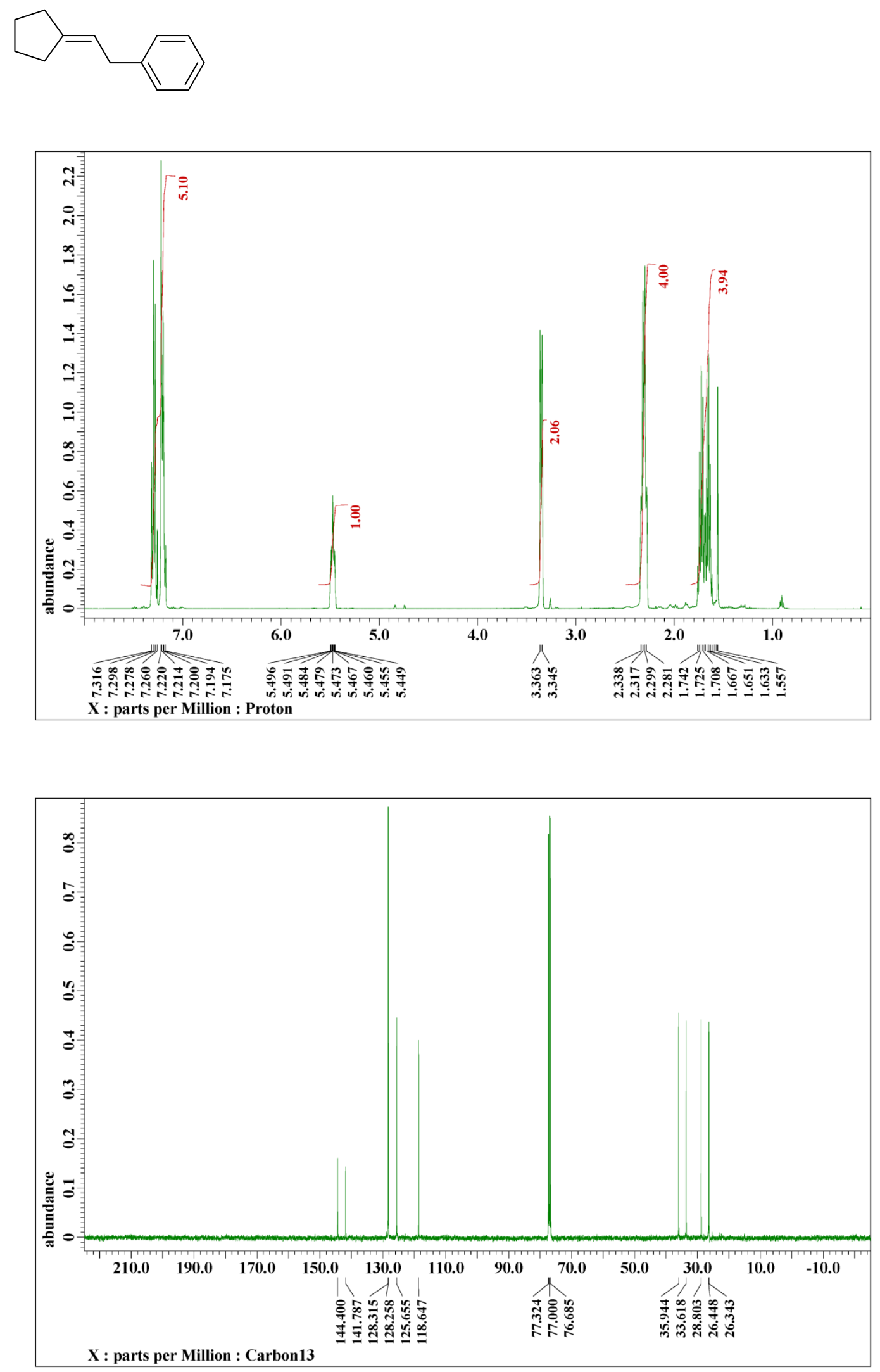
${ }^{1} \mathrm{H}\left(400 \mathrm{MHz}, \mathrm{CDCl}_{3}\right.$, upper) and ${ }^{13} \mathrm{C}\left\{{ }^{1} \mathrm{H}\right\} \quad\left(100 \mathrm{MHz}, \mathrm{CDCl}_{3}\right.$, lower) NMR spectra of 1-(2-cyclopentylideneethyl)-4-methoxybenzene (3ab)
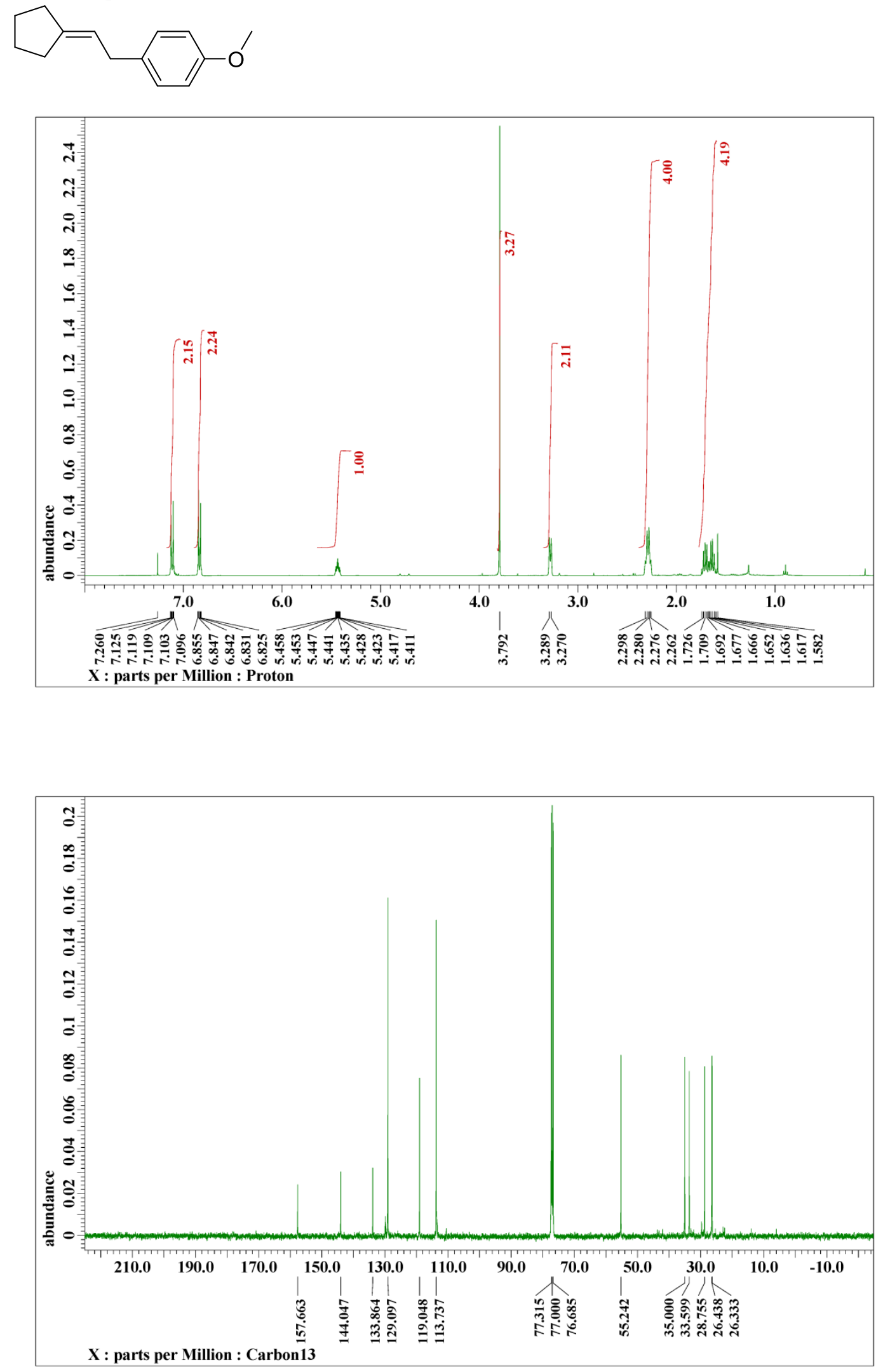
${ }^{1} \mathrm{H}\left(400 \mathrm{MHz}, \mathrm{CDCl}_{3}\right.$, upper) and ${ }^{13} \mathrm{C}\left\{{ }^{1} \mathrm{H}\right\}$ (100 $\mathrm{MHz}, \mathrm{CDCl}_{3}$, lower) NMR spectra of 1-(2-cyclopentylideneethyl)-4-methylbenzene (3ac)
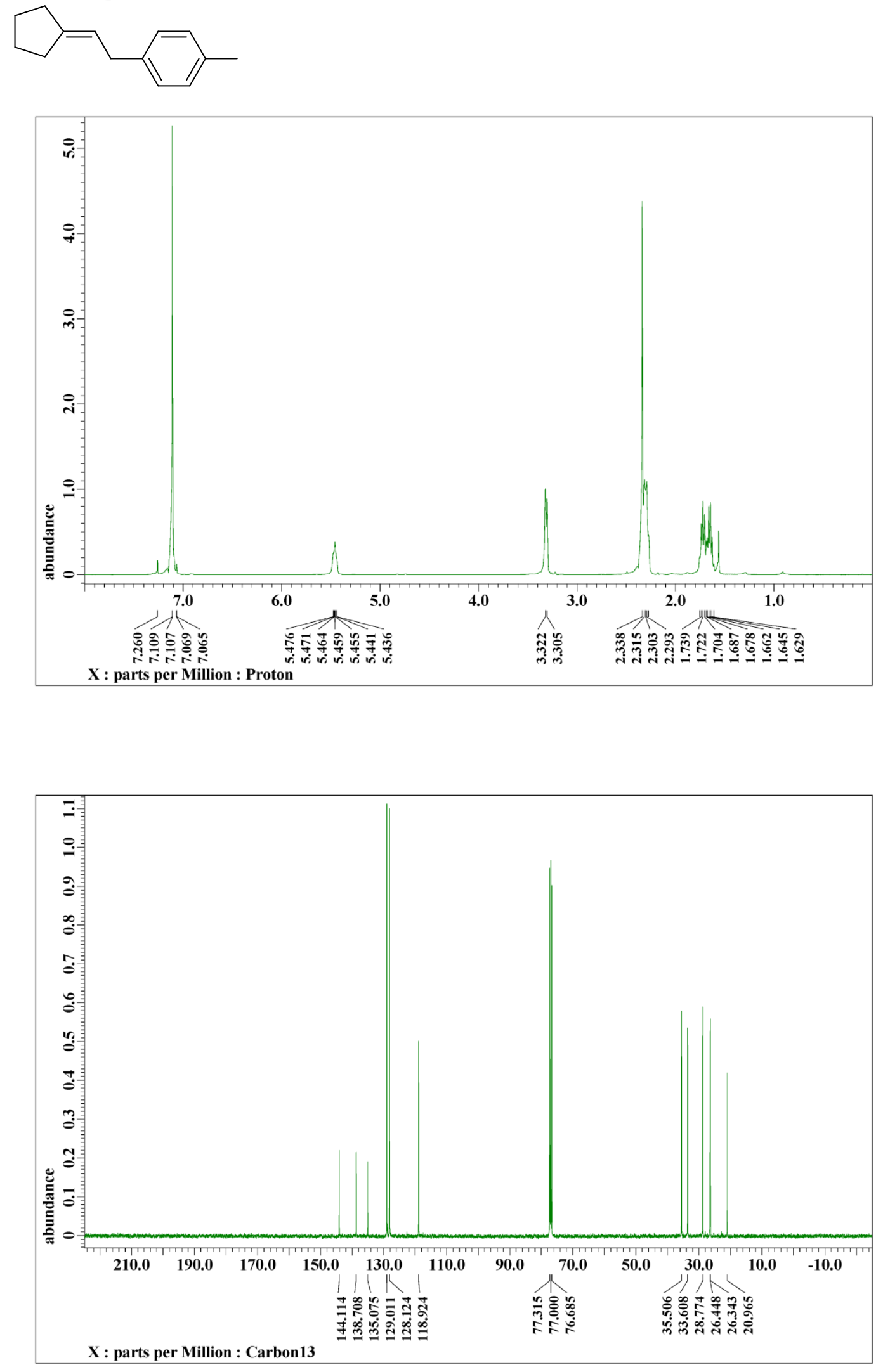
${ }^{1} \mathrm{H}\left(400 \mathrm{MHz}, \mathrm{CDCl}_{3}\right.$, upper) and ${ }^{13} \mathrm{C}\left\{{ }^{1} \mathrm{H}\right\} \quad\left(100 \mathrm{MHz}, \mathrm{CDCl}_{3}\right.$, lower) NMR spectra of 4-(2-cyclopentylideneethyl)-1,1'-biphenyl (3ad)
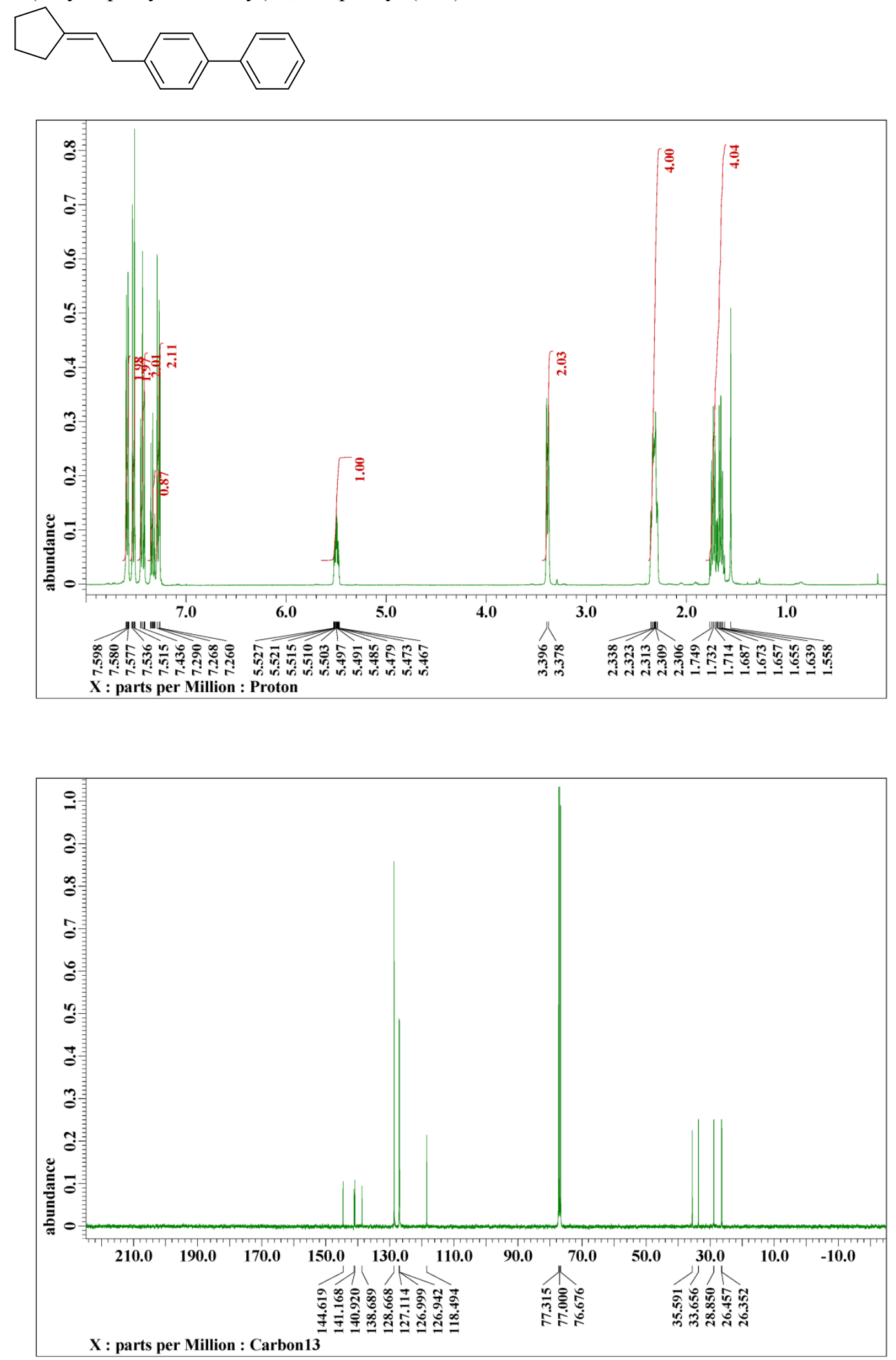
${ }^{1} \mathrm{H}\left(400 \mathrm{MHz}, \mathrm{CDCl}_{3}\right.$, upper) and ${ }^{13} \mathrm{C}\left\{{ }^{1} \mathrm{H}\right\} \quad\left(100 \mathrm{MHz}, \mathrm{CDCl}_{3}\right.$, lower) NMR spectra of 1-chloro-4-(2-cyclopentylideneethyl)benzene (3ae)
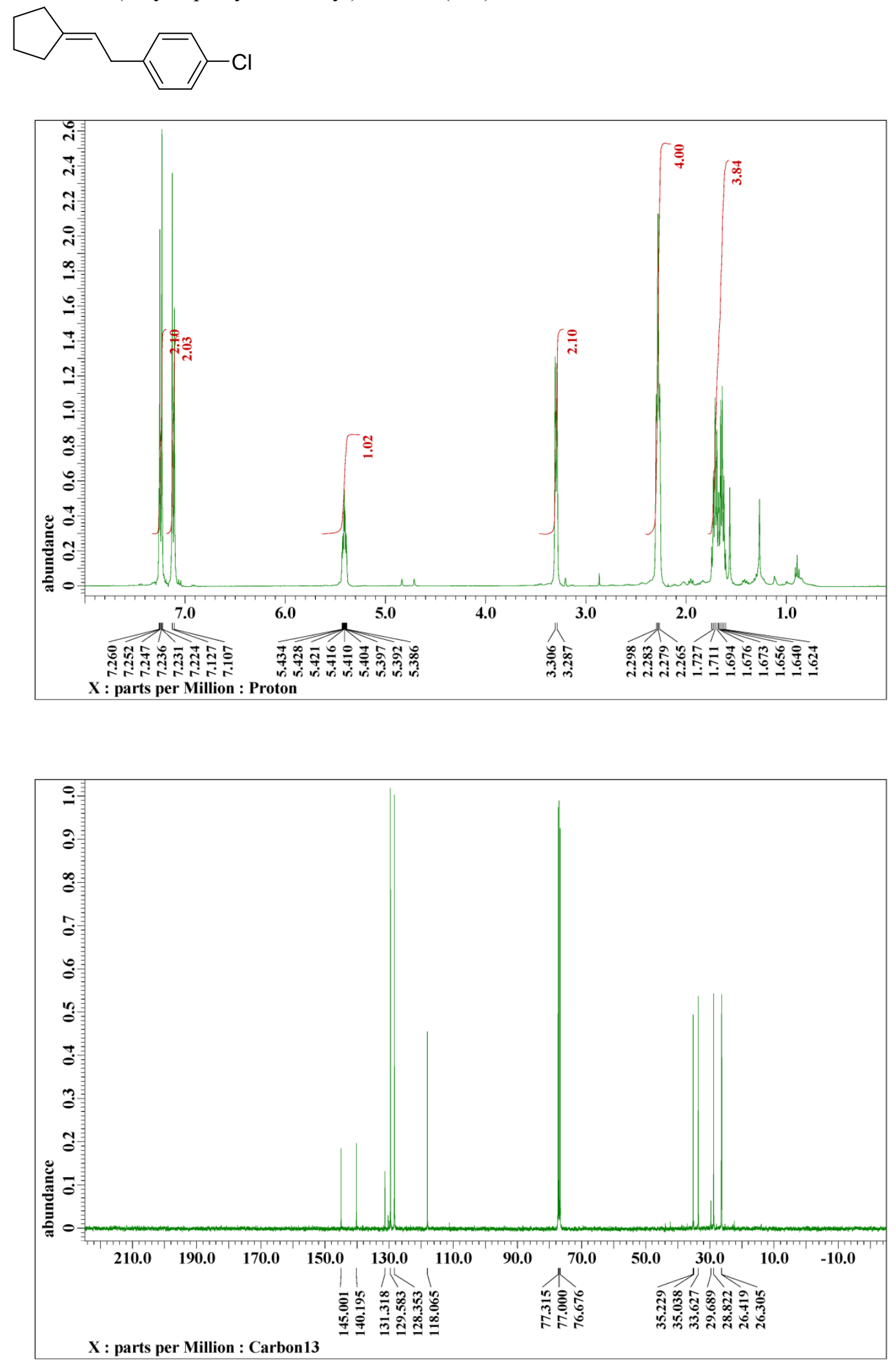
${ }^{1} \mathrm{H}\left(400 \mathrm{MHz}, \mathrm{CDCl}_{3}\right.$, upper) and ${ }^{13} \mathrm{C}\left\{{ }^{1} \mathrm{H}\right\} \quad\left(100 \mathrm{MHz}, \mathrm{CDCl}_{3}\right.$, lower) NMR spectra of 1-(2-cyclopentylideneethyl)-3-methylbenzene (3ag)
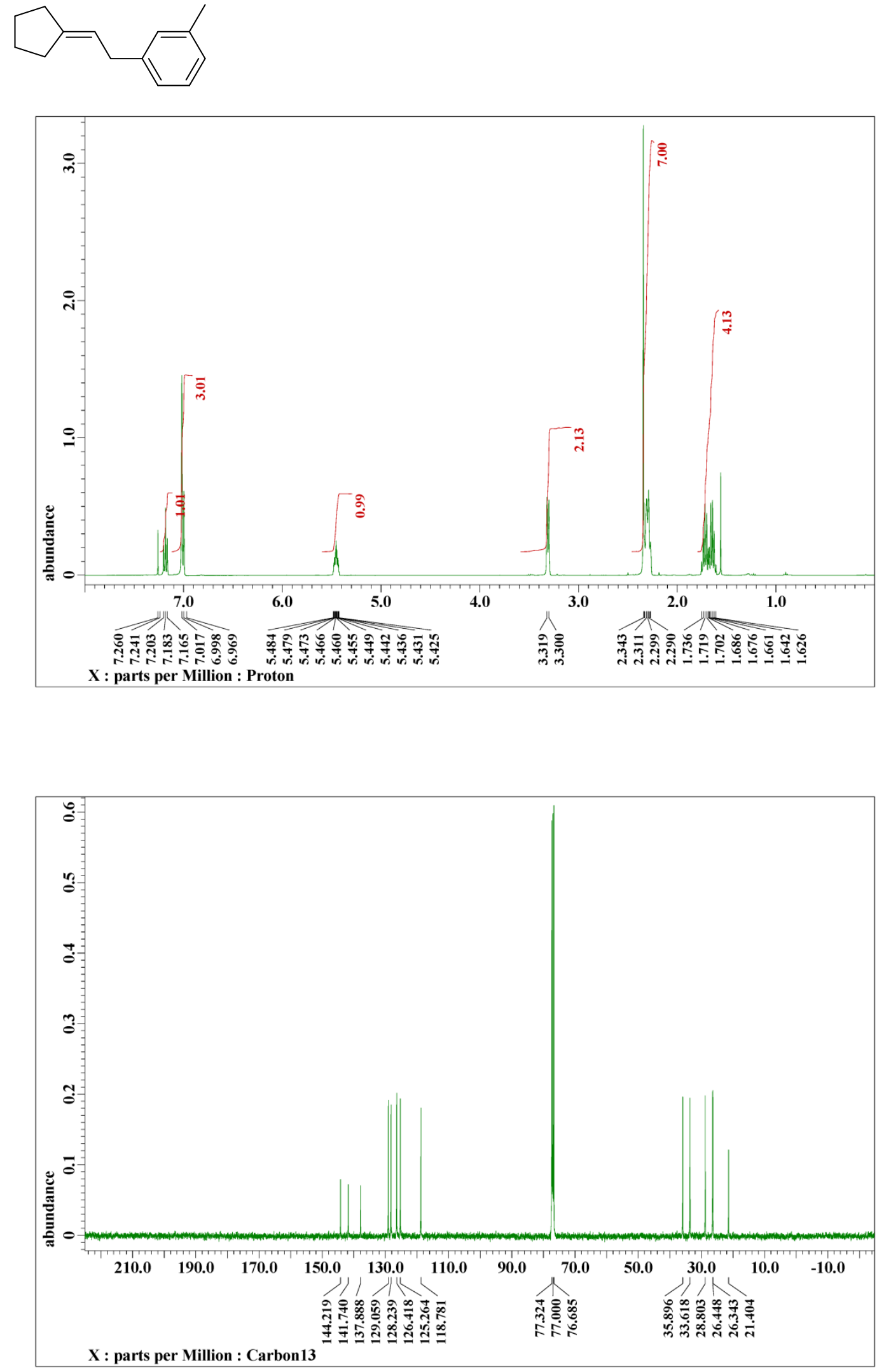
${ }^{1} \mathrm{H}\left(400 \mathrm{MHz}, \mathrm{CDCl}_{3}\right.$, upper) and ${ }^{13} \mathrm{C}\left\{{ }^{1} \mathrm{H}\right\} \quad\left(100 \mathrm{MHz}, \mathrm{CDCl}_{3}\right.$, lower) NMR spectra of 1-(2-cyclopentylideneethyl)-2-methylbenzene (3ah)
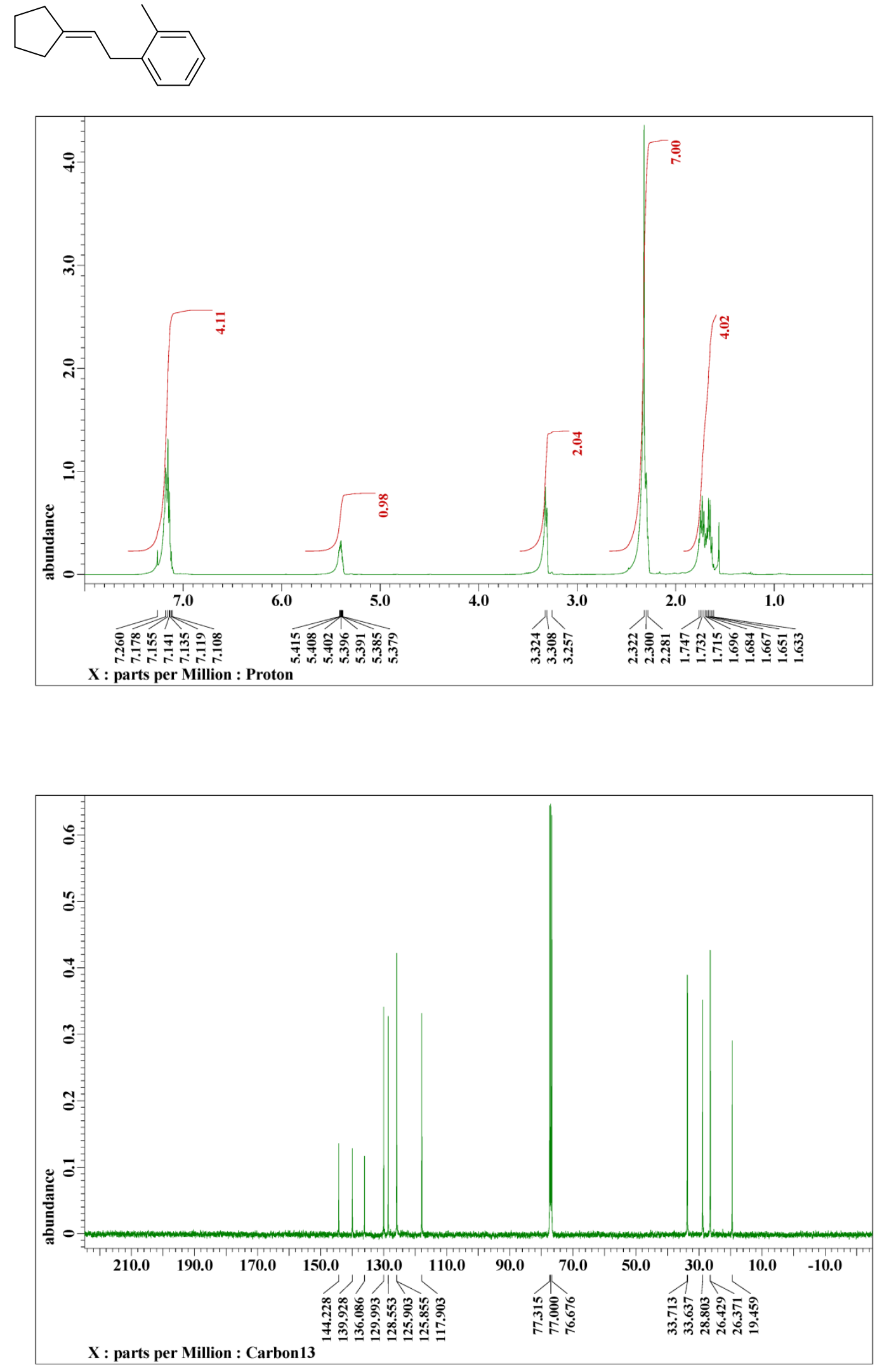
${ }^{1} \mathrm{H}\left(400 \mathrm{MHz}, \mathrm{CDCl}_{3}\right.$, upper) and ${ }^{13} \mathrm{C}\left\{{ }^{1} \mathrm{H}\right\} \quad\left(100 \mathrm{MHz}, \mathrm{CDCl}_{3}\right.$, lower) NMR spectra of 1-(2-cyclopentylideneethyl)naphthalene (3ai)
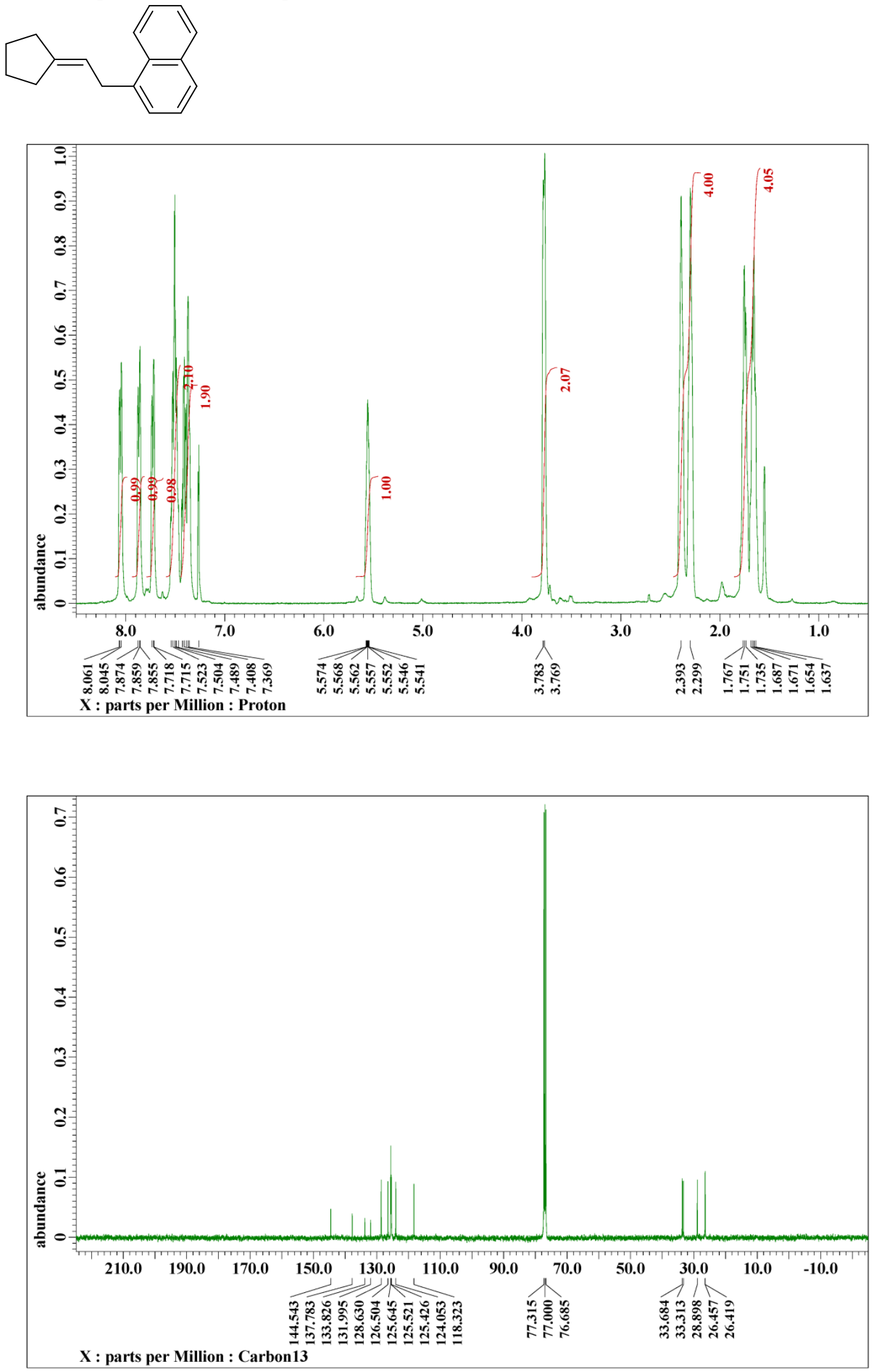
${ }^{1} \mathrm{H}\left(400 \mathrm{MHz}, \mathrm{CDCl}_{3}\right.$, upper) and ${ }^{13} \mathrm{C}\left\{{ }^{1} \mathrm{H}\right\} \quad\left(100 \mathrm{MHz}, \mathrm{CDCl}_{3}\right.$, lower) NMR spectra of decylidenecyclopentane (3aj)
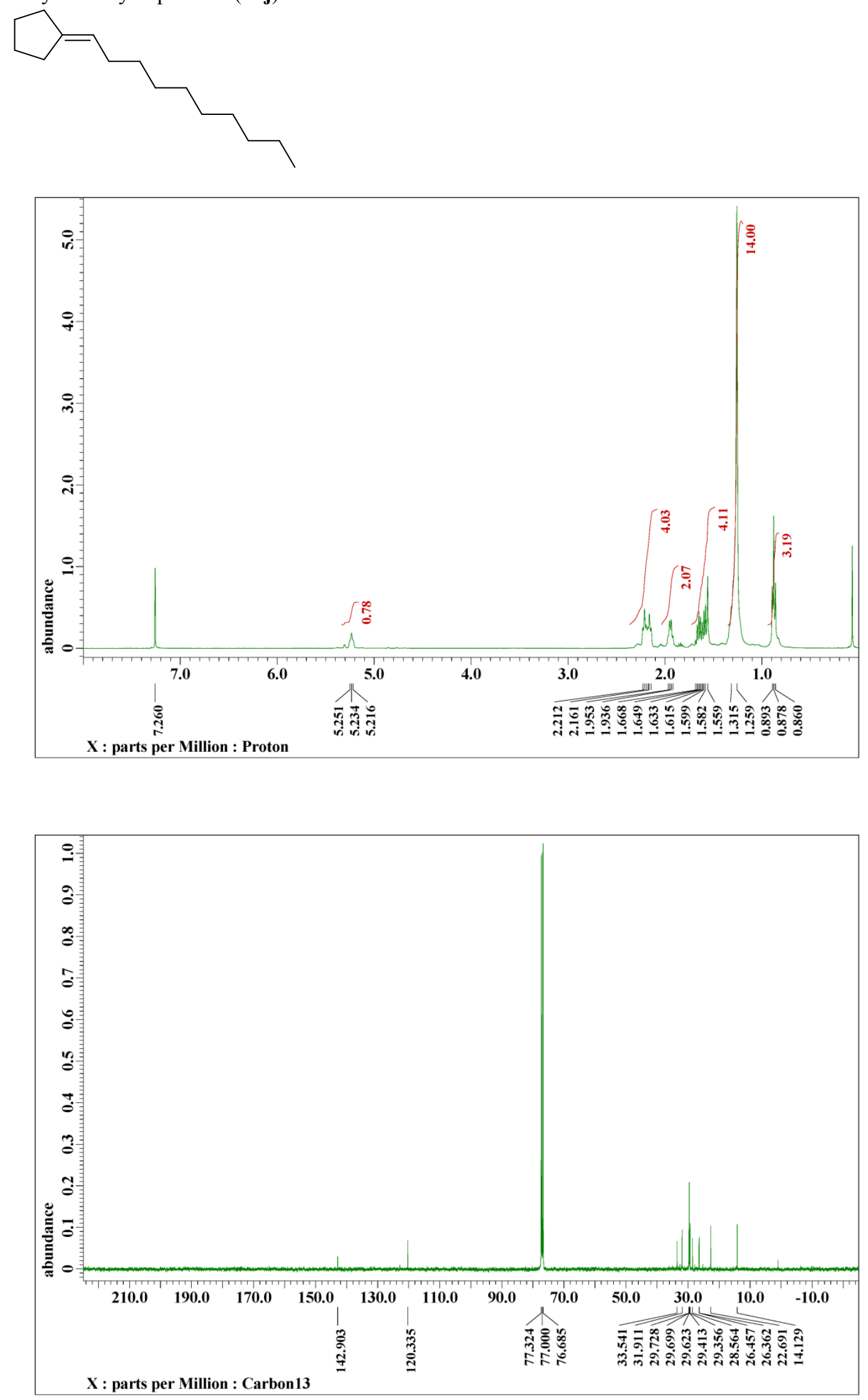
${ }^{1} \mathrm{H}\left(400 \mathrm{MHz}, \mathrm{CDCl}_{3}\right.$, upper) and ${ }^{13} \mathrm{C}\left\{{ }^{1} \mathrm{H}\right\} \quad\left(100 \mathrm{MHz}, \mathrm{CDCl}_{3}\right.$, lower) NMR spectra of (2-methylpentylidene)cyclopentane (3ak)
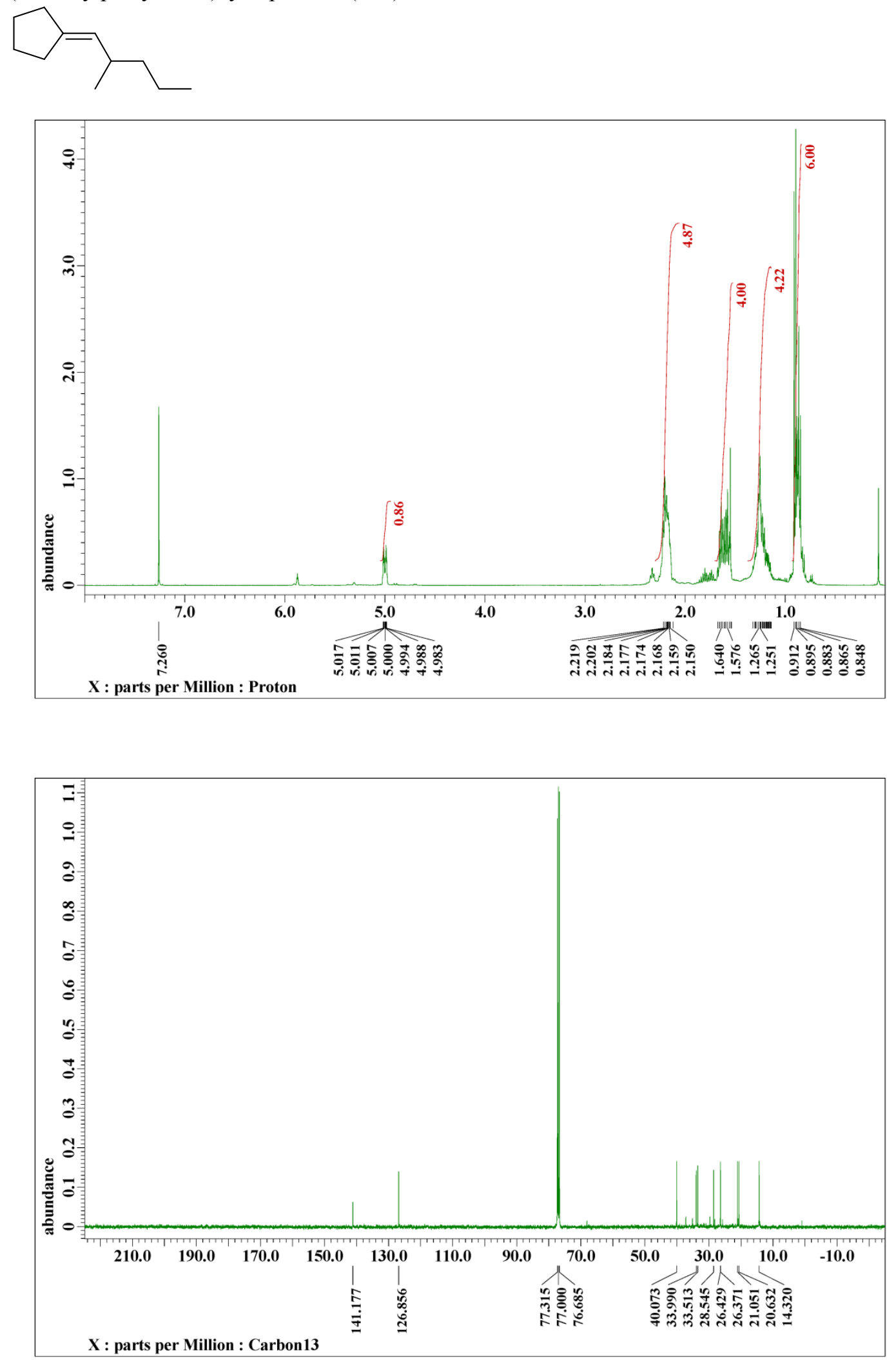
${ }^{1} \mathrm{H}\left(400 \mathrm{MHz}, \mathrm{CDCl}_{3}\right.$, upper) and ${ }^{13} \mathrm{C}\left\{{ }^{1} \mathrm{H}\right\} \quad\left(100 \mathrm{MHz}, \mathrm{CDCl}_{3}\right.$, lower) NMR spectra of (cyclopentylidenemethyl)cyclohexane (3al)
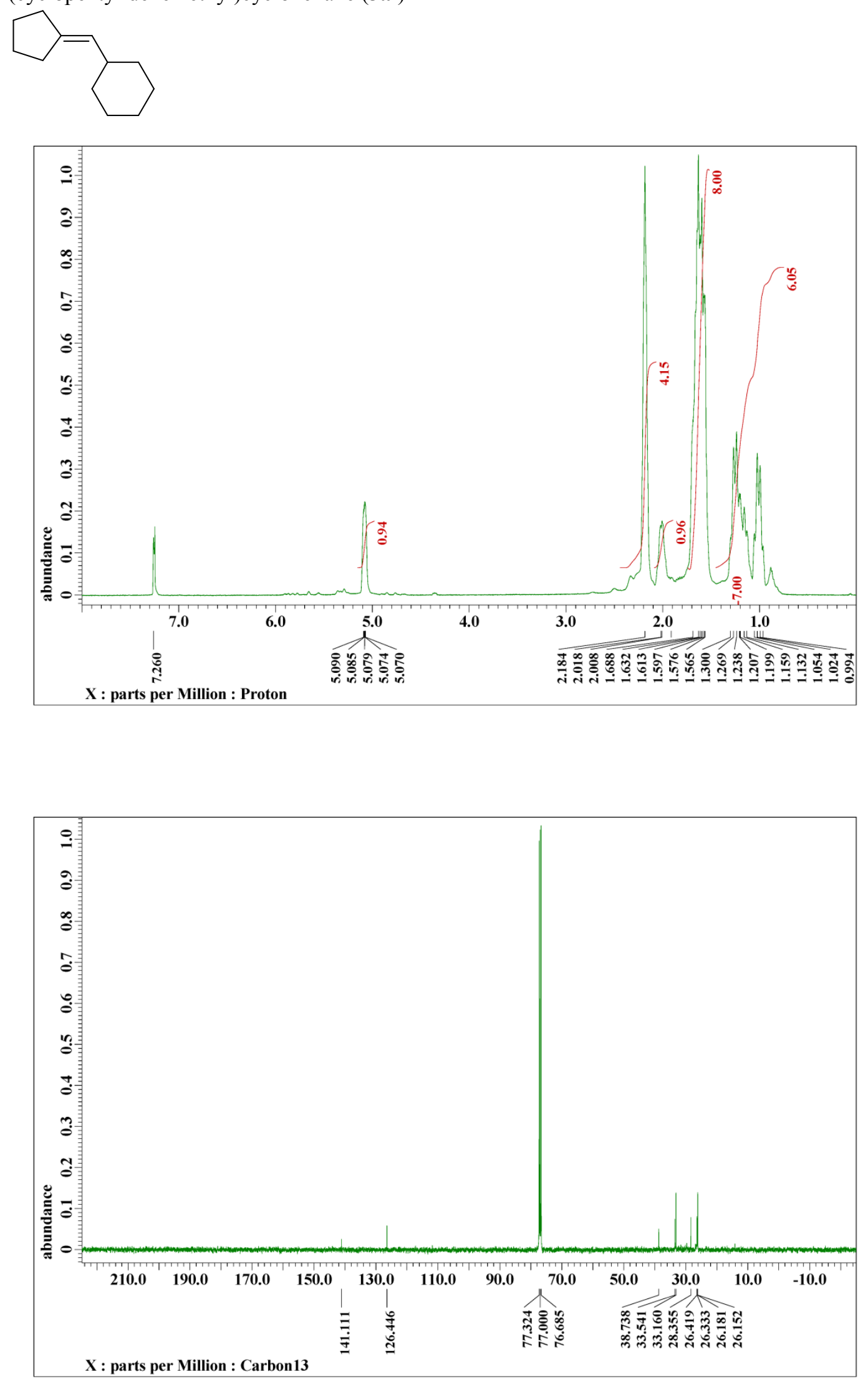
${ }^{1} \mathrm{H}\left(400 \mathrm{MHz}, \mathrm{CDCl}_{3}\right.$, upper) and ${ }^{13} \mathrm{C}\left\{{ }^{1} \mathrm{H}\right\} \quad\left(100 \mathrm{MHz}, \mathrm{CDCl}_{3}\right.$, lower) NMR spectra of ((2-cyclopentylideneethoxy)methyl)benzene (3an)
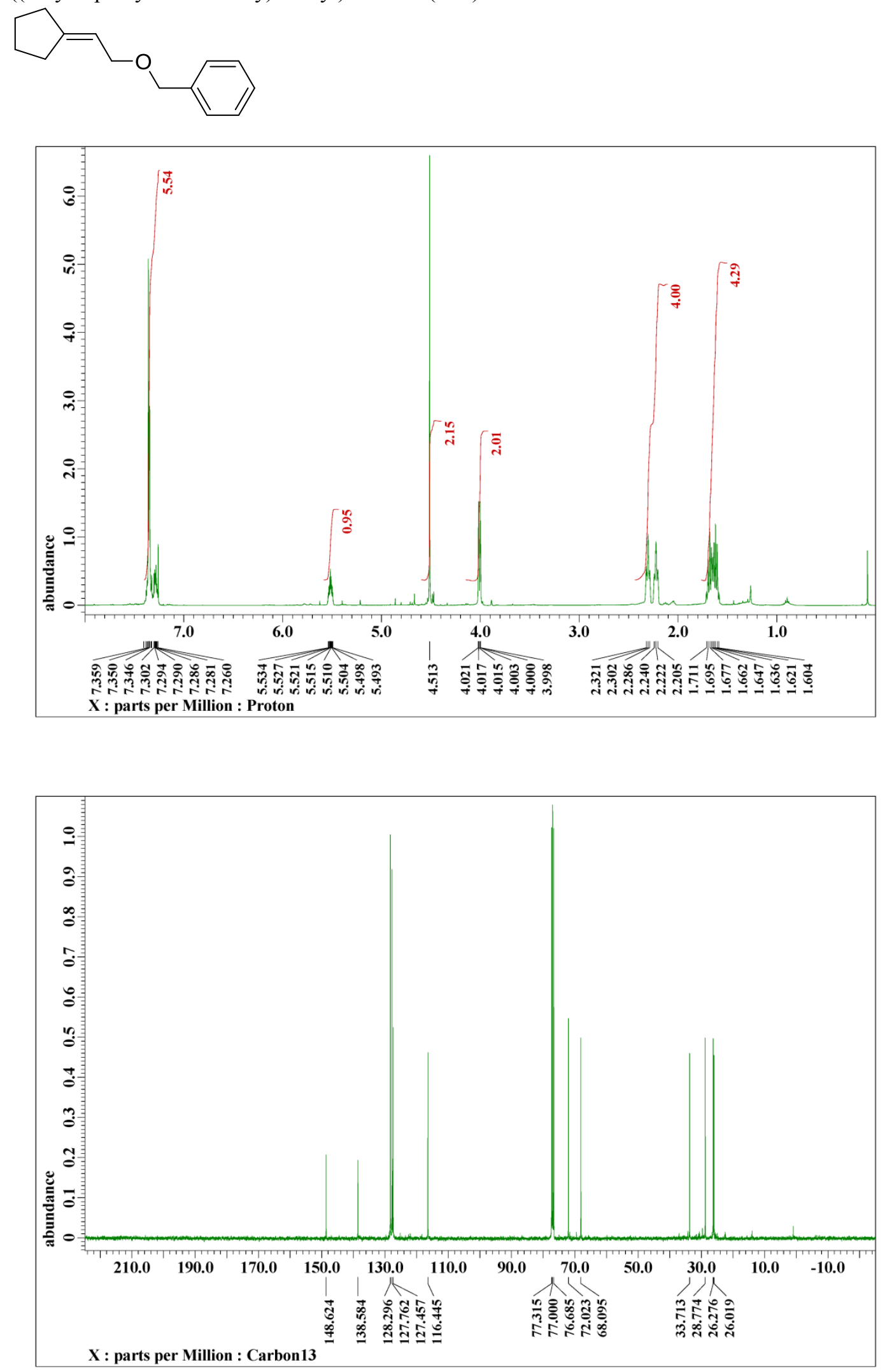
${ }^{1} \mathrm{H}\left(400 \mathrm{MHz}, \mathrm{CDCl}_{3}\right.$, upper) and ${ }^{13} \mathrm{C}\left\{{ }^{1} \mathrm{H}\right\} \quad\left(100 \mathrm{MHz}, \mathrm{CDCl}_{3}\right.$, lower) NMR spectra of $N, N$-dibenzyl-2-cyclopentylideneethan-1-amine (3ao)
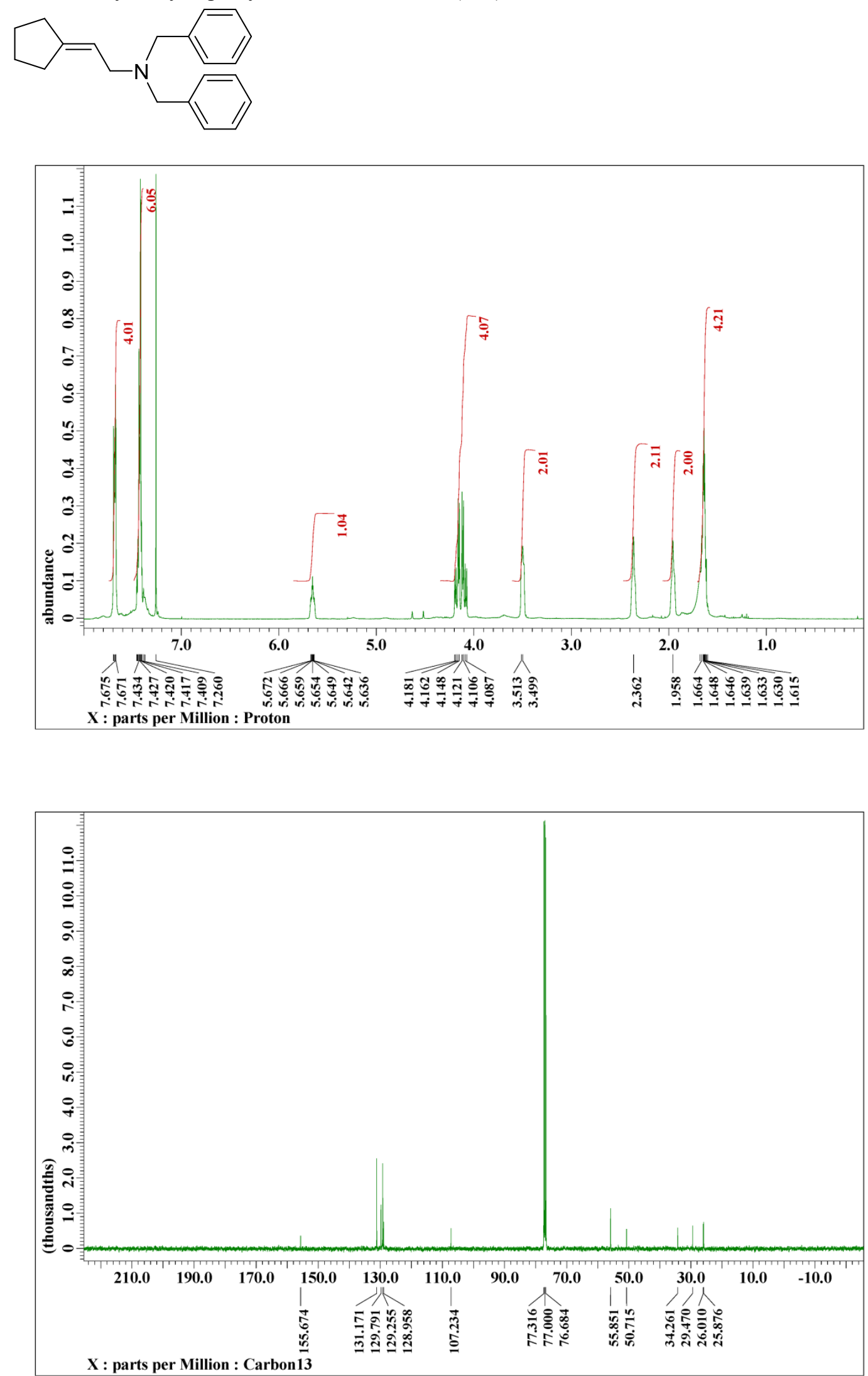
${ }^{1} \mathrm{H}\left(400 \mathrm{MHz}, \mathrm{CDCl}_{3}\right.$, upper) and ${ }^{13} \mathrm{C}\left\{{ }^{1} \mathrm{H}\right\} \quad\left(100 \mathrm{MHz}, \mathrm{CDCl}_{3}\right.$, lower) NMR spectra of 2-(2-cyclopentylideneethyl)furan (3aq)
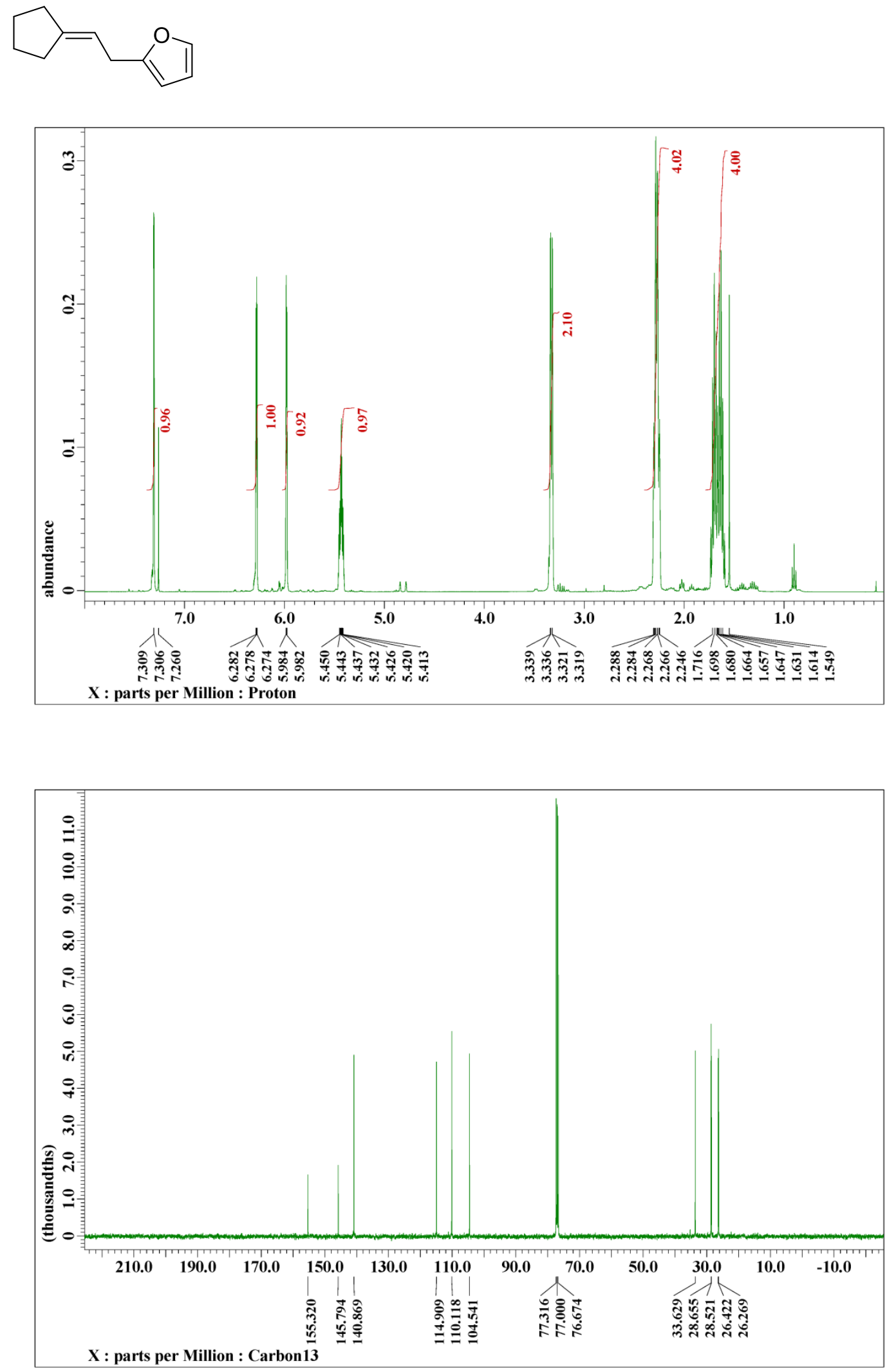
${ }^{1} \mathrm{H}\left(400 \mathrm{MHz}, \mathrm{CDCl}_{3}\right.$, upper) and ${ }^{13} \mathrm{C}\left\{{ }^{1} \mathrm{H}\right\} \quad\left(100 \mathrm{MHz}, \mathrm{CDCl}_{3}\right.$, lower) NMR spectra of 2-(2-cyclopentylideneethyl)thiophene (3ar)
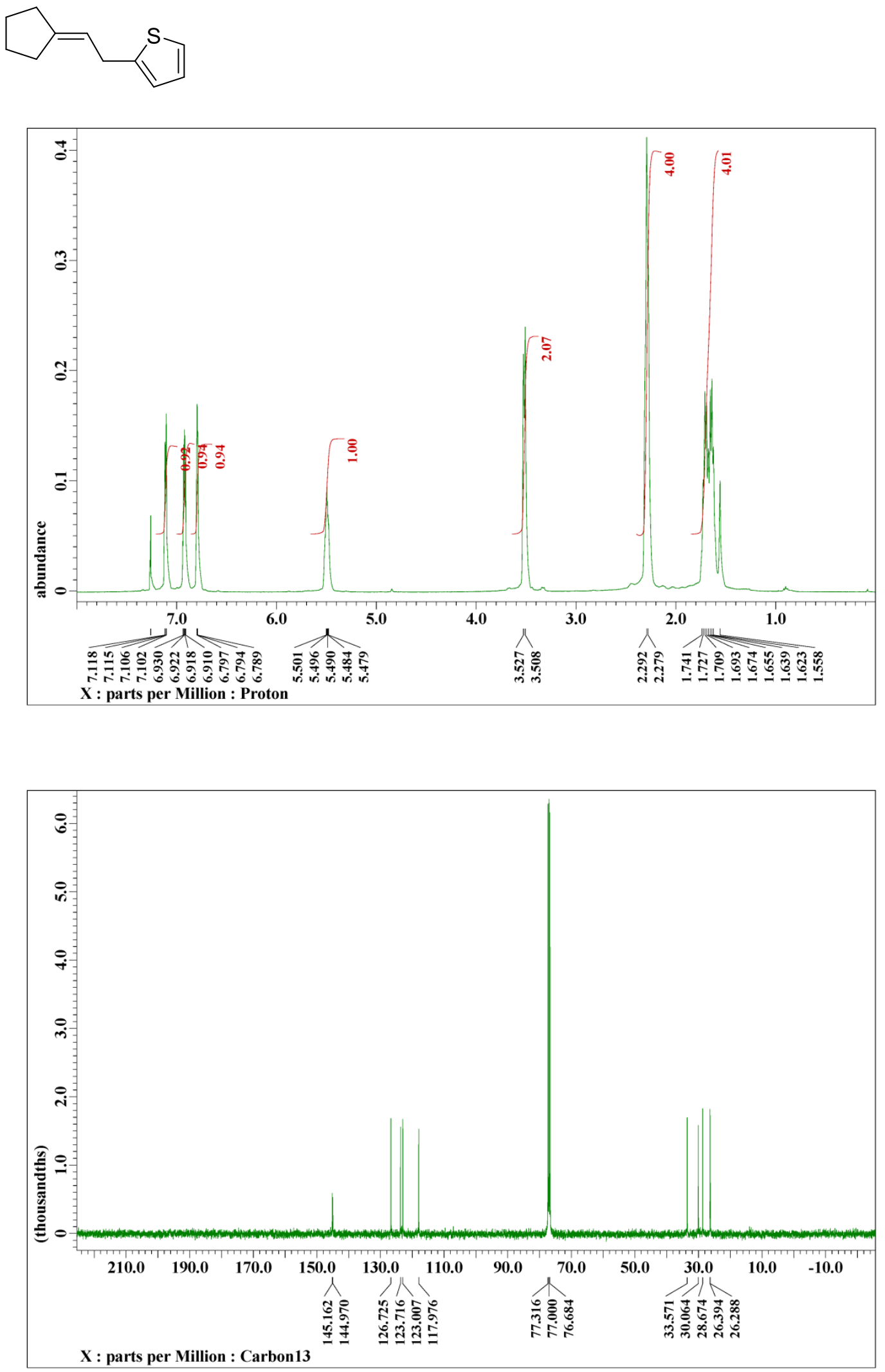
${ }^{1} \mathrm{H}\left(400 \mathrm{MHz}, \mathrm{CDCl}_{3}\right.$, upper) and ${ }^{13} \mathrm{C}\left\{{ }^{1} \mathrm{H}\right\} \quad\left(100 \mathrm{MHz}, \mathrm{CDCl}_{3}\right.$, lower) NMR spectra of (2-cyclopentylidenepropyl)benzene (3ba)
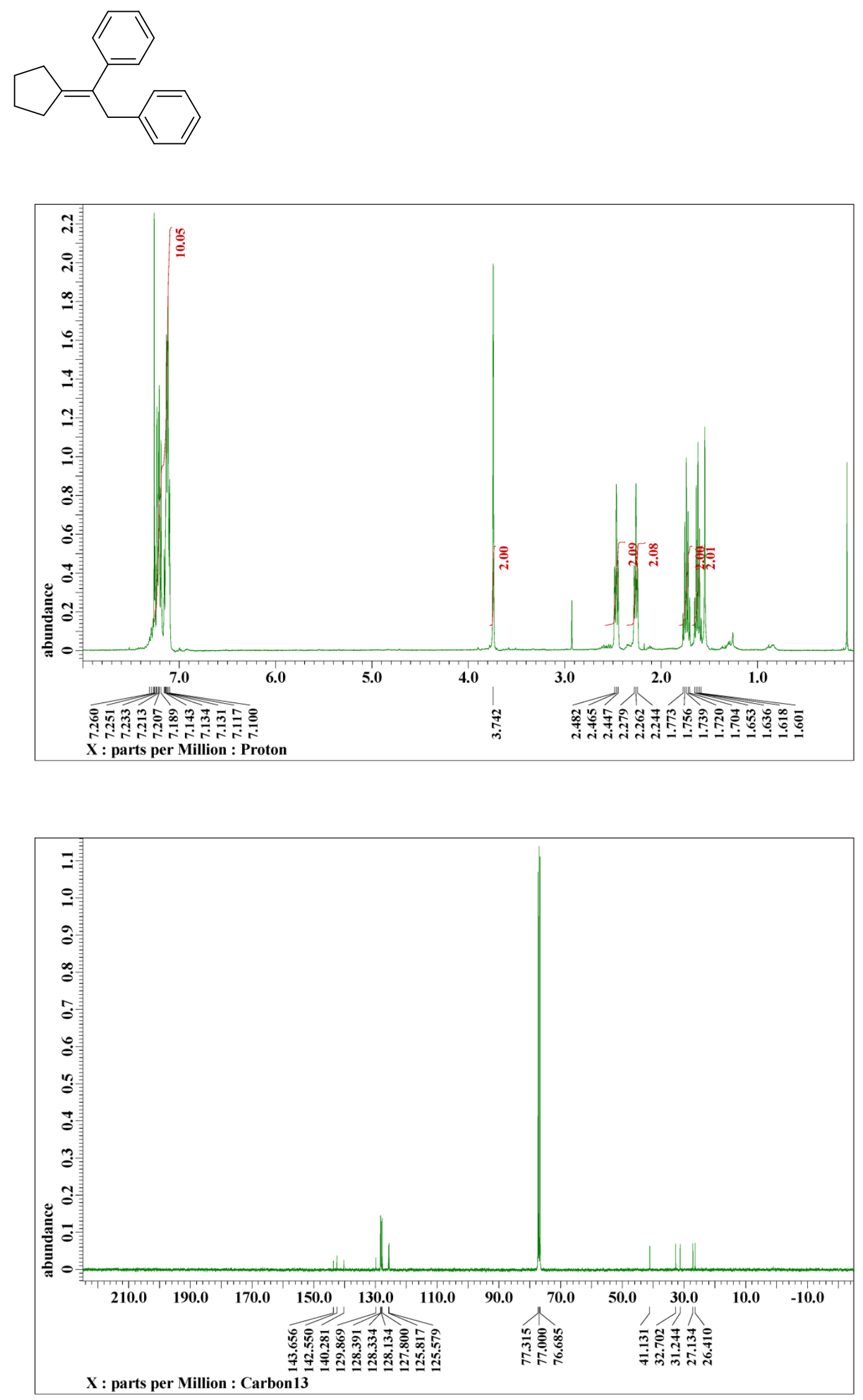
${ }^{1} \mathrm{H}\left(400 \mathrm{MHz}, \mathrm{CDCl}_{3}\right.$, upper) and ${ }^{13} \mathrm{C}\left\{{ }^{1} \mathrm{H}\right\} \quad\left(100 \mathrm{MHz}, \mathrm{CDCl}_{3}\right.$, lower) NMR spectra of (2-cyclopentylidenepropyl)benzene (3ca)
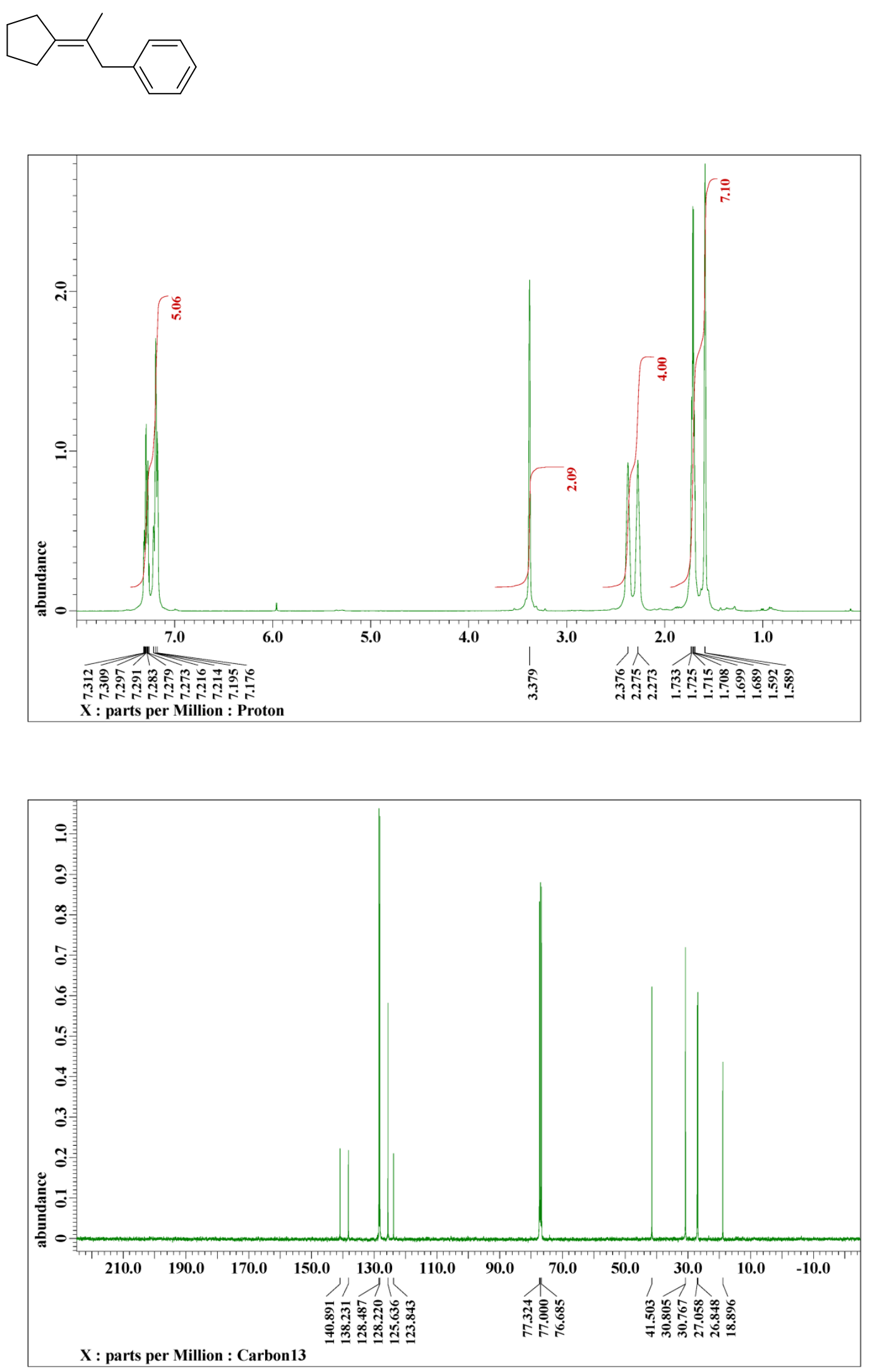
${ }^{1} \mathrm{H}\left(400 \mathrm{MHz}, \mathrm{CDCl}_{3}\right.$, upper) and ${ }^{13} \mathrm{C}\left\{{ }^{1} \mathrm{H}\right\} \quad\left(100 \mathrm{MHz}, \mathrm{CDCl}_{3}\right.$, lower) NMR spectra of (E)-(2-(2-phenylcyclopentylidene)ethyl)benzene ((E)-3da)
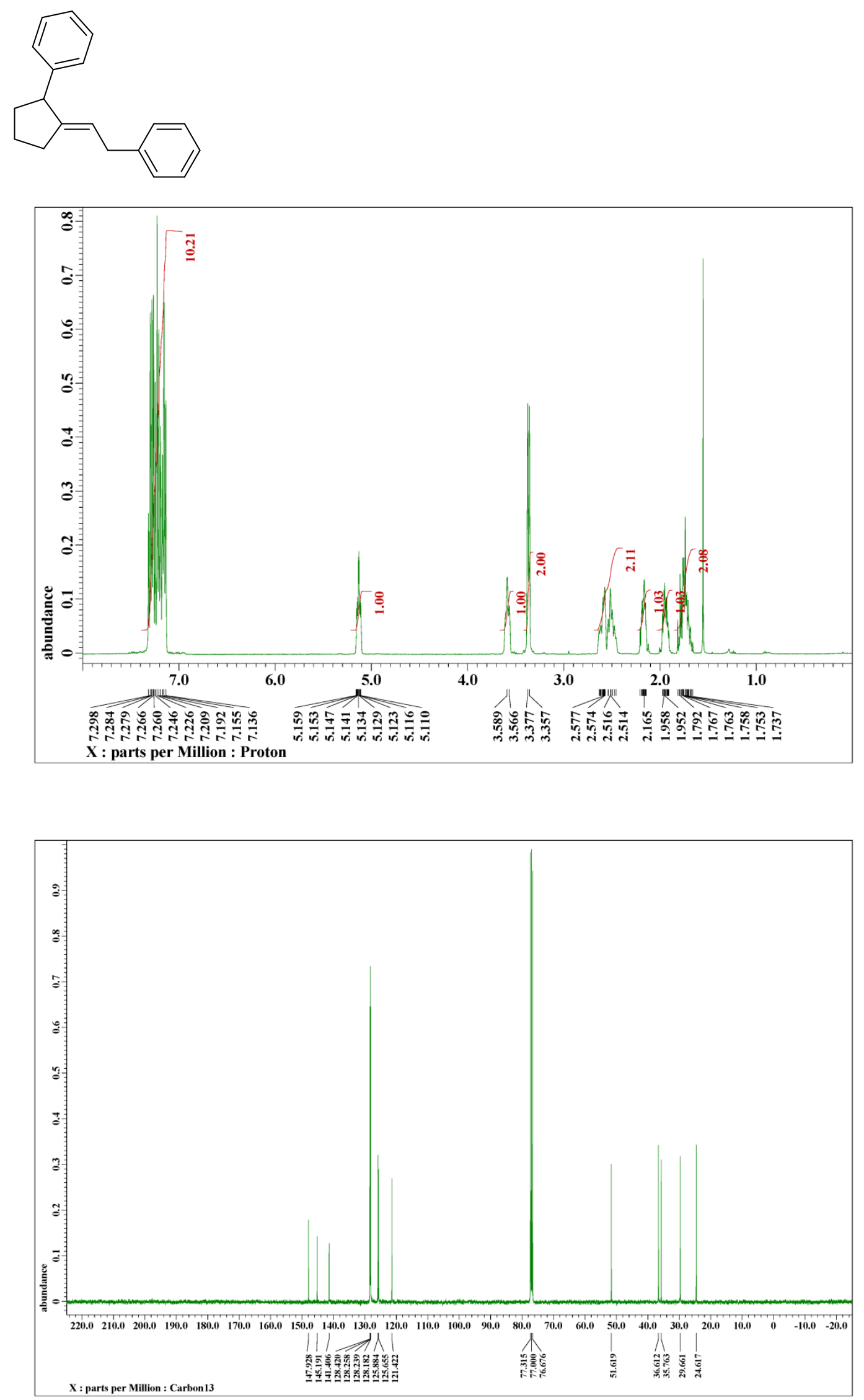
${ }^{1} \mathrm{H}\left(400 \mathrm{MHz}, \mathrm{CDCl}_{3}\right.$, upper) and ${ }^{13} \mathrm{C}\left\{{ }^{1} \mathrm{H}\right\} \quad\left(100 \mathrm{MHz}, \mathrm{CDCl}_{3}\right.$, lower) NMR spectra of (Z)-(2-(2-phenylcyclopentylidene)ethyl)benzene ((Z)-3da)
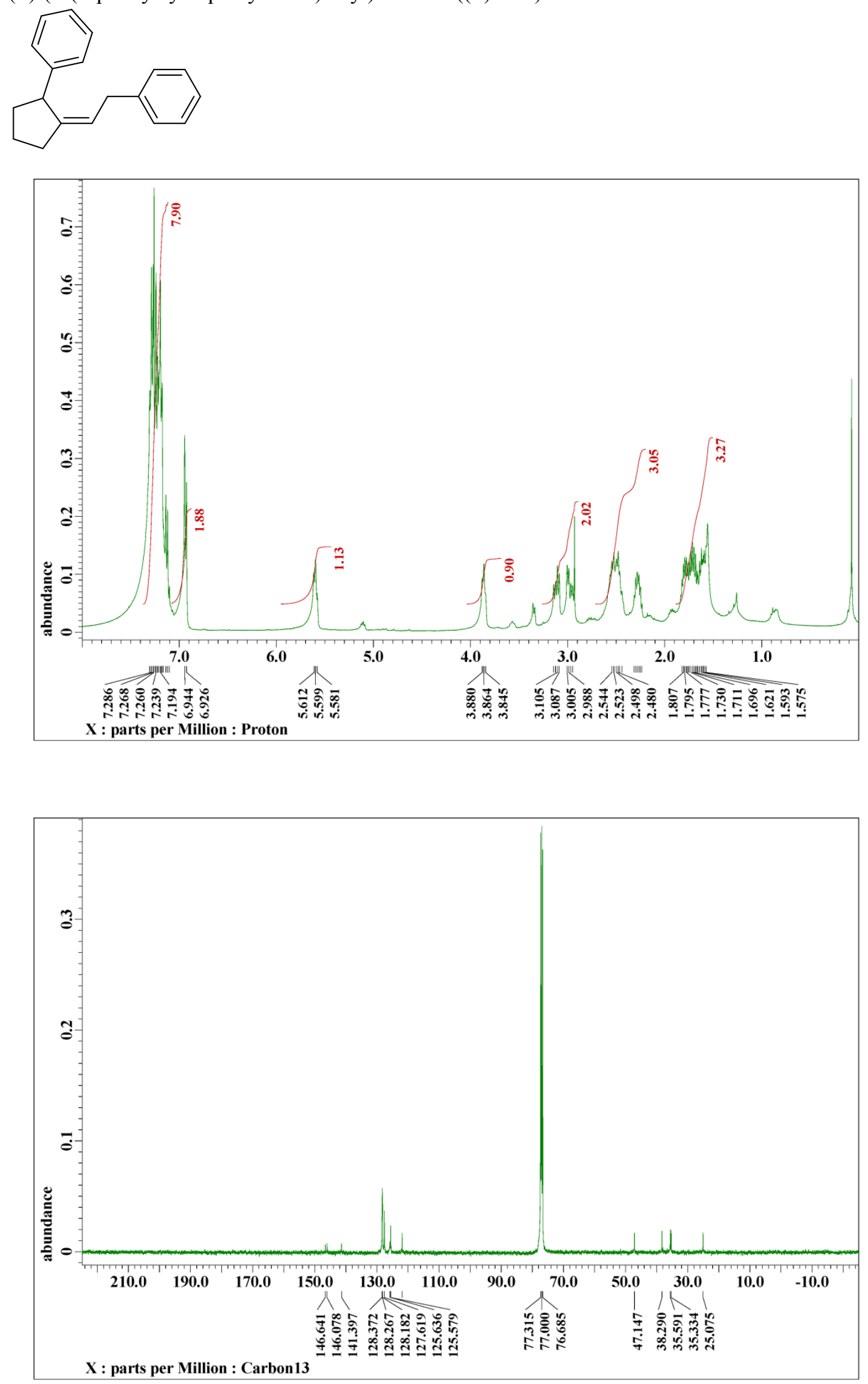
${ }^{1} \mathrm{H}\left(400 \mathrm{MHz}, \mathrm{CDCl}_{3}\right.$, upper) and ${ }^{13} \mathrm{C}\left\{{ }^{1} \mathrm{H}\right\}\left(100 \mathrm{MHz}, \mathrm{CDCl}_{3}\right.$, lower $)$ NMR spectra of a mixture of (E)-(2-(2-ethylcyclopentylidene)ethyl)benzene ((E)-3ea) \& (Z)-3ea
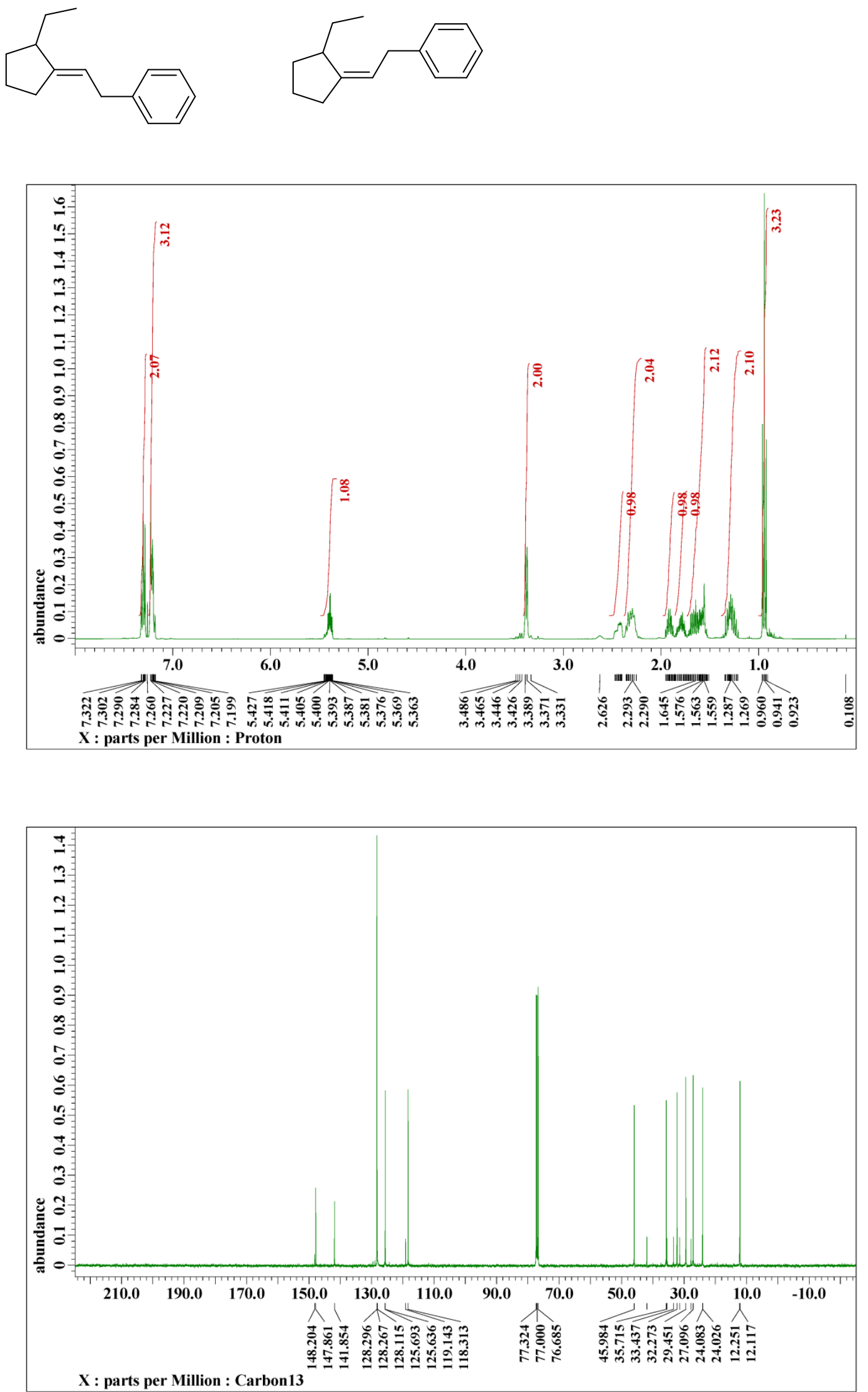
${ }^{1} \mathrm{H}\left(400 \mathrm{MHz}, \mathrm{CDCl}_{3}\right.$, upper) and ${ }^{13} \mathrm{C}\left\{{ }^{1} \mathrm{H}\right\}\left(100 \mathrm{MHz}, \mathrm{CDCl}_{3}\right.$, lower $)$ NMR spectra of a mixture of (E)-(2-(2-butylcyclopentylidene)ethyl)benzene ((E)-3fa) \& (Z)-3fa
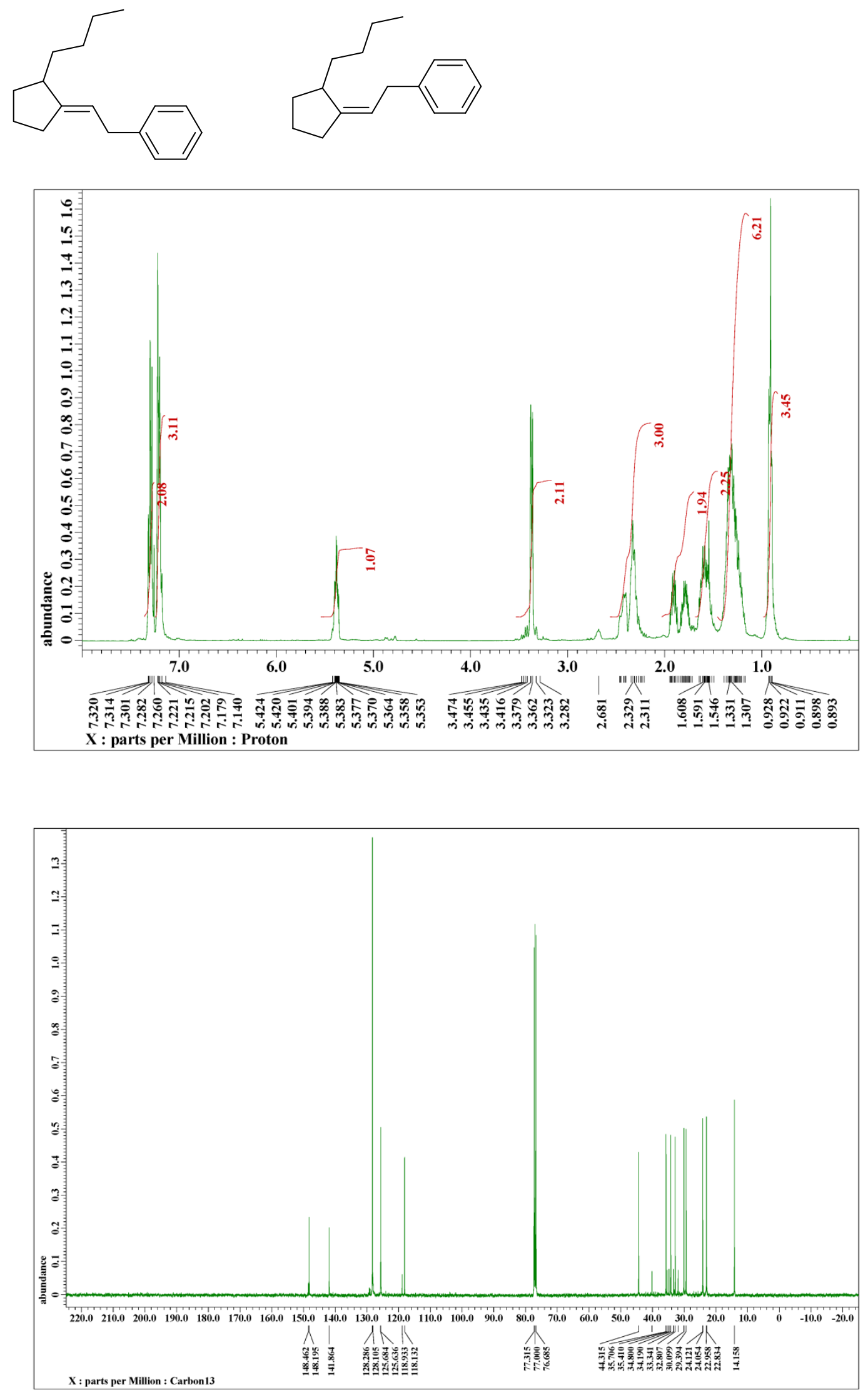
${ }^{1} \mathrm{H}\left(400 \mathrm{MHz}, \mathrm{CDCl}_{3}\right.$, upper) and ${ }^{13} \mathrm{C}\left\{{ }^{1} \mathrm{H}\right\}\left(100 \mathrm{MHz}, \mathrm{CDCl}_{3}\right.$, lower $)$ NMR spectra of a mixture of (E)-(2-(2-heptylcyclopentylidene)ethyl)benzene ((E)-3ga) \& (Z)-3ga
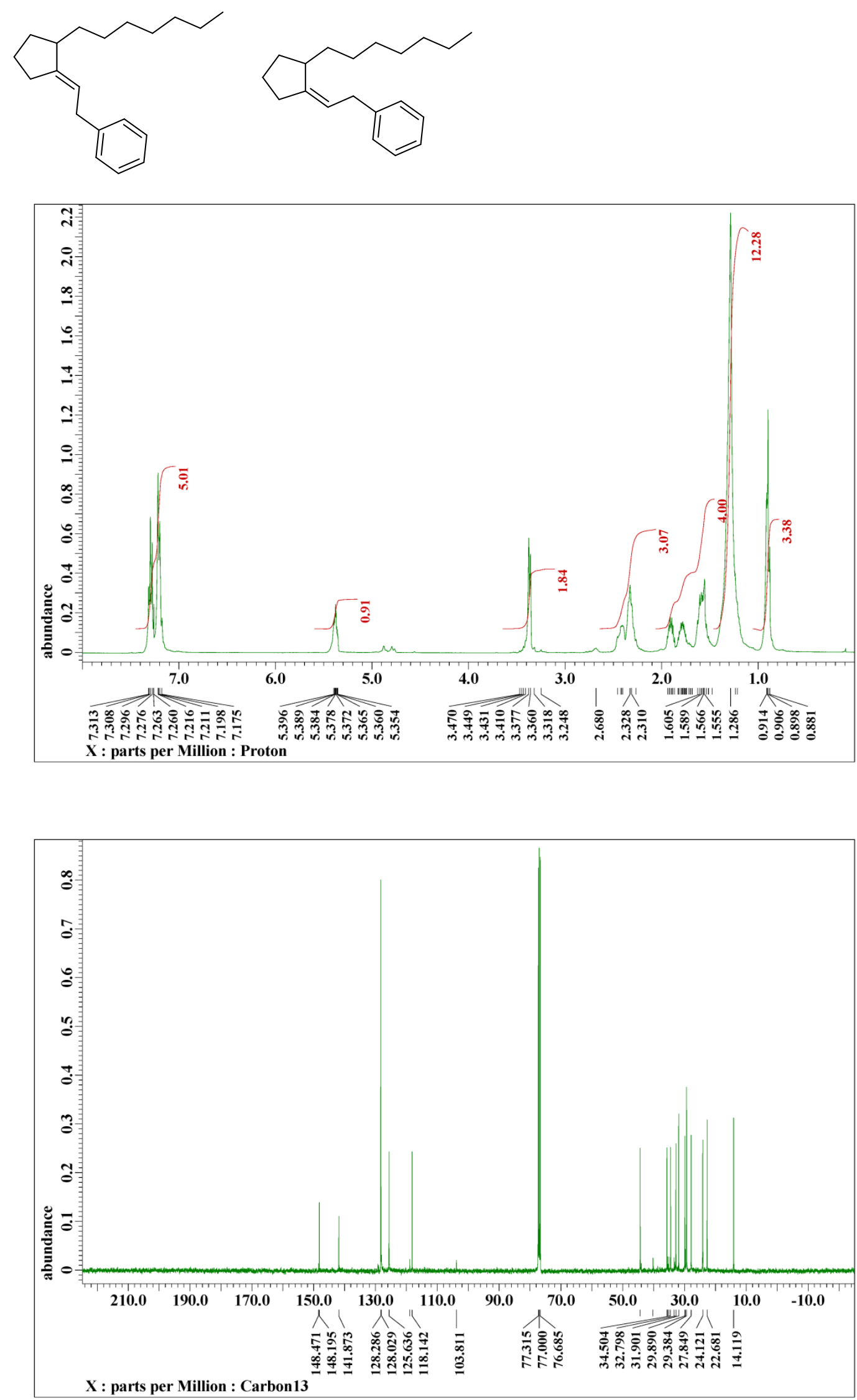
${ }^{1} \mathrm{H}\left(400 \mathrm{MHz}, \mathrm{CDCl}_{3}\right.$, upper) and ${ }^{13} \mathrm{C}\left\{{ }^{1} \mathrm{H}\right\}\left(100 \mathrm{MHz}, \mathrm{CDCl}_{3}\right.$, lower $)$ NMR spectra of a mixture of (E)-(2-(2-cyclohexylcyclopentylidene)ethyl)benzene ((E)-3ha) \& (Z)-3ha
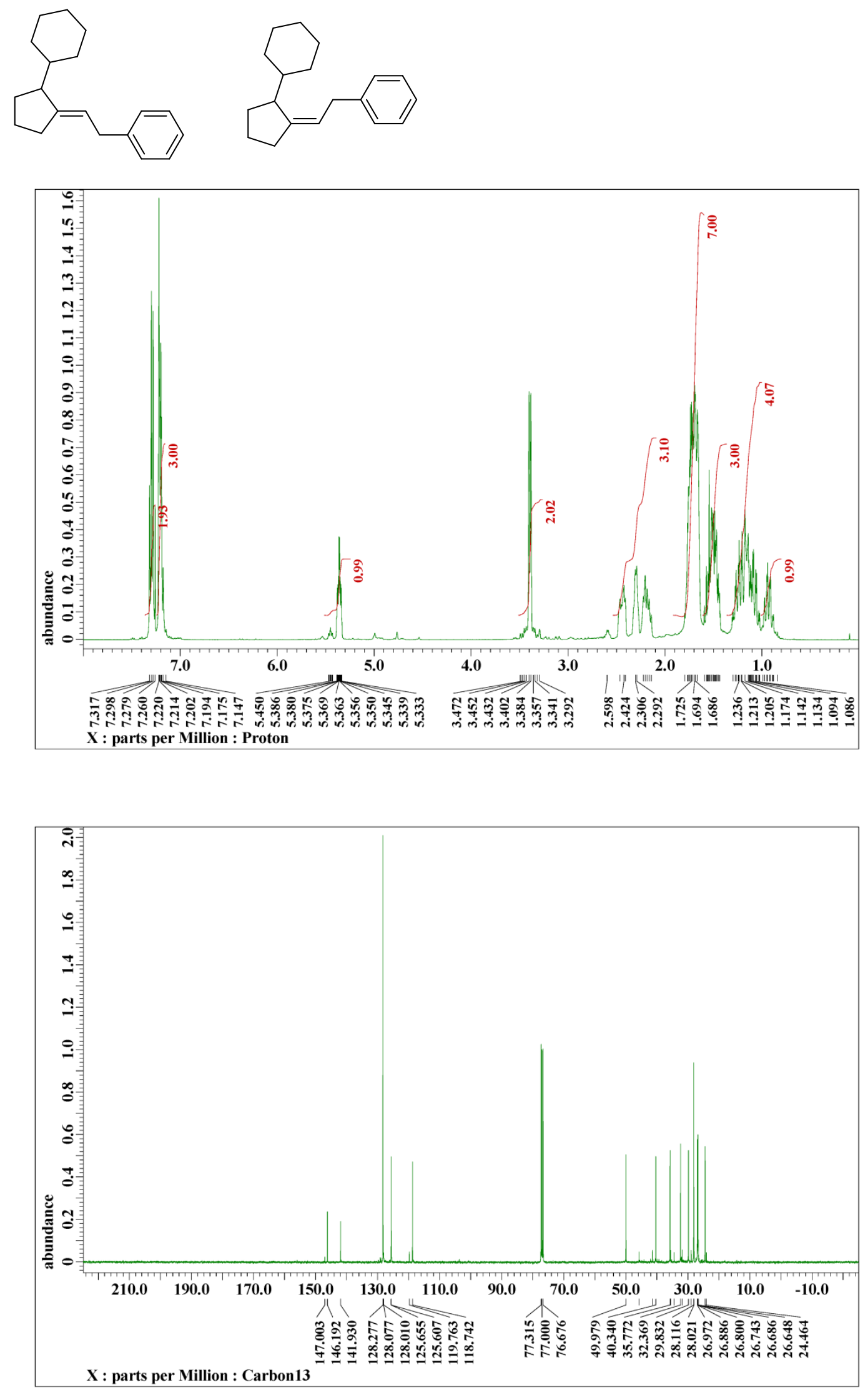
${ }^{1} \mathrm{H}\left(400 \mathrm{MHz}, \mathrm{CDCl}_{3}\right.$, upper) and ${ }^{13} \mathrm{C}\left\{{ }^{1} \mathrm{H}\right\} \quad\left(100 \mathrm{MHz}, \mathrm{CDCl}_{3}\right.$, lower) NMR spectra of (E)-(2-(2,2-dimethylcyclopentylidene)ethyl)benzene ((E)-3ia)
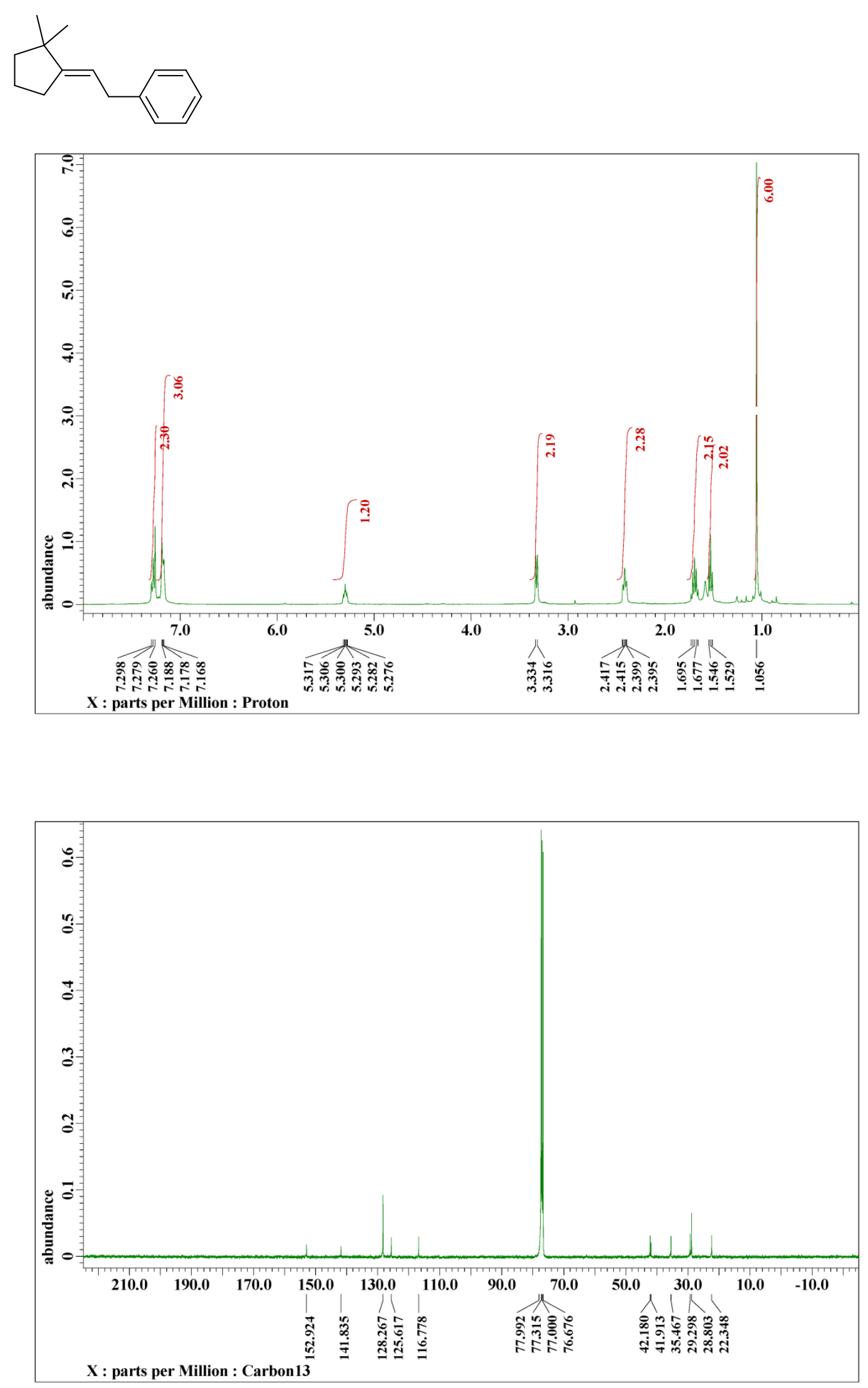
${ }^{1} \mathrm{H}\left(400 \mathrm{MHz}, \mathrm{CDCl}_{3}\right.$, upper) and ${ }^{13} \mathrm{C}\left\{{ }^{1} \mathrm{H}\right\} \quad\left(100 \mathrm{MHz}, \mathrm{CDCl}_{3}\right.$, lower) NMR spectra of (E)-1-(2-(2,2-Dimethylcyclopentylidene)ethyl)naphthalene ((E)-3ii)
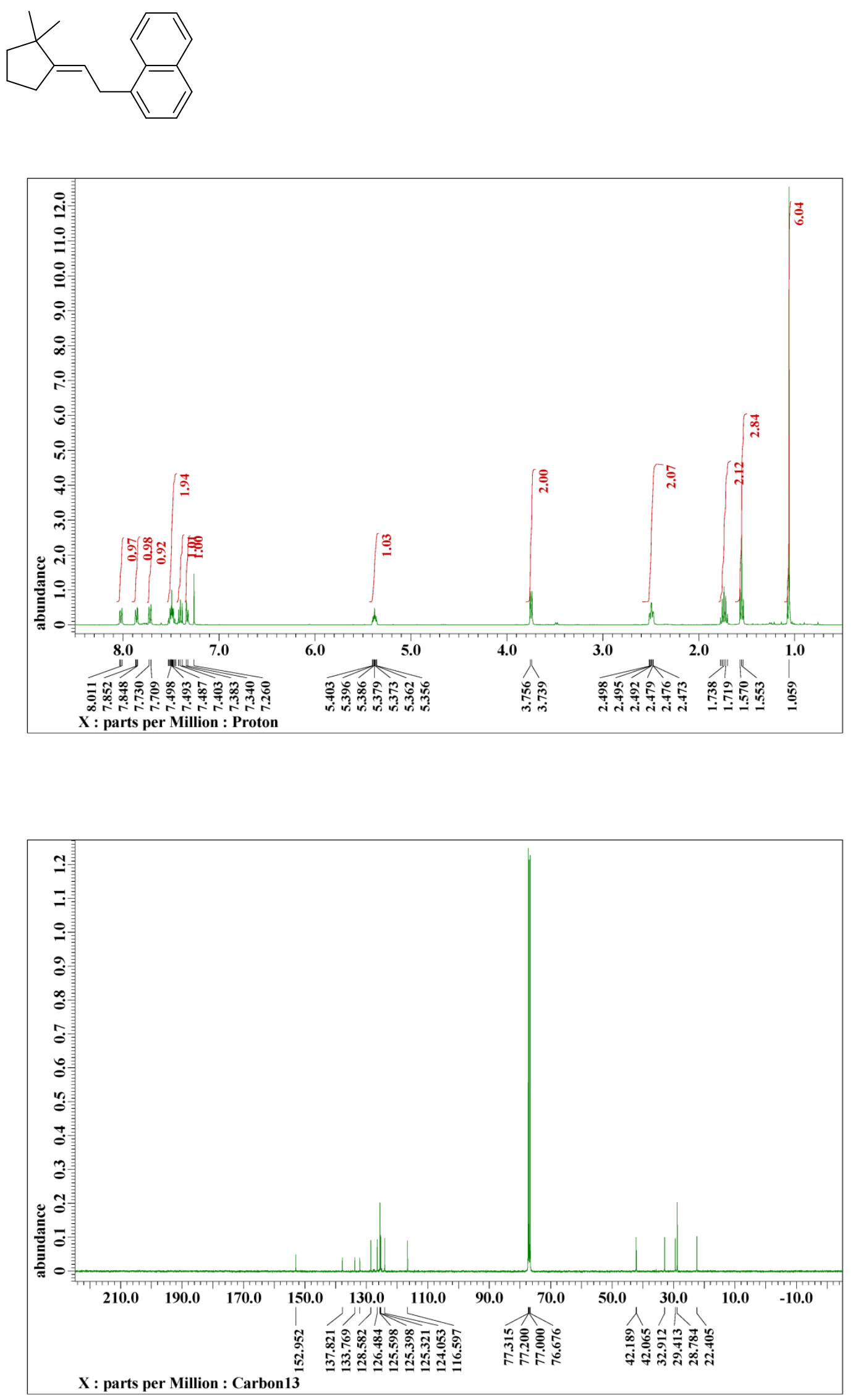
${ }^{1} \mathrm{H}\left(400 \mathrm{MHz}, \mathrm{CDCl}_{3}\right.$, upper) and ${ }^{13} \mathrm{C}\left\{{ }^{1} \mathrm{H}\right\} \quad\left(100 \mathrm{MHz}, \mathrm{CDCl}_{3}\right.$, lower) NMR spectra of (E)-(2-(2-phenylcyclopentylidene)propyl)benzene ((E)-3ja) \& (Z)-3ja
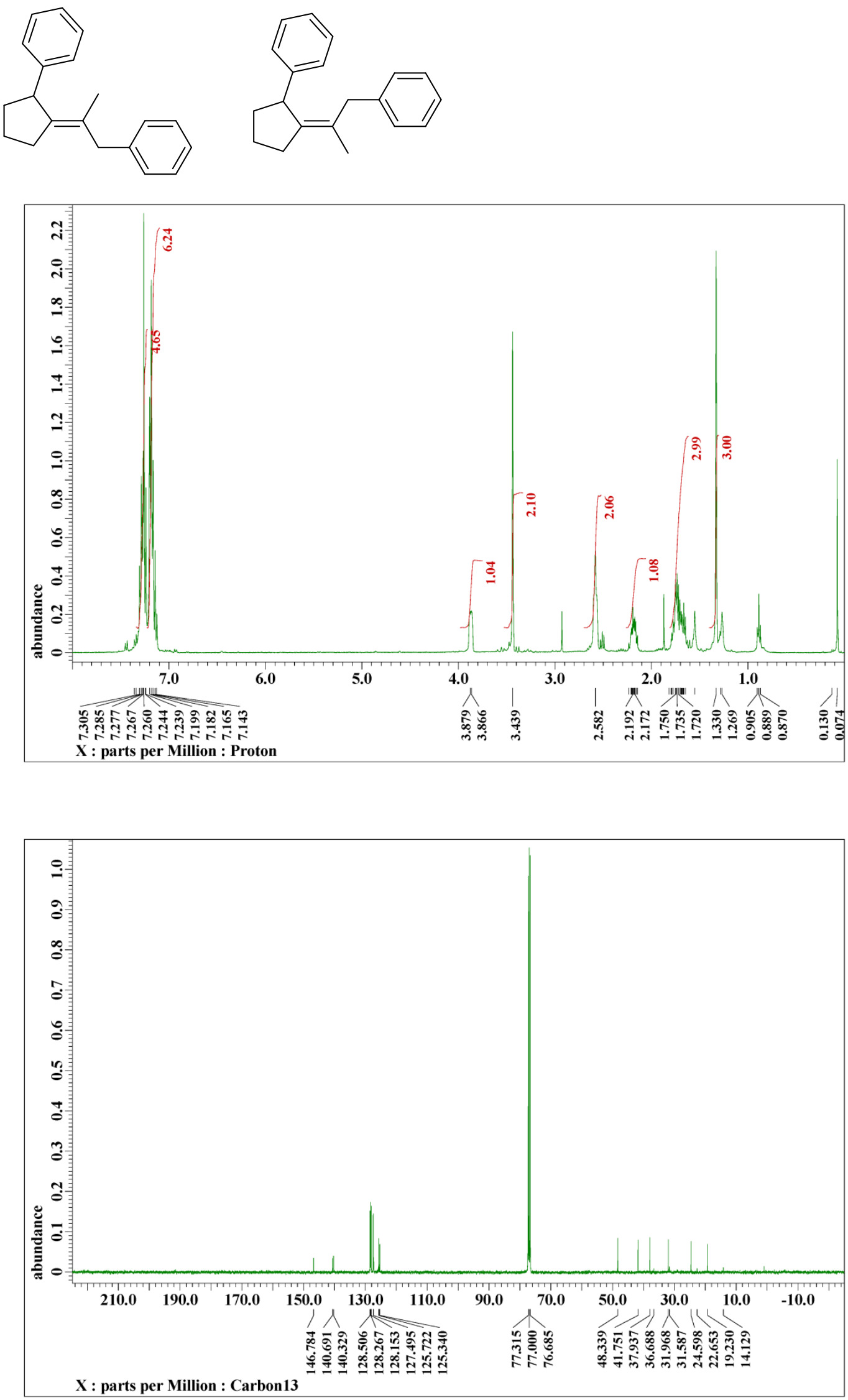
${ }^{1} \mathrm{H}\left(400 \mathrm{MHz}, \mathrm{CDCl}_{3}\right.$, upper) and ${ }^{13} \mathrm{C}\left\{{ }^{1} \mathrm{H}\right\}\left(100 \mathrm{MHz}, \mathrm{CDCl}_{3}\right.$, lower) NMR spectra of dimethyl 2-(3-iodopropyl)-2-(prop-2-yn-1-yl)malonate (4b)
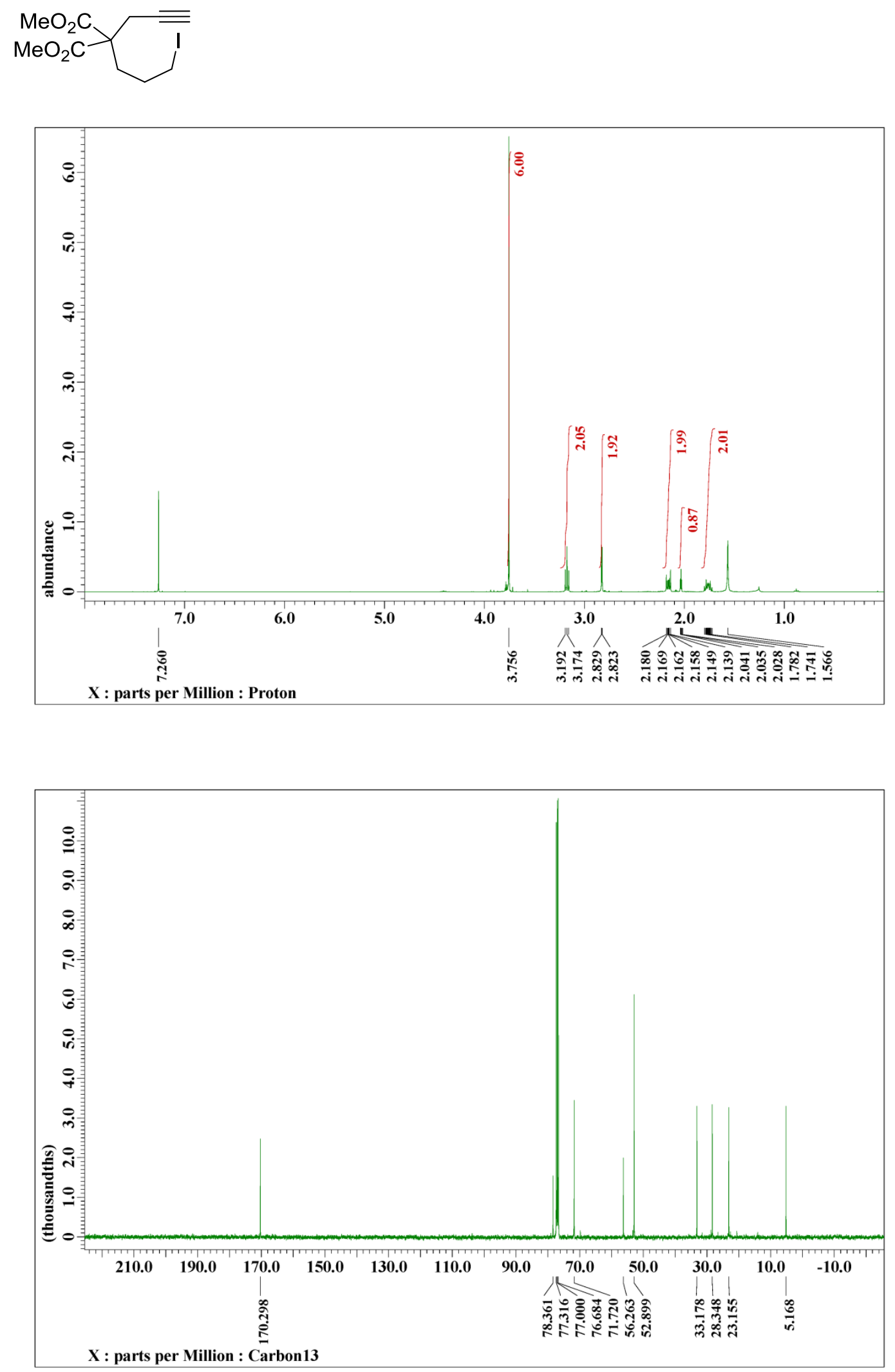
${ }^{1} \mathrm{H}\left(400 \mathrm{MHz}, \mathrm{CDCl}_{3}\right.$, upper) and ${ }^{13} \mathrm{C}\left\{{ }^{1} \mathrm{H}\right\}\left(100 \mathrm{MHz}, \mathrm{CDCl}_{3}\right.$, lower $)$ NMR spectra of (E)-(2-(iodomethylene)cyclopentyl)benzene $((E)-7 \mathbf{d})$
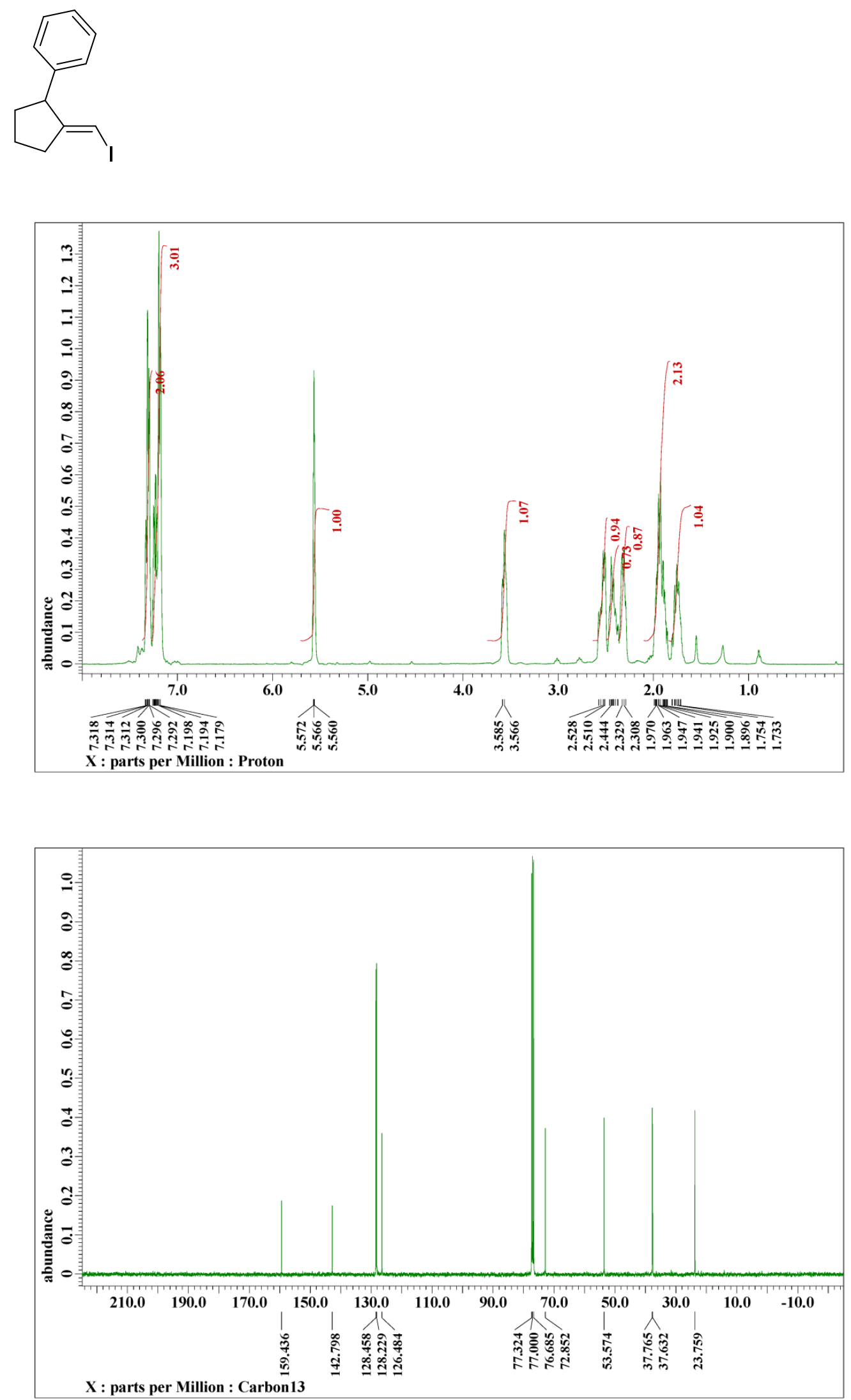
S11. HRMS analysis reports for each compound.

HRMS analysis reports for (6-iodohex-1-yn-3-yl)benzene (1d)

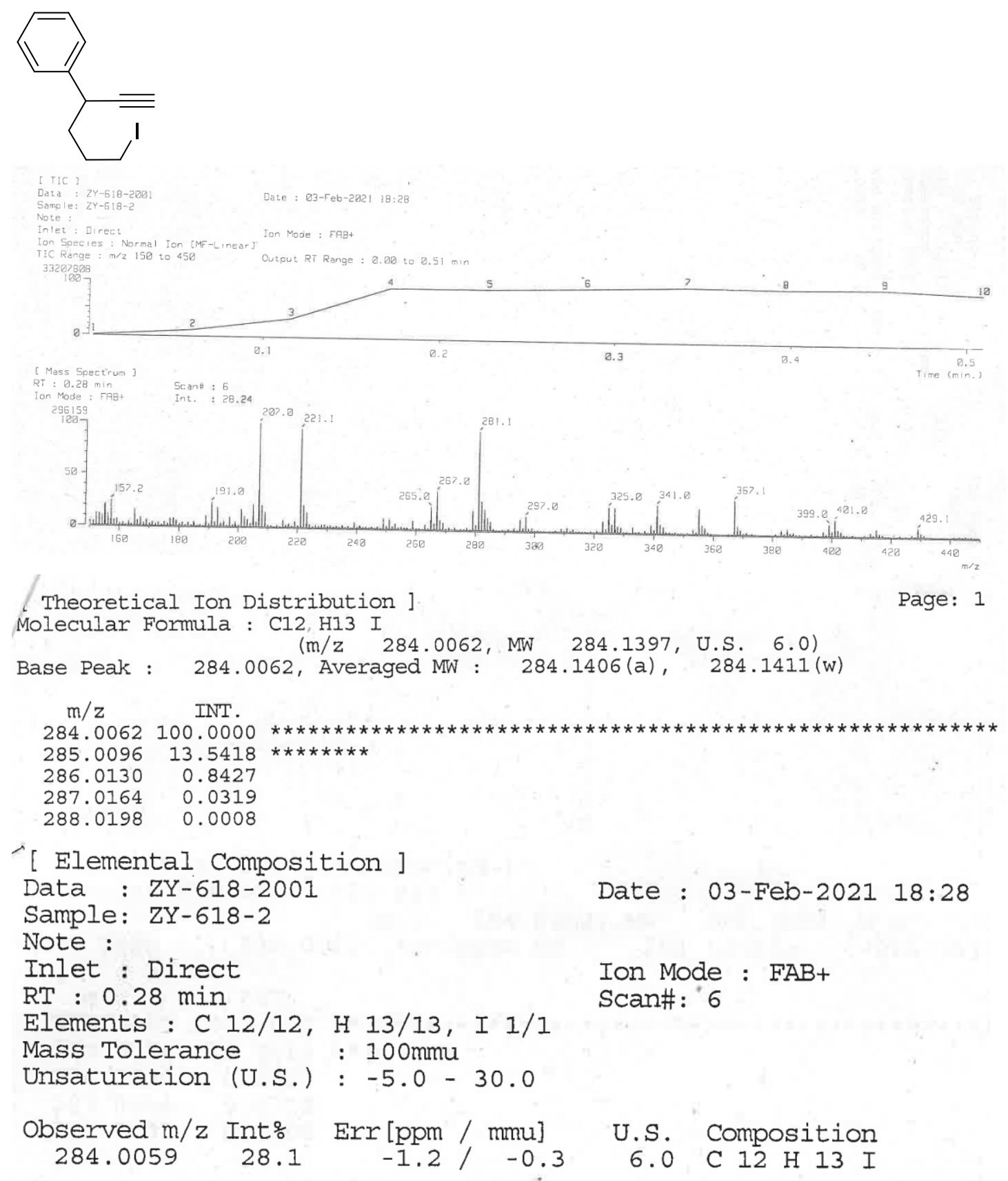


HRMS analysis reports for 3-ethyl-6-iodohex-1-yne (1e)

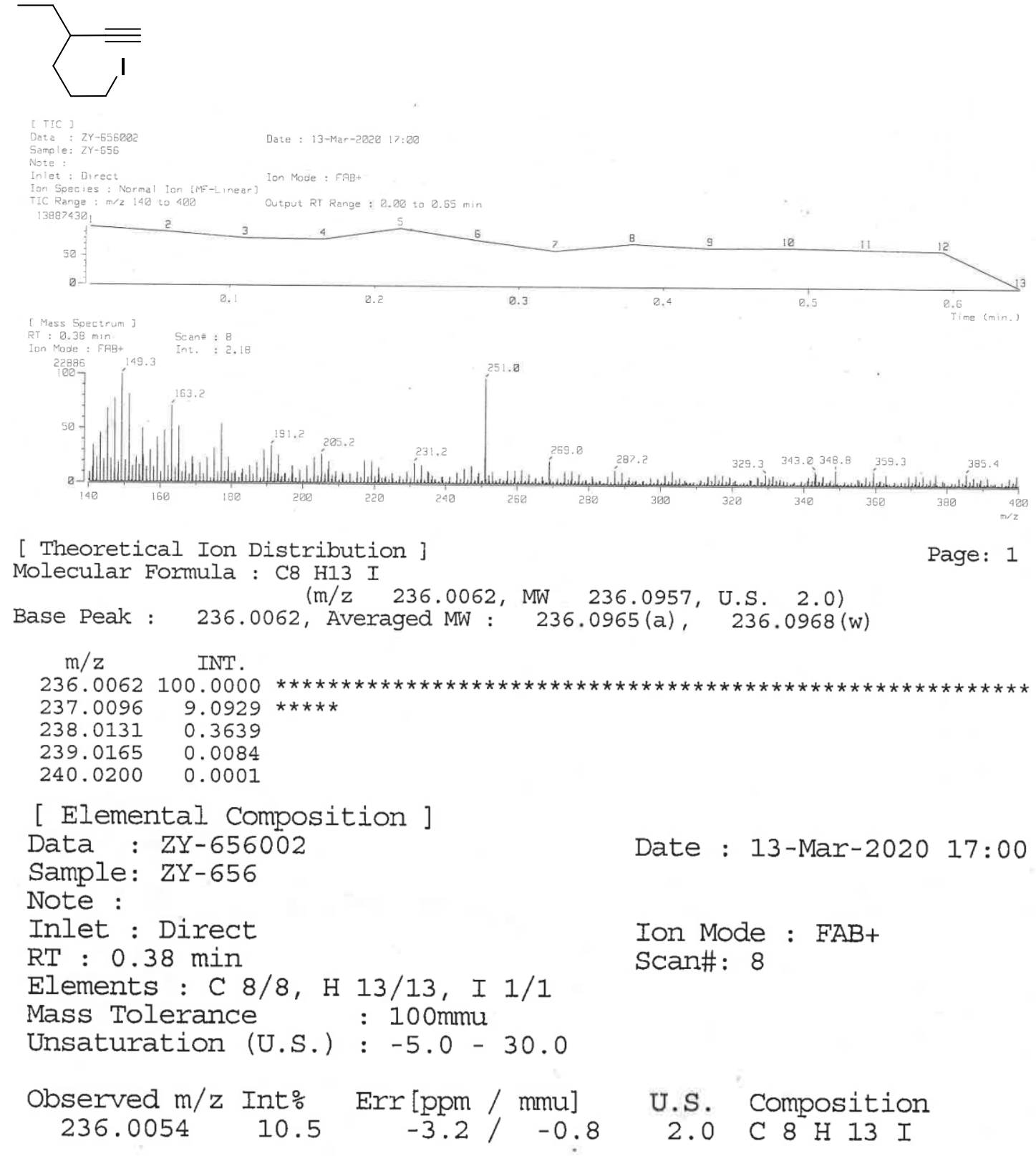


HRMS analysis reports for 4-ethynyl-1-iodooctane (1f)

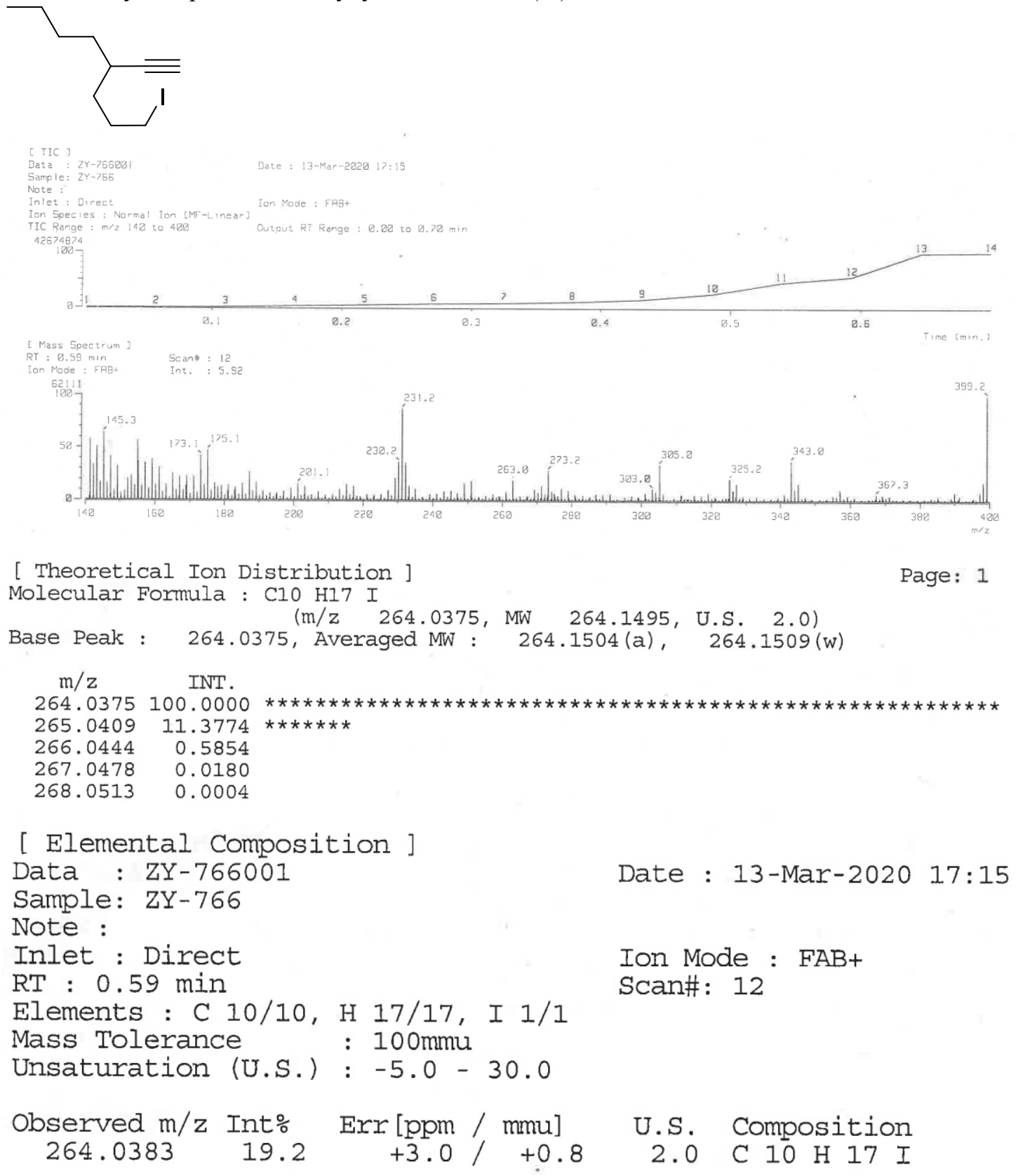


HRMS analysis reports for 4-ethynyl-1-iodoundecane (1g)

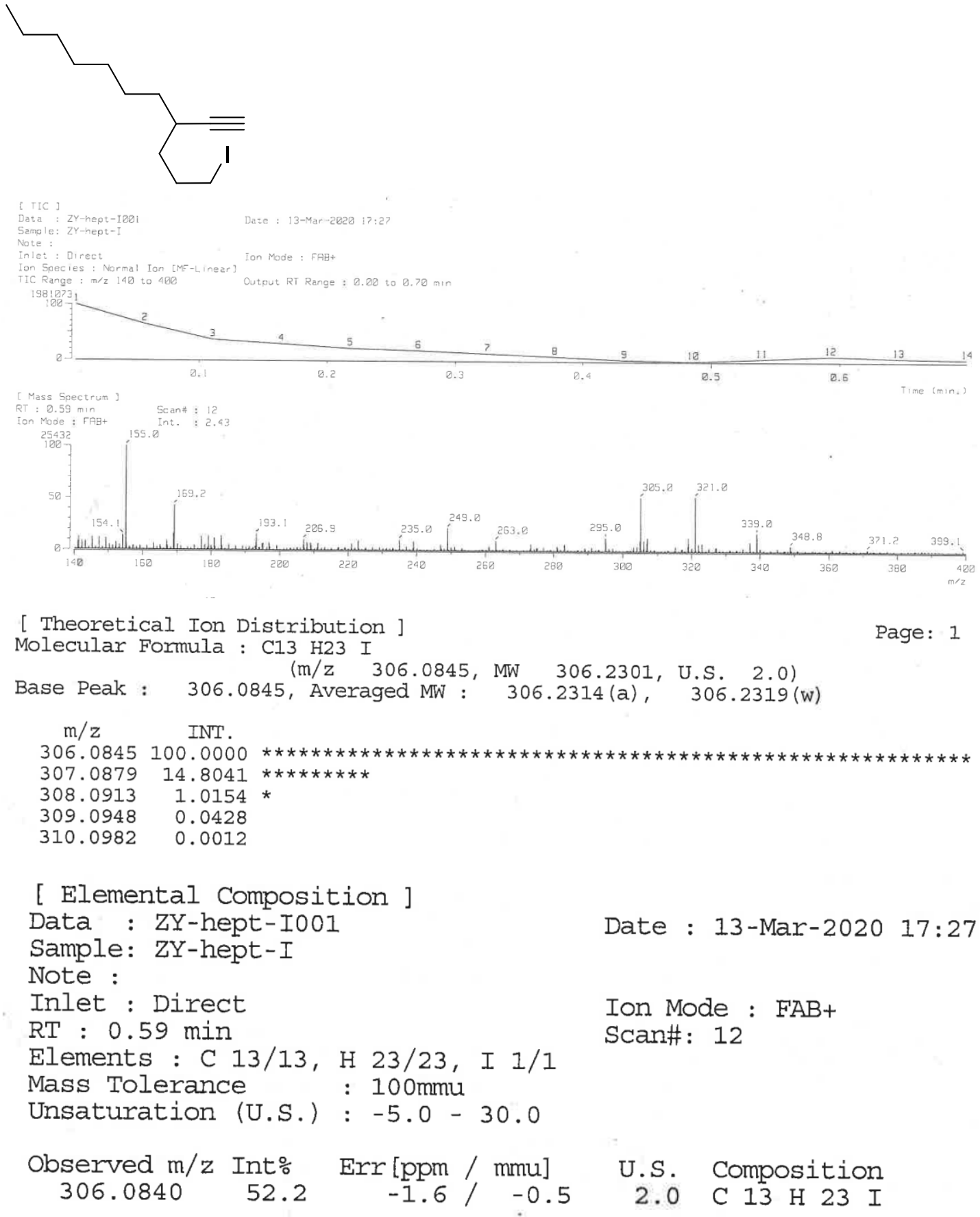


HRMS analysis reports for (6-iodohex-1-yn-3-yl)cyclohexane (1h)

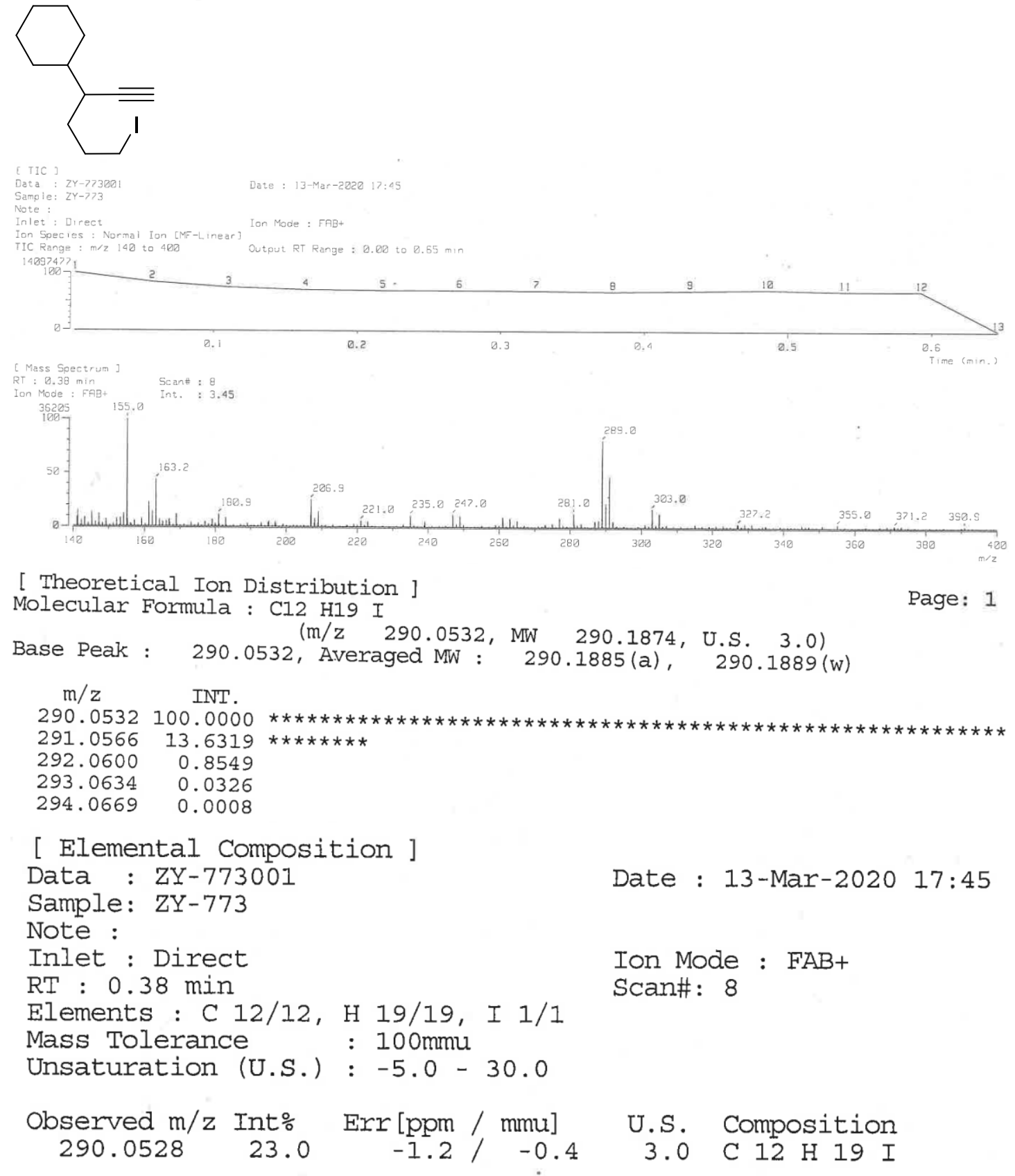


HRMS analysis reports for (7-iodohept-2-yn-4-yl)benzene (1j)

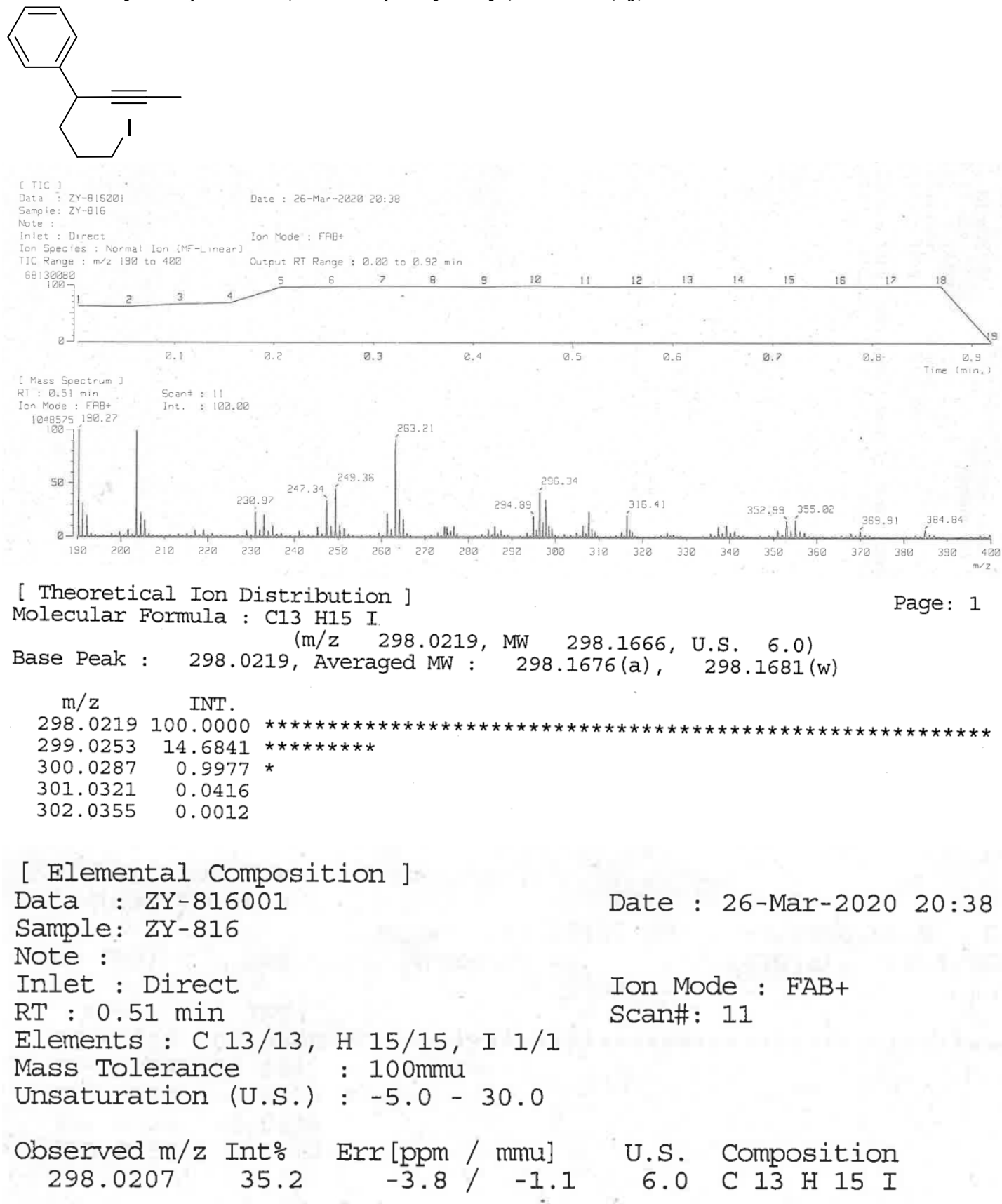


HRMS analysis reports for diethyl

4-(4-cyanobenzyl)-2,6-dimethyl-1,4-dihydropyridine-3,5-dicarboxylate (2f)

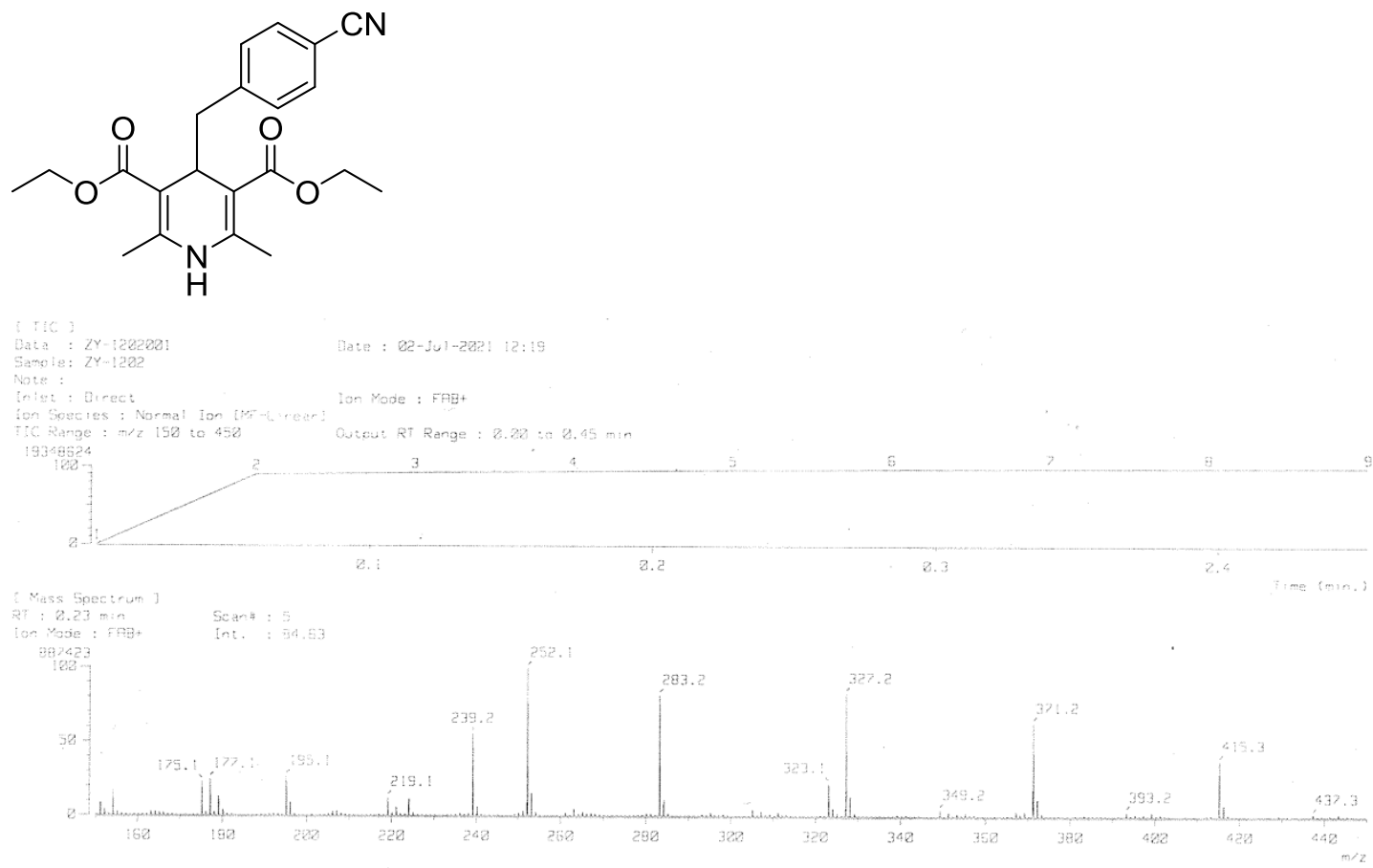

[ Theoretical Ion Distribution ]

Page: 1

Molecular Formula : C2I H24 O4 N2

$(\mathrm{m} / \mathrm{z} \quad 368.1736$, MW 368.4326, U.S. 11.0)

Base Peak : 368.1736, Averaged MW : 368.4339(a), 368.4346(w)

$\mathrm{m} / \mathrm{z} \quad$ INT.

368.1736100 .0000

369.176824 .6040

$370.1796 \quad 3.6974 * *$

$371.1822 \quad 0.4139$

$372.1848 \quad 0.0372$

$373.1874 \quad 0.0028$

$374.1899 \quad 0.0002$

[ Elemental Composition ]

Data : ZY-1202001

Sample: ZY-1202

Note :

Inlet : Direct

$\mathrm{RT}: 0.23 \mathrm{~min}$

Elements : C 21/21, H 24/24, O 4/4, N 2/2

Date : 02-Jul-2021 12:19

Mass Tolerance : 100mmu

Unsaturation (U.S.) : $-5.0-30.0$

Observed $\mathrm{m} / \mathrm{z}$ Int\% Err [ppm / mmu] U.S. Composition $\begin{array}{lllllllll}368.1741 & 63.3+1.3 / & +0.5 & 11.0 & \mathrm{C} 21 \mathrm{H} & 2404 \mathrm{~N} 2\end{array}$ 
HRMS analysis reports for diethyl

4-(furan-2-ylmethyl)-2,6-dimethyl-1,4-dihydropyridine-3,5-dicarboxylate (2q)<smiles>CCOC(=O)C1=C(C)NC(C)=C(C(=O)OCC)C1Cc1ccco1</smiles>

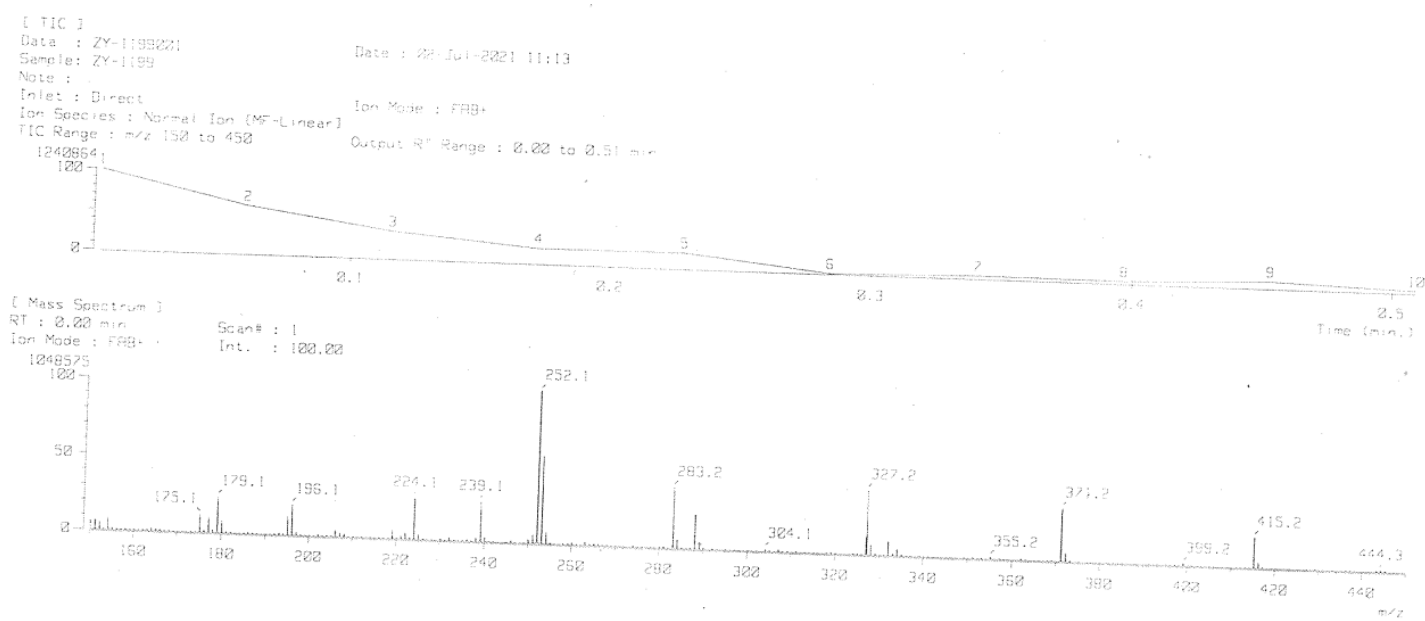

[ Theoretical Ion Distribution ]

Molecular Formula : C18 H23 $05 \mathrm{~N}$

Page: 1

333.1576, MW 333.3843, U.S. 8.0)

$$
\begin{array}{cr}
\mathrm{m} / \mathrm{z} & \multicolumn{1}{c}{\text { INT. }} \\
333.1576 & 100.0000 \\
334.1609 & 20.9231 \\
335.1635 & 3.0792 \\
336.1661 & 0.3394 \\
337.1686 & 0.0305 \\
338.1711 & 0.0023 \\
339.1736 & 0.0002
\end{array}
$$

[ Elemental Composition ]

Data : ZY-1199001

Sample: ZY-1199

Note :

Inlet : Direct

$\mathrm{RT}: 0.00 \mathrm{~min}$

Elements : C $18 / 18, \mathrm{H} 23 / 23$,

$333.3854(\mathrm{a}), \quad 333.3861(\mathrm{w})$

Mass Tolerance : $100 \mathrm{mmu}$

Unsaturation (U.S.) : $-5.0-30.0$
Observed $\mathrm{m} / \mathrm{z}$ Int:
Err [ppm / mmu] $+0.8 /+0.3$
U.S. Composition 333.1579 42.6
8.0
$\mathrm{C} 18 \mathrm{H} 23 \circ 5 \mathrm{~N}$

Ion Mode : FAB+ Scan\# : 1

Date : 02-Jul-2021 11:13 N $1 / 1$ 
HRMS analysis reports for 2-cyclopentylideneethyl)benzene (3aa)

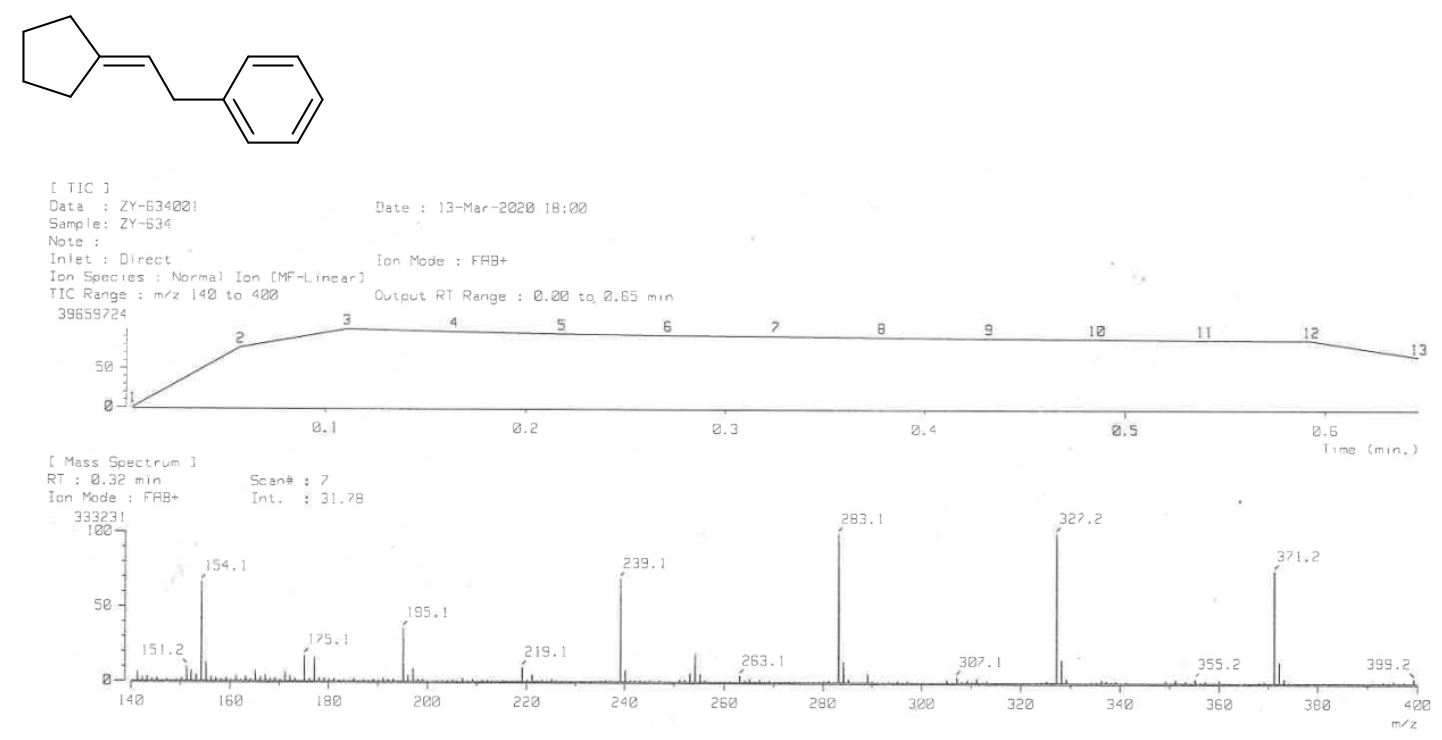

[ Theoretical Ion Distribution ]

Molecular Formula : C13 H16

Base Peak : 172.1252 (m/z 172.1252, MW 172.2700, U.S. 6.0)

172.1252, Averaged MW : $172.2711(\mathrm{a}), \quad 172.2719(\mathrm{w})$

$\mathrm{m} / \mathrm{z} \quad$ INT.

$\begin{array}{rr}172.1252 & 100.0000 \\ 173.1286 & 14.6991\end{array}$

$173.128614 .6991 * * * * * * * * *$

$174.13200 .9999 *$

$175.1354 \quad 0.0417$

$176.1389 \quad 0.0012$

[ Elemental Composition ]

Data : ZY-634001

Sample: ZY-634

Note :

Inlet : Direct

RT : $0.32 \mathrm{~min}$

Elements : C 13/13, H 16/16

Date : 13-Mar-2020 18:00

Mass Tolerance : 100mmu

Unsaturation (U.S.) : $-5.0-30.0$

Observed m/z Int\% Err [ppm / mmu] U.S. Composition
172.1247
17.3
$-2.8 /-0.5$
$6.0 \mathrm{C} 13 \mathrm{H} 16$ 
HRMS analysis reports for 1-(2-cyclopentylideneethyl)-4-methoxybenzene (3ab)

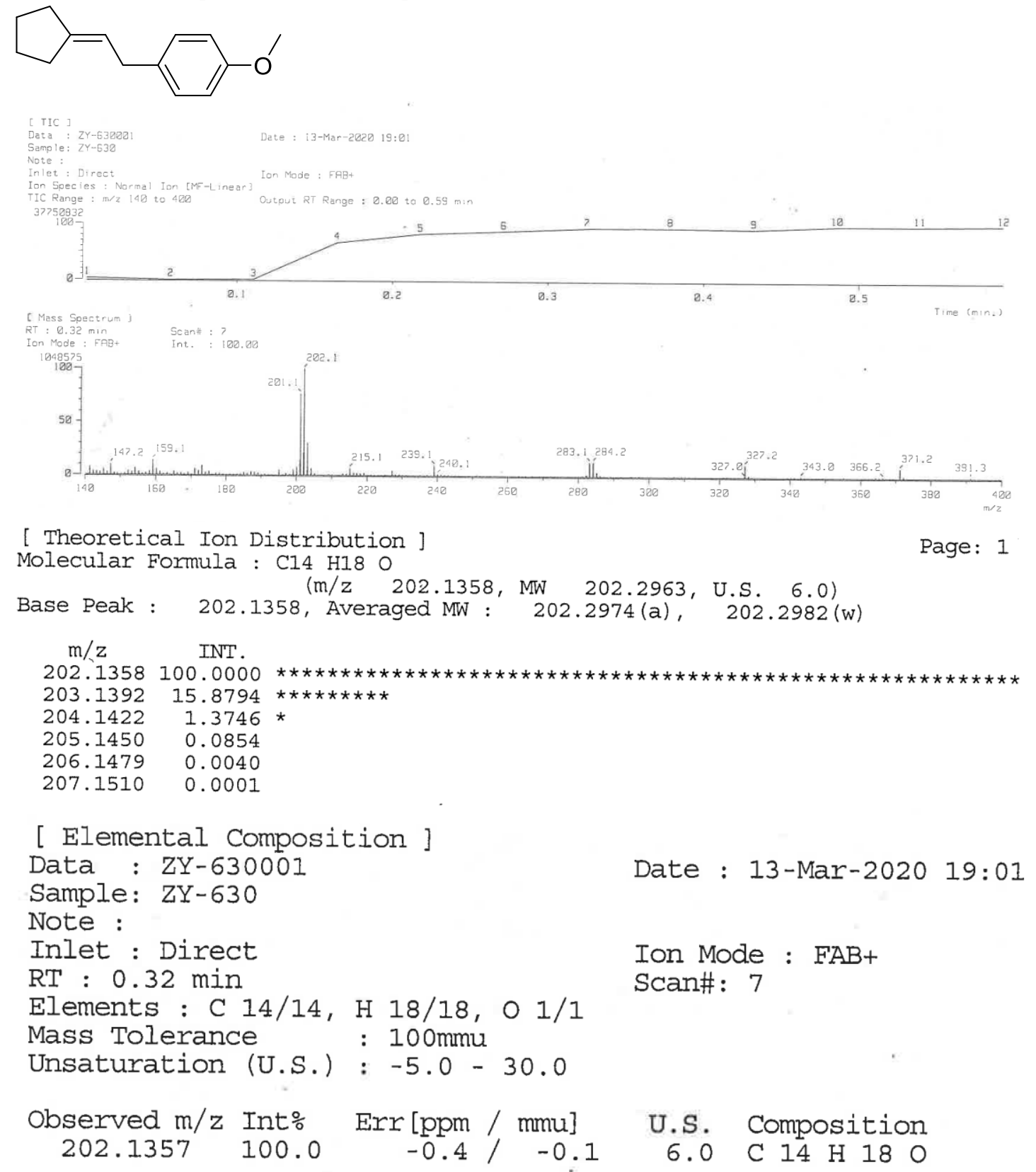


HRMS analysis reports for 1-(2-cyclopentylideneethyl)-4-methylbenzene (3ac)

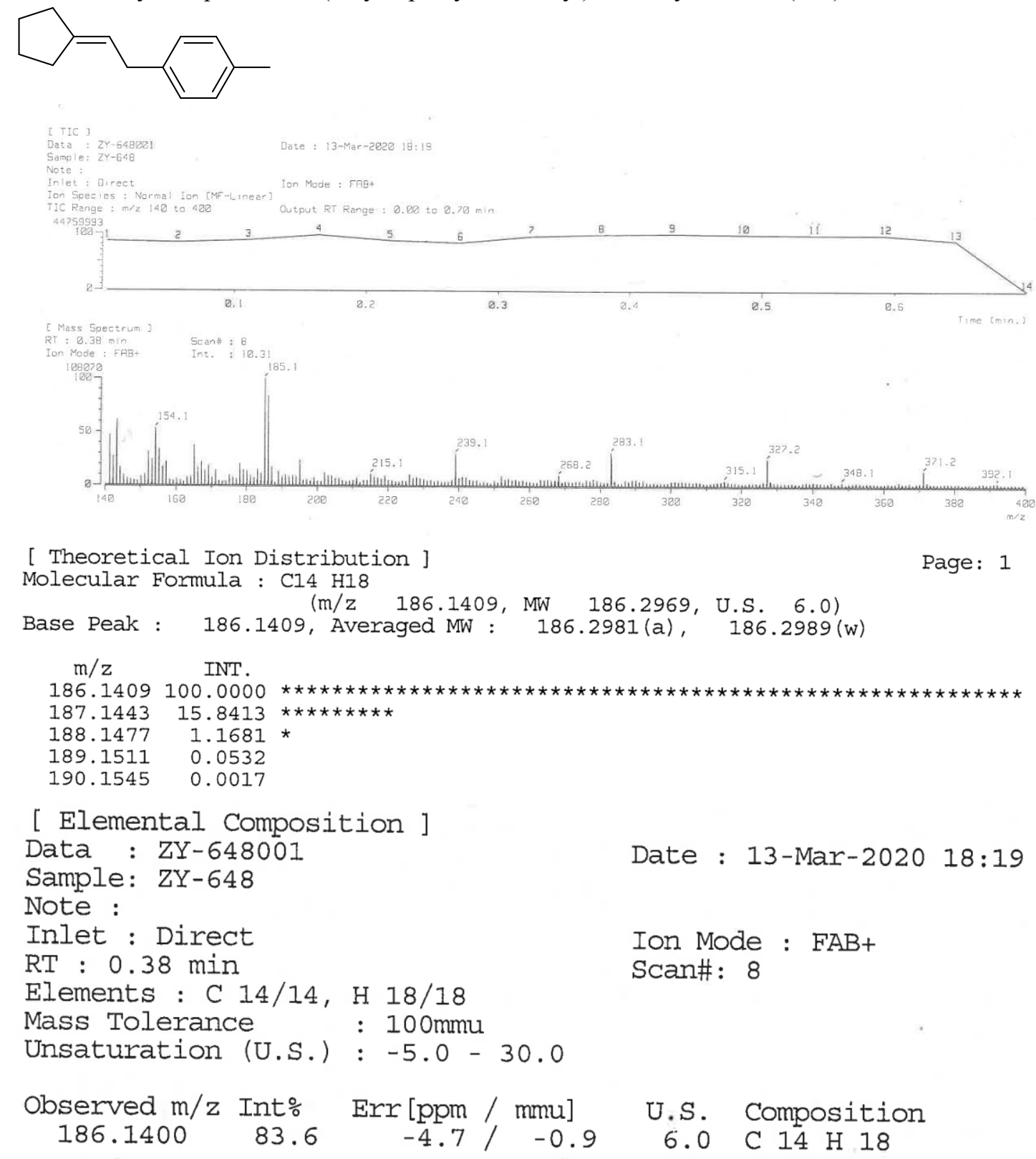


HRMS analysis reports for 4-(2-cyclopentylideneethyl)-1,1'-biphenyl (3ad)

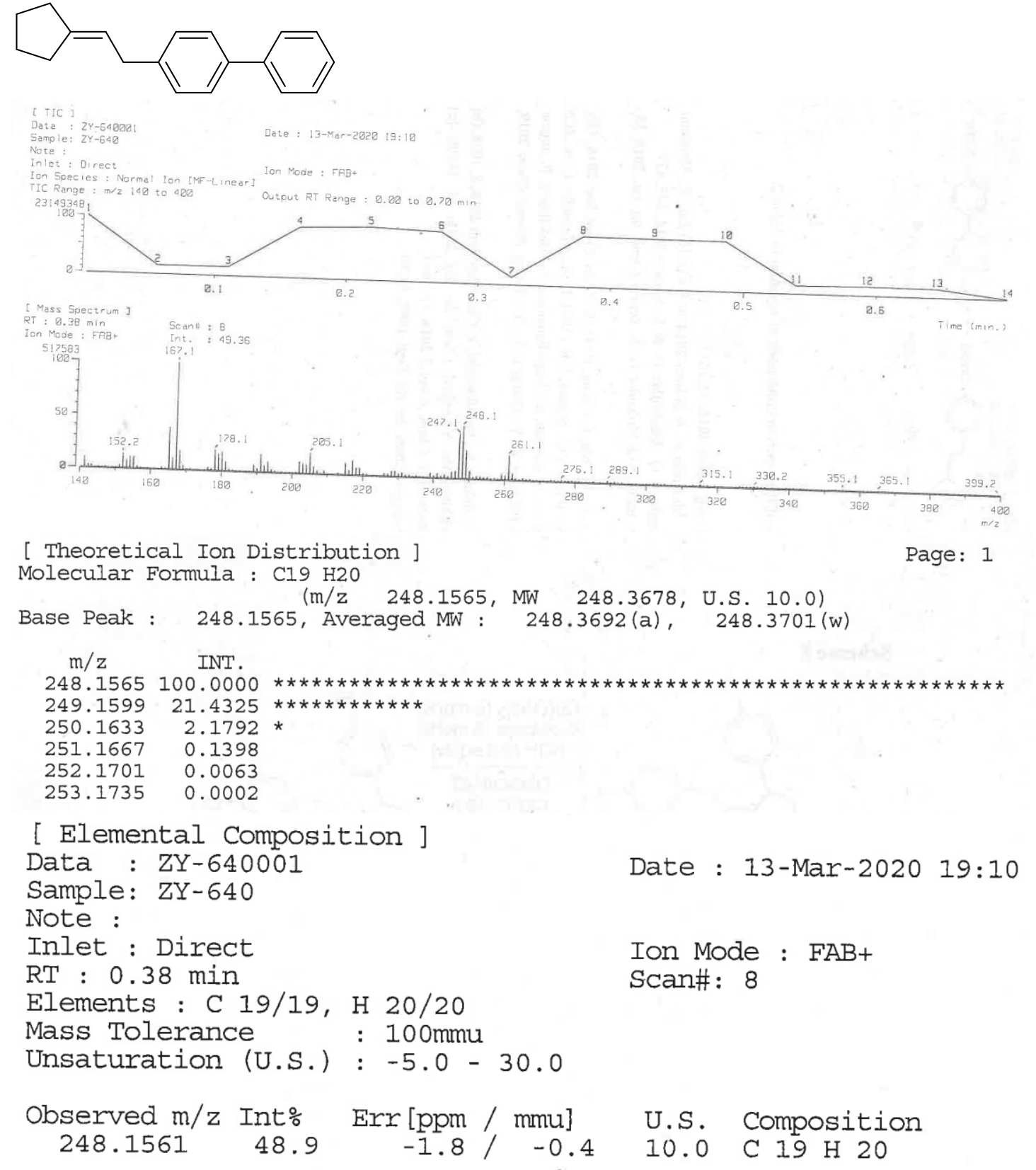


HRMS analysis reports for 1-chloro-4-(2-cyclopentylideneethyl)benzene (3ae)

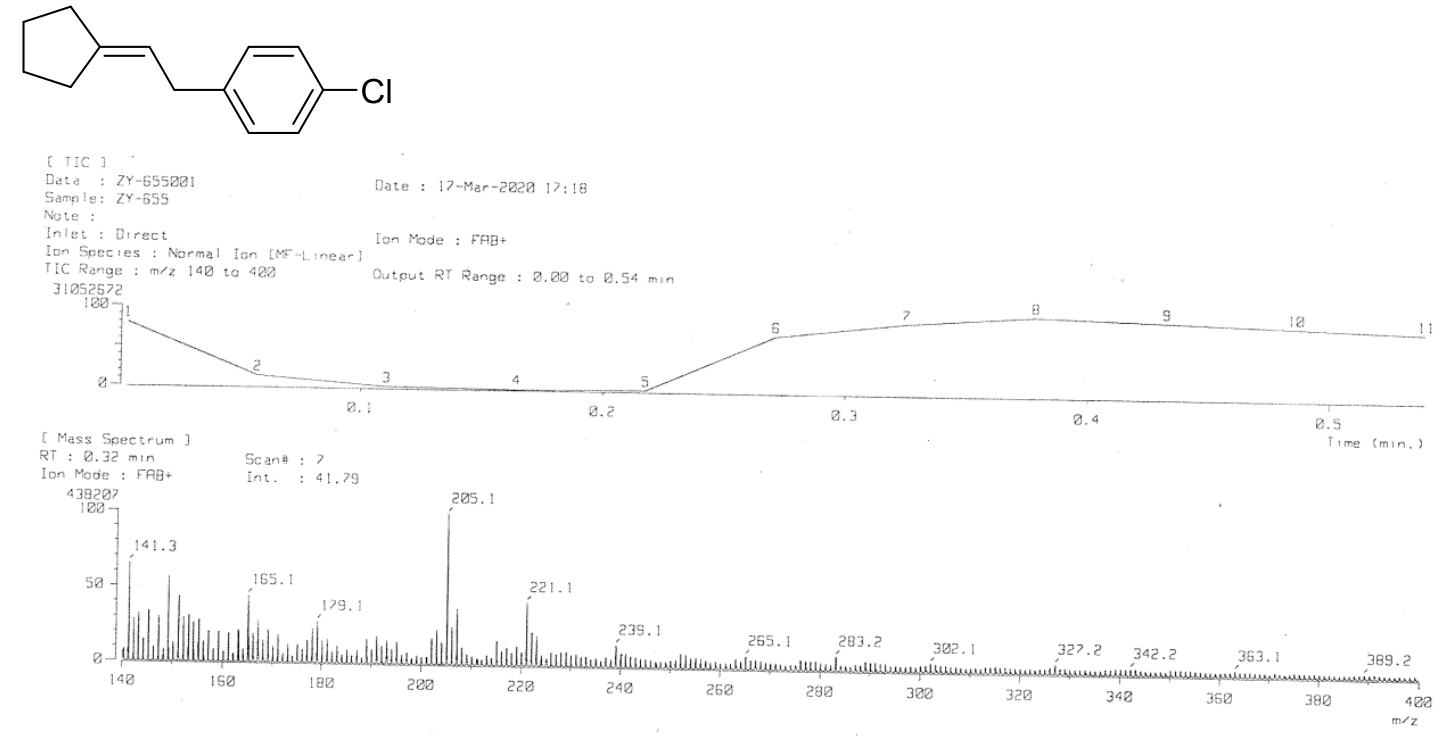

[ Theoretical Ion Distribution ]

Molecular Formula : C13 H15 Cl

Page: 1

Base Peak : 206.0862 (m/z 206.0862, MW 206.7151, U.S. 6.0)

$\begin{array}{cc}\text { Base Peak : } & \text { 206.0862, Averaged MW : } \\ \mathrm{m} / \mathrm{z} & \text { INT. } \\ 206.0862 & 100.0000 * * * * * * * * * * * * * * * * * * \\ 207.0896 & 14.6841 \quad * * * * * * * * \\ 208.0836 & 32.9760 * * * * * * * * * * * * * * * * * \\ 209.0868 & 4.7373 * * * \\ 210.0901 & 0.3202 \\ 211.0935 & 0.0133 \\ 212.0969 & 0.0004 \\ \text { [ Elemental Composition ] }\end{array}$

Data : ZY-655001

Sample: ZY-655

Note :

Inlet : Direct

$\mathrm{RT}: 0.32 \mathrm{~min}$

Elements : C 13/13, H 15/15, Cl 1/1

Date : 17-Mar-2020 17:18

Mass Tolerance : 100mmu

Unsaturation (U.S.) : $-5.0-30.0$

Observed m/z Int\% Err [ppm / mmu U.S. Composition

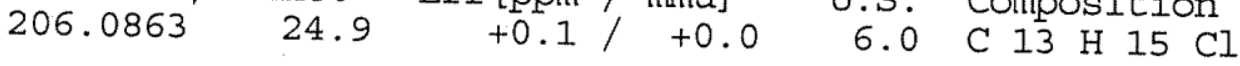


HRMS analysis reports for 1-(2-cyclopentylideneethyl)-3-methylbenzene (3ag)

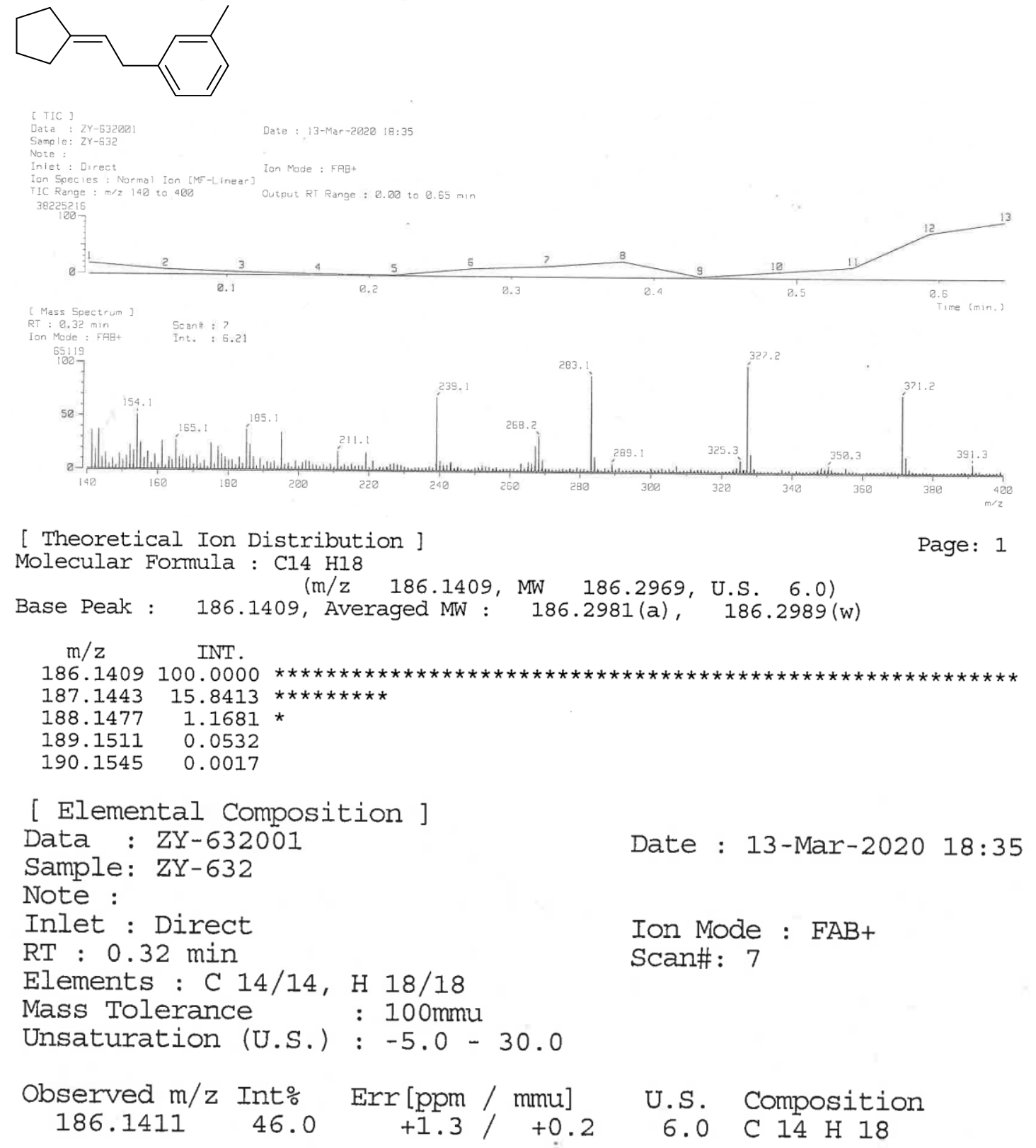


HRMS analysis reports for 1-(2-cyclopentylideneethyl)-2-methylbenzene (3ah)

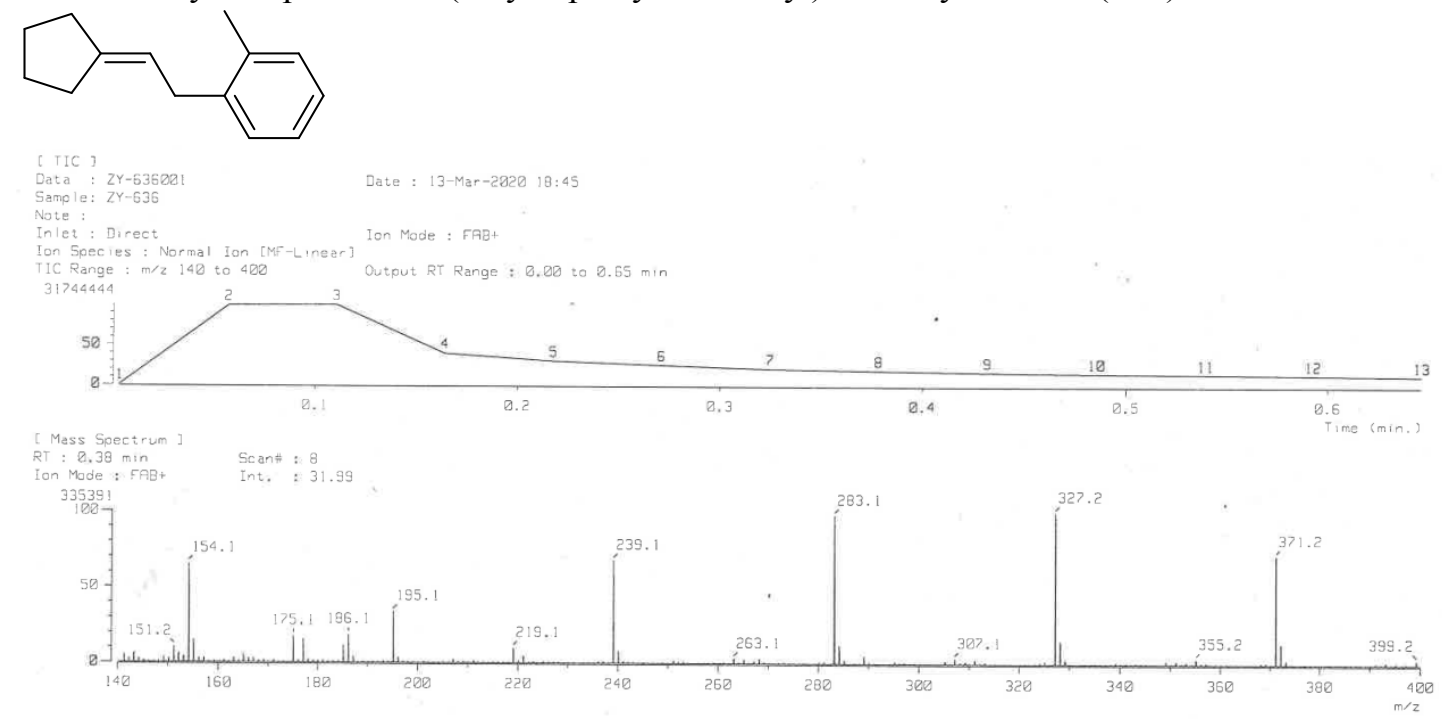

[ Theoretical Ion Distribution ]

Molecular Formula : C14 $\mathrm{H} 18$

Page: 1

(m/z 186.1409, MW 186.2969, U.S. 6.0$)$
Base Peak : $\quad$ 186.1409, Averaged MW : $186.2981(\mathrm{a}), \quad 186.2989(\mathrm{w})$

$\begin{array}{cr}\mathrm{m} / \mathrm{z} & \text { INT. } \\ 186.1409 & 100.0000 \\ 187.1443 & 15.8413 \\ 188.1477 & 1.1681 \\ 189.1511 & 0.0532 \\ 190.1545 & 0.0017\end{array}$

[ Elemental Composition ]

Data : ZY-636001

Sample: ZY-636

Note :

Inlet : Direct

$\mathrm{RT}: 0.38 \mathrm{~min}$

Elements : C 14/14, H 18/18

Mass Tolerance : 100mmu

Unsaturation (U.S.) : $-5.0-30.0$

Observed $\mathrm{m} / \mathrm{z}$ Int: Err [ppm / mmu U.S. Composition

$\begin{array}{lllllllll}186.1413 & 28.2+2.1 / & +0.4 & 6.0 & \mathrm{C} 14 \mathrm{H} 18\end{array}$


HRMS analysis reports for 1-(2-cyclopentylideneethyl)naphthalene (3ai)

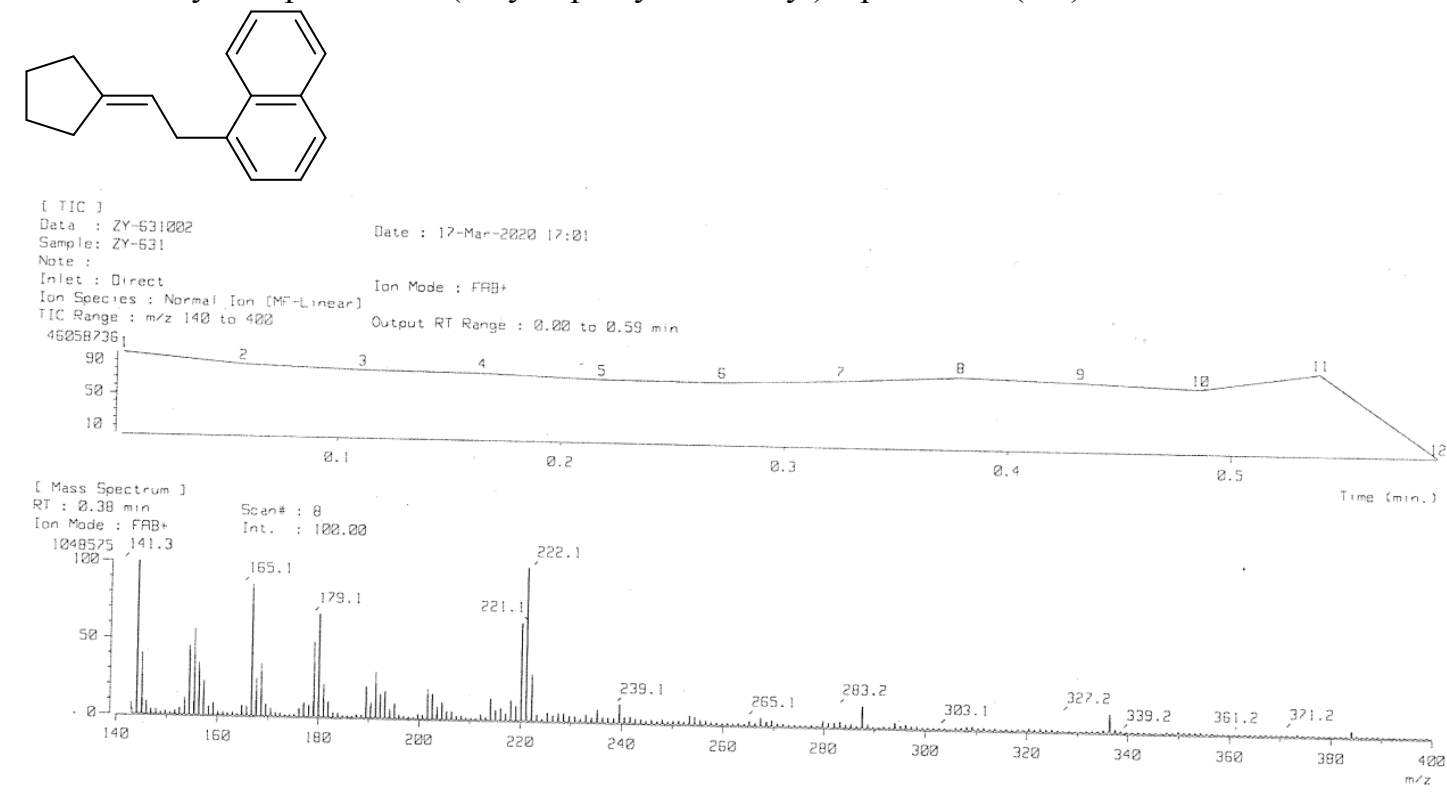

[ Theoretical Ion Distribution ]

Molecular Formula : C17

Page: 1

Base Peak : 222.1409 222.1409, MW 222.3299, U.S. 9.0)

$\mathrm{m} / \mathrm{z} \quad$ INT.

222.1409100 .0000

$\begin{array}{rr}223.1442 & 19.1780 \\ 224.1476 & 1.7338\end{array}$

225.15110 .0982

$226.1545 \quad 0.0039$

227.15790 .0001

[ Elemental Composition ]

Data : ZY-631002

Sample: $\mathrm{ZY}-631$

Note :

Inlet : Direct

$\mathrm{RT}: 0.38 \mathrm{~min}$

Elements : C 17/17, H 18/18

Mass Tolerance : $100 \mathrm{mmu}$

Unsaturation (U.S.) : $-5.0-30.0$

Observed m/z Int\% Err [ppm / mmu U.S. Composition
222.1402
30.5
$-2.9 /-0.7$
9.0 C 17 H 18 
HRMS analysis reports for decylidenecyclopentane (3aj)

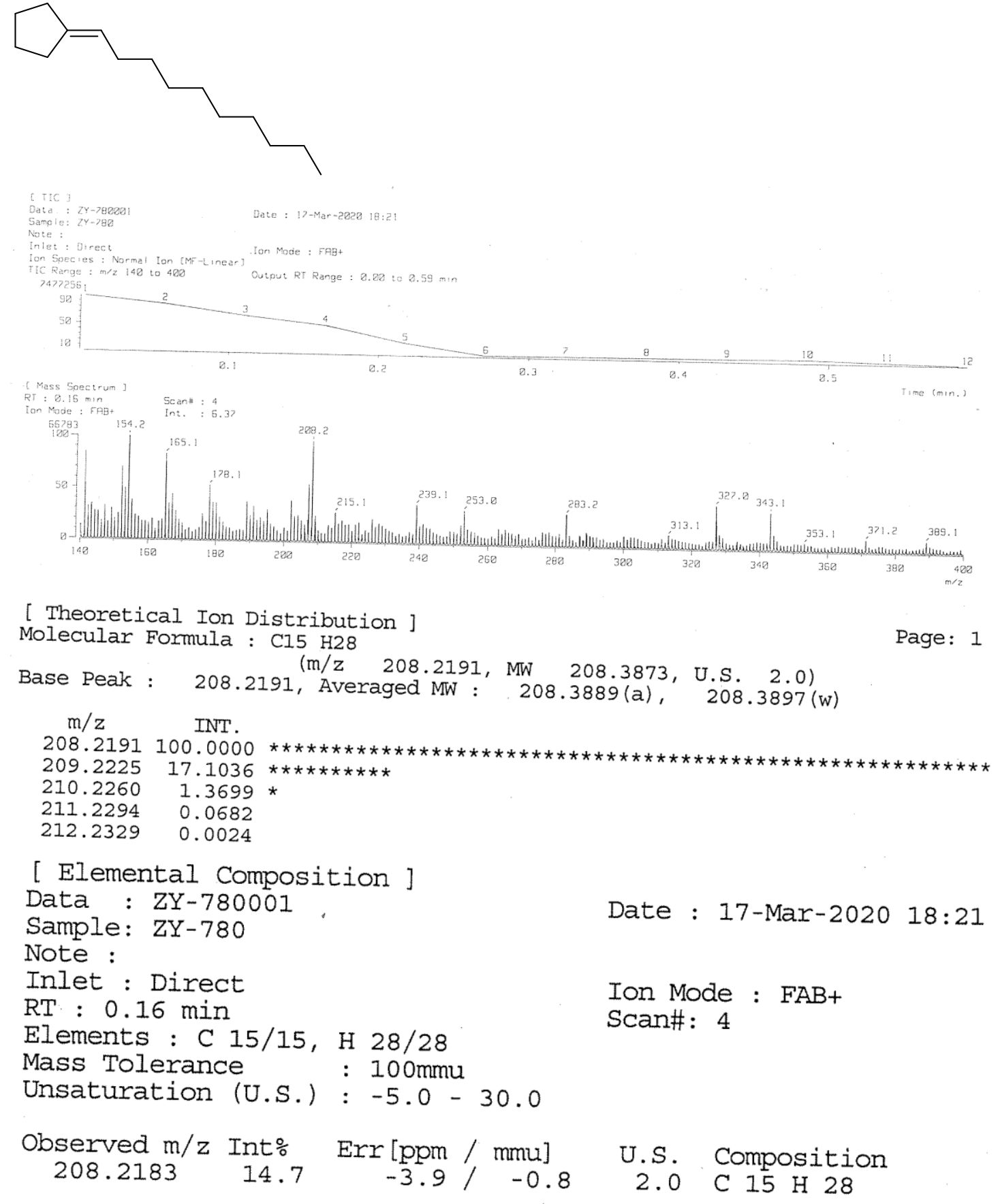


HRMS analysis reports for (2-methylpentylidene)cyclopentane (3ak)

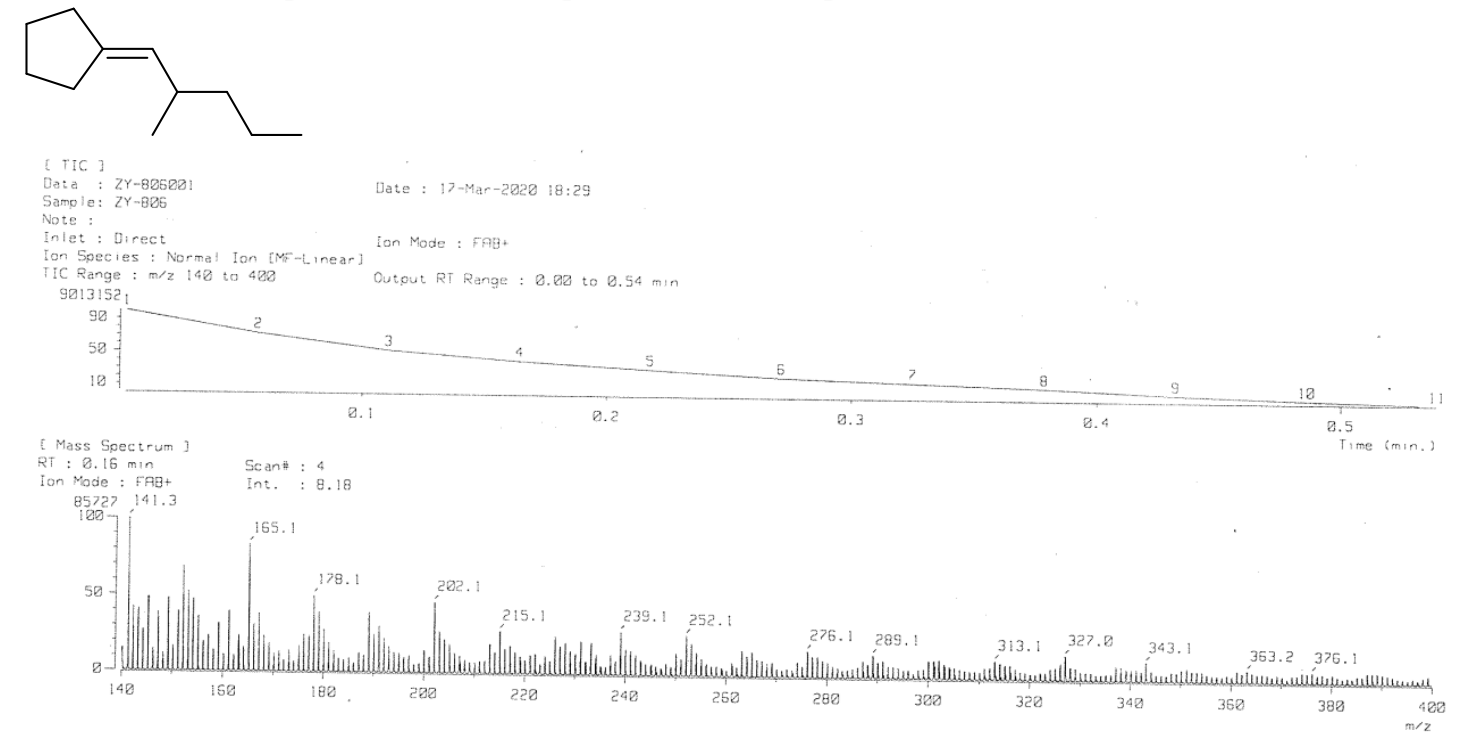

[ Theoretical Ion Distribution ]

Molecular Formula : C11 H2O

Page: 1

Base Peak : $\quad 152 . \mathrm{m} / \mathrm{z}$ 152.1565, MW 152.2798, U.S. 2.0)

$\mathrm{m} / \mathrm{z} \quad$ INT.

152.1565100 .0000

$\begin{array}{rr}153.1599 & 12.5346 \\ 154.1634 & 0.7175\end{array}$

$155.1668 \quad 0.0248$

$156.1703 \cdot 0.0006$

[ Elemental Composition]

Data : ZY-806001

Sample: ZY-806

Date : 17-Mar-2020 18:29

Note :

Inlet : Direct

RT : $0.16 \mathrm{~min}$

Elements : C 11/11, H 20/20

Ion Mode : FAB+

Mass Tolerance : $100 \mathrm{mmu}$

Unsaturation (U.S.) : $-5.0-30.0$

Observed m/z Int\% Err [ppm / mmu U.S. Composition

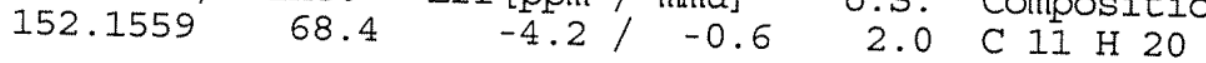


HRMS analysis reports for (cyclopentylidenemethyl)cyclohexane (3al)

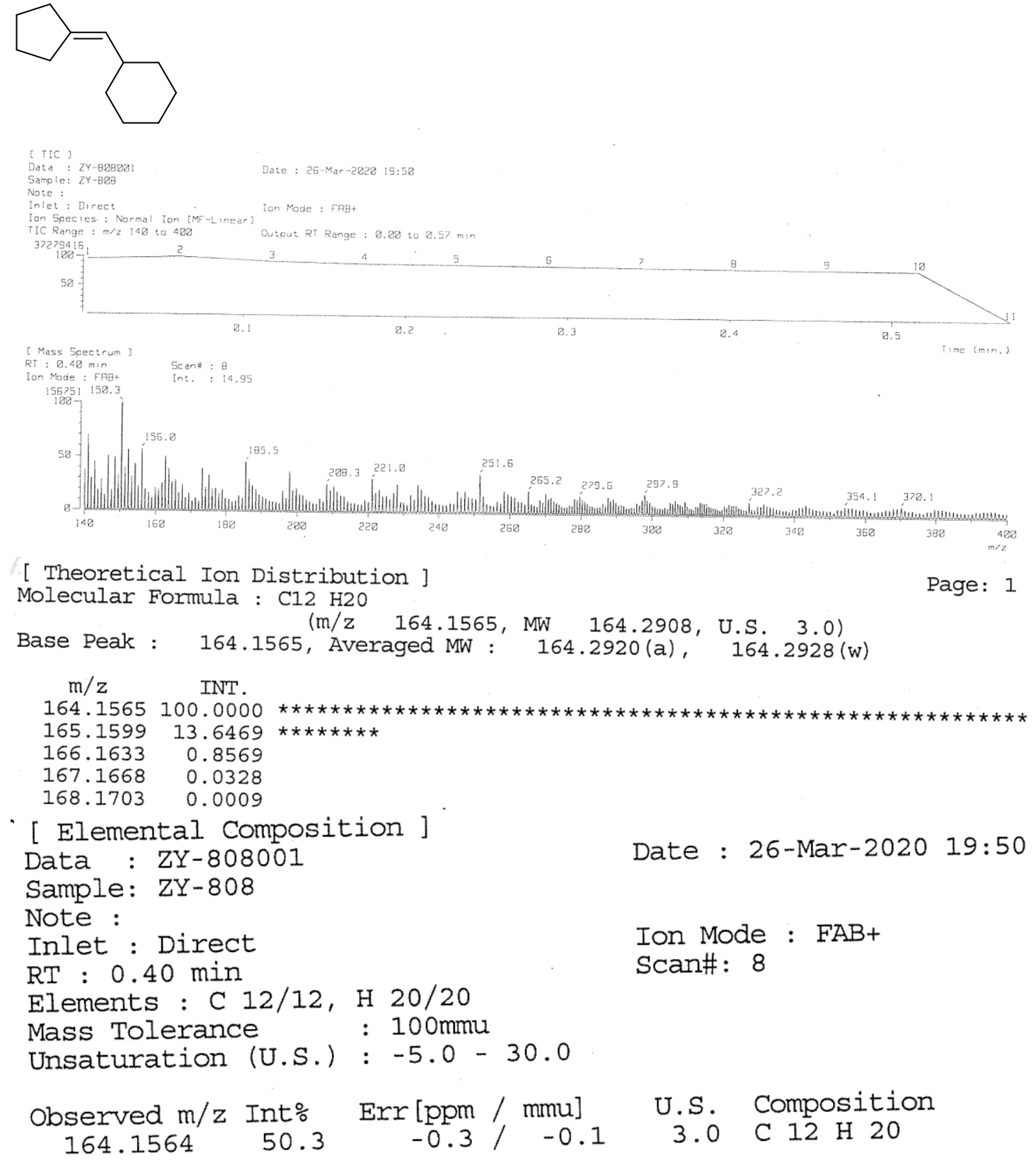


HRMS analysis reports for ((2-cyclopentylideneethoxy)methyl)benzene (3an)

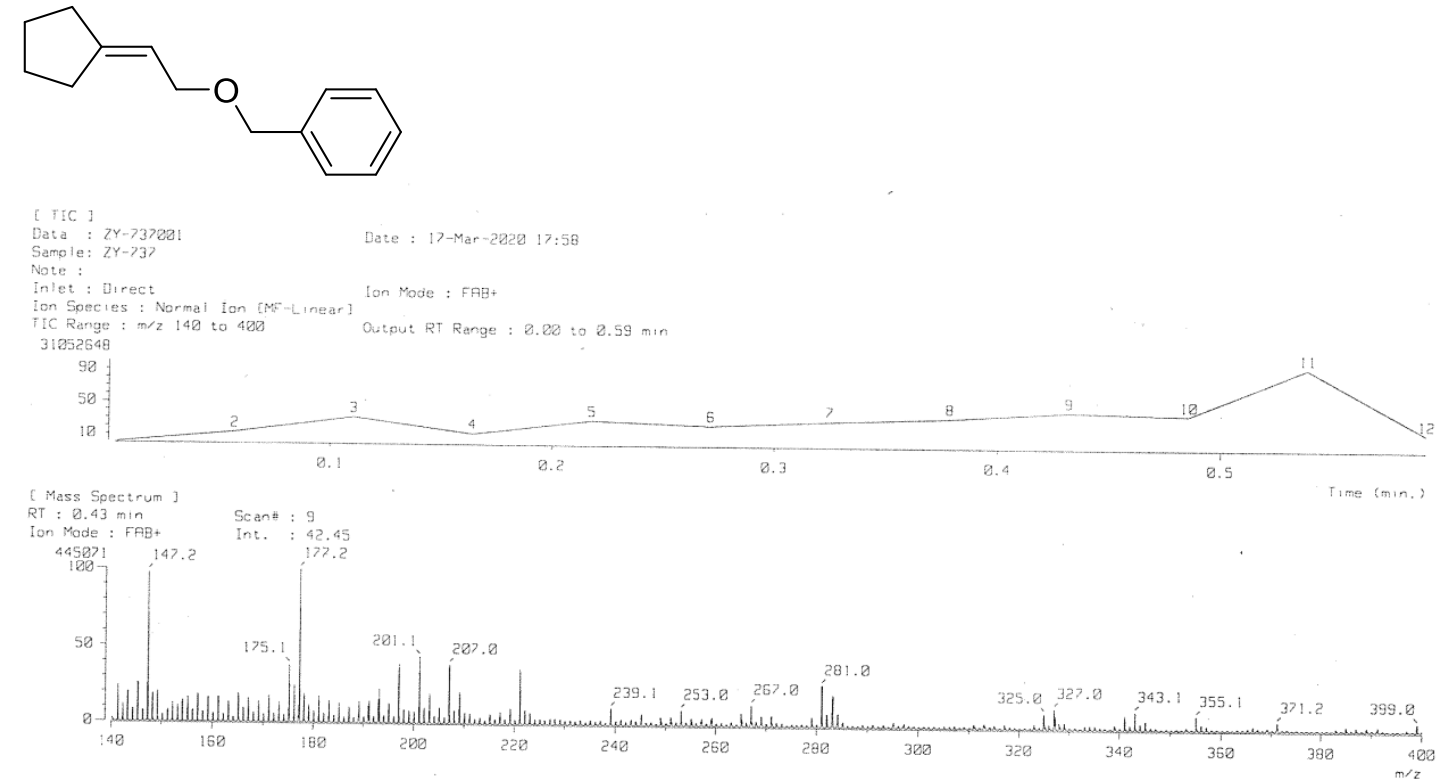

[ Theoretical Ion Distribution ]

Molecular Formula : $\mathrm{C} 14 \mathrm{H} 18 \mathrm{O}$

Page: 1

Base Peak : $\quad 202.1358$ (m/z 202.1358, MW 202.2963, U.S. 6.0)

\begin{tabular}{cr}
$\mathrm{m} / \mathrm{z}$ & \multicolumn{1}{c}{ INT. } \\
202.1358 & 100.0000 \\
203.1392 & 15.8794 \\
204.1422 & 1.3746 \\
205.1450 & 0.0854 \\
206.1479 & 0.0040 \\
207.1510 & 0.0001
\end{tabular}

[ Elemental Composition]

Data : ZY-737001

Sample: ZY-737

Date : 17-Mar-2020 17:58

Note :

Inlet : Direct

$\mathrm{RT}: 0.43 \mathrm{~min}$

Elements : C 14/14, H 18/18, O 1/1

Ion Mode : FAB+

Mass Tolerance : $100 \mathrm{mmu}$

Unsaturation (U.S.) : $-5.0-30.0$

Observed $\mathrm{m} / \mathrm{z}$ Int\% Err [ppm / mmu U.S. Composition

$\begin{array}{lllllllll}202.1352 & 10.4 & -2.7 & -0.5 & 6.0 & \text { C } 14 \text { H } 18 & 0\end{array}$ 
HRMS analysis reports for $N, N$-dibenzyl-2-cyclopentylideneethan-1-amine (3ao)

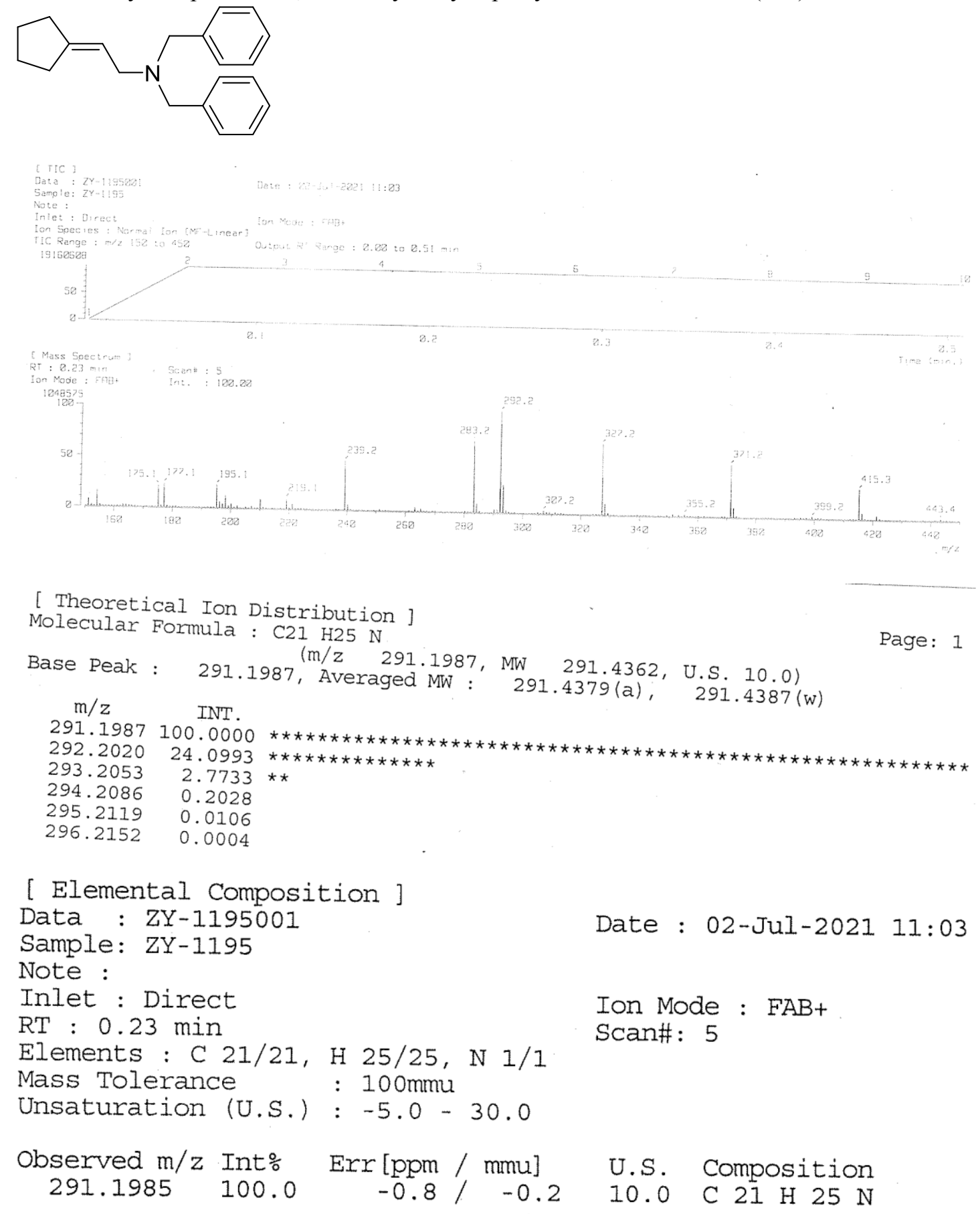


HRMS analysis reports for 2-(2-cyclopentylideneethyl)furan (3aq)

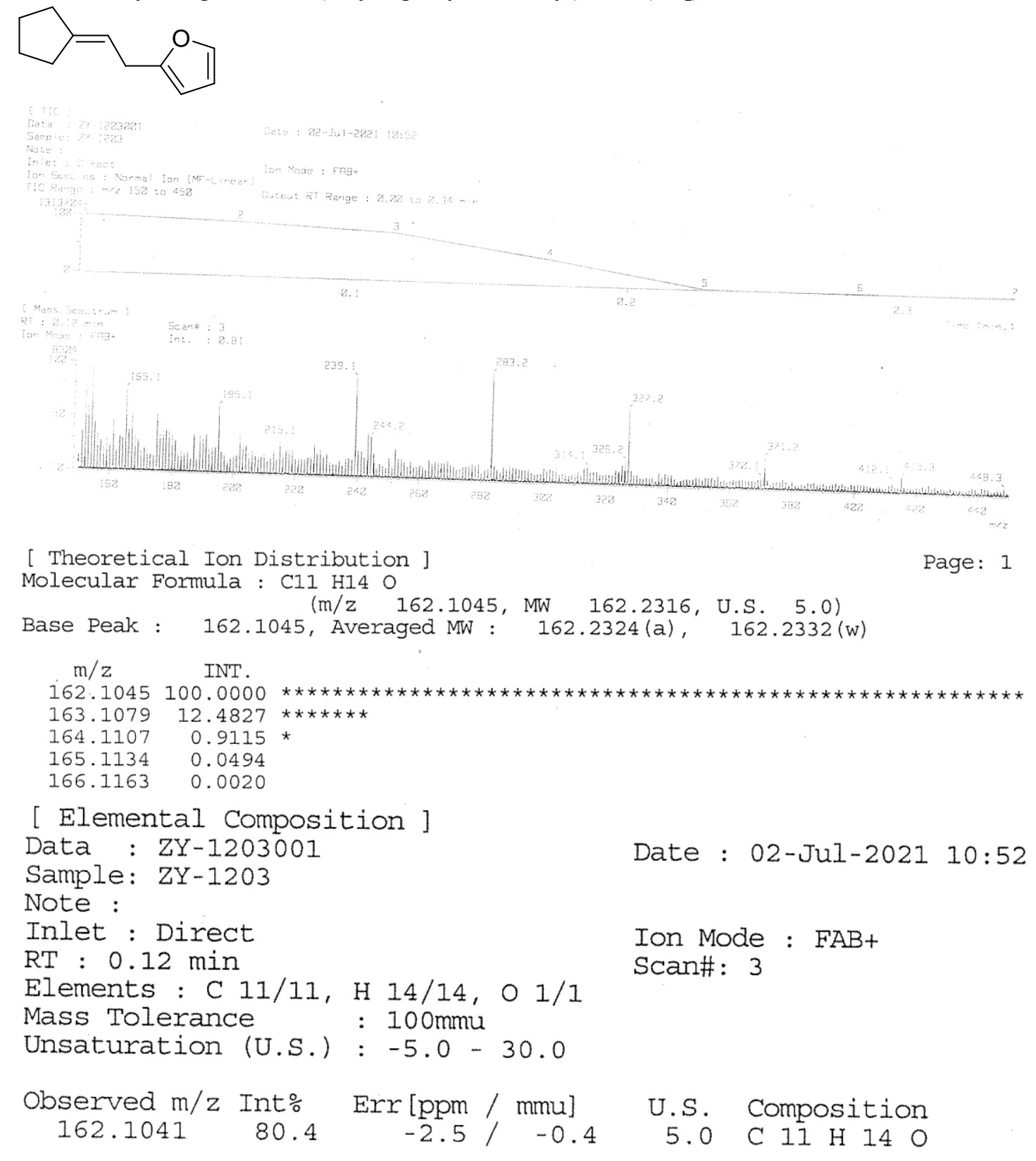


HRMS analysis reports for 2-(2-cyclopentylideneethyl)thiophene (3ar)

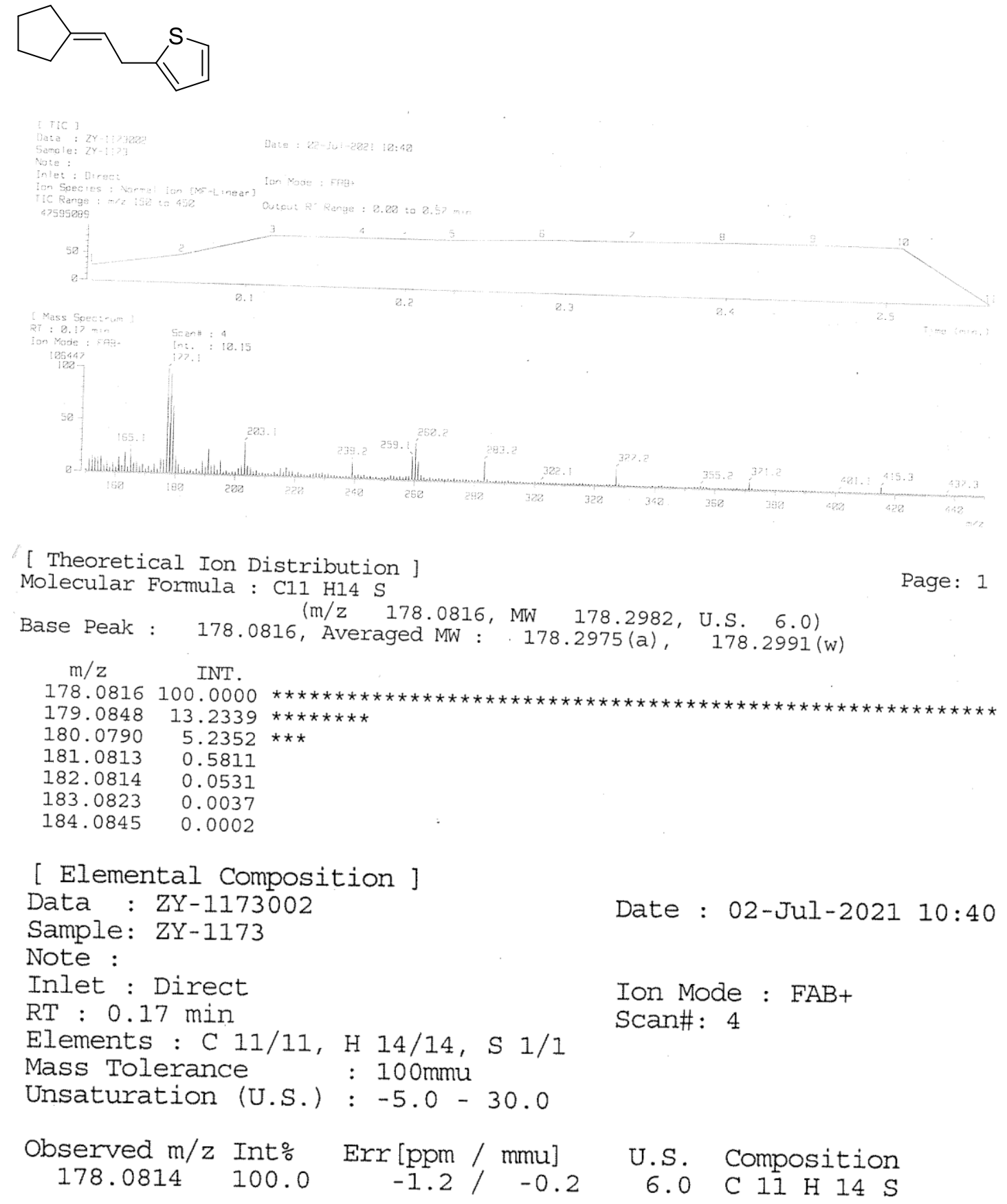


HRMS analysis reports for (2-cyclopentylidenepropyl)benzene (3ba)

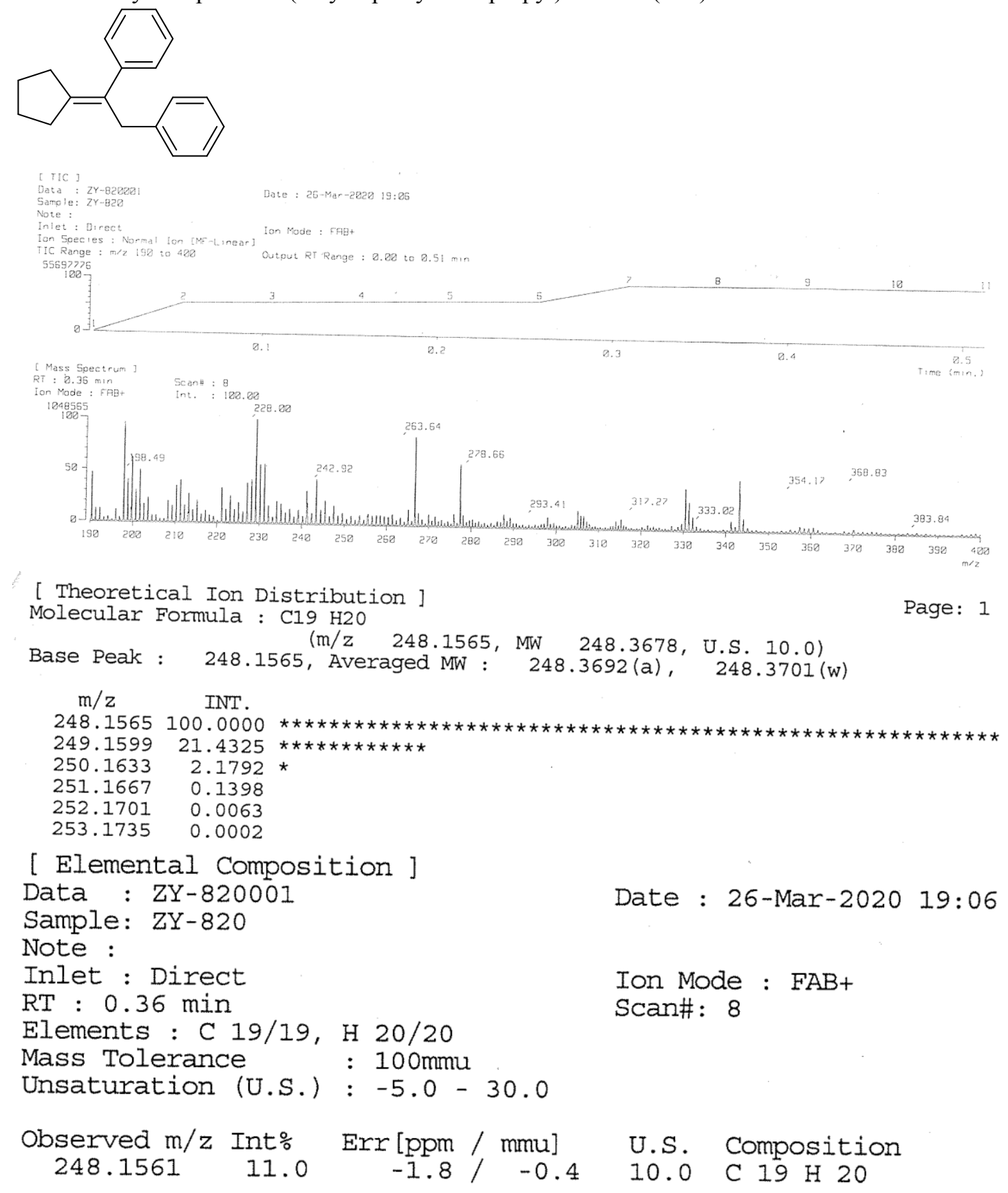


HRMS analysis reports for (2-cyclopentylidenepropyl)benzene (3ca)

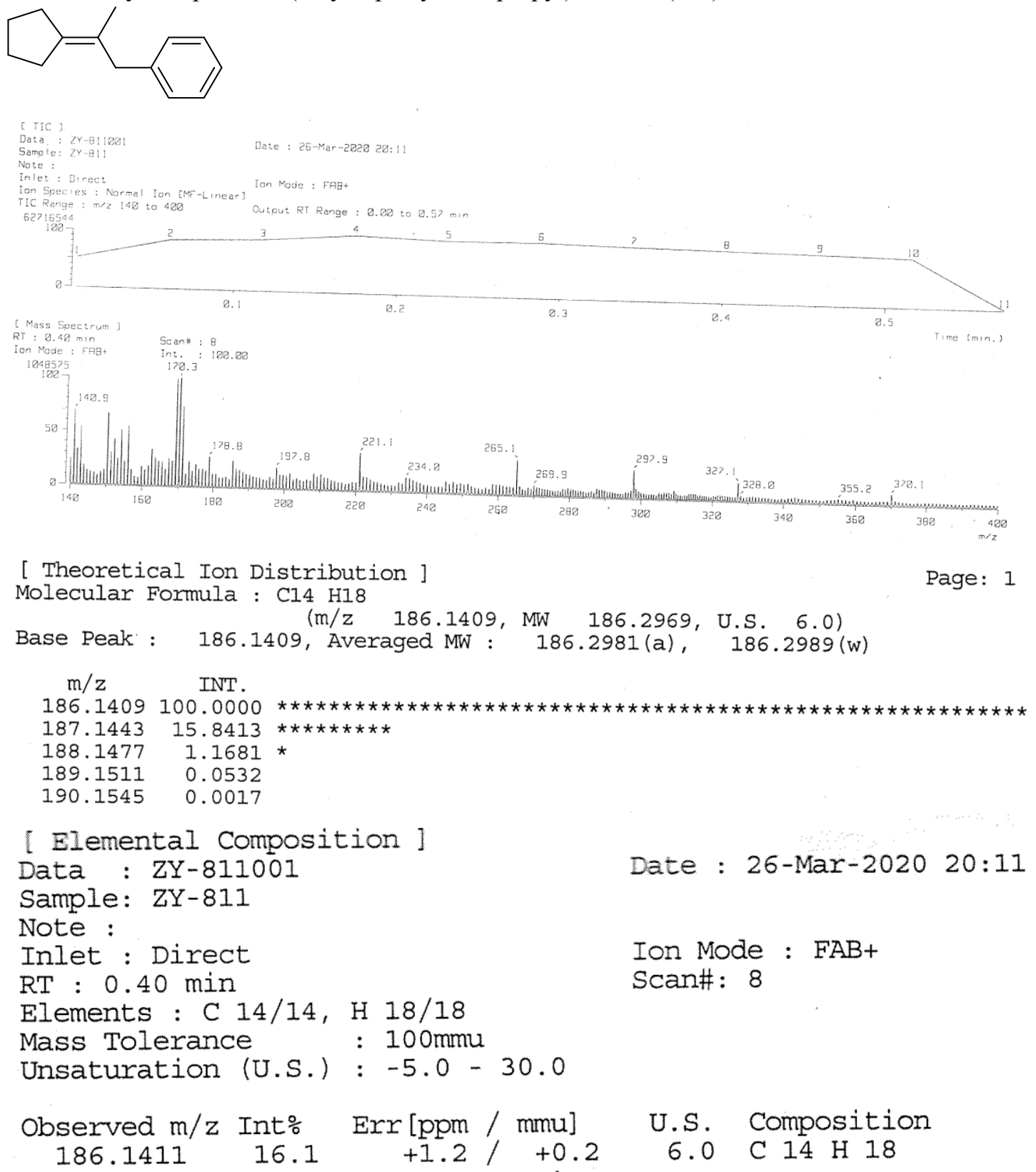




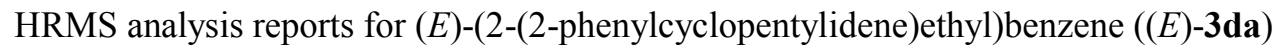

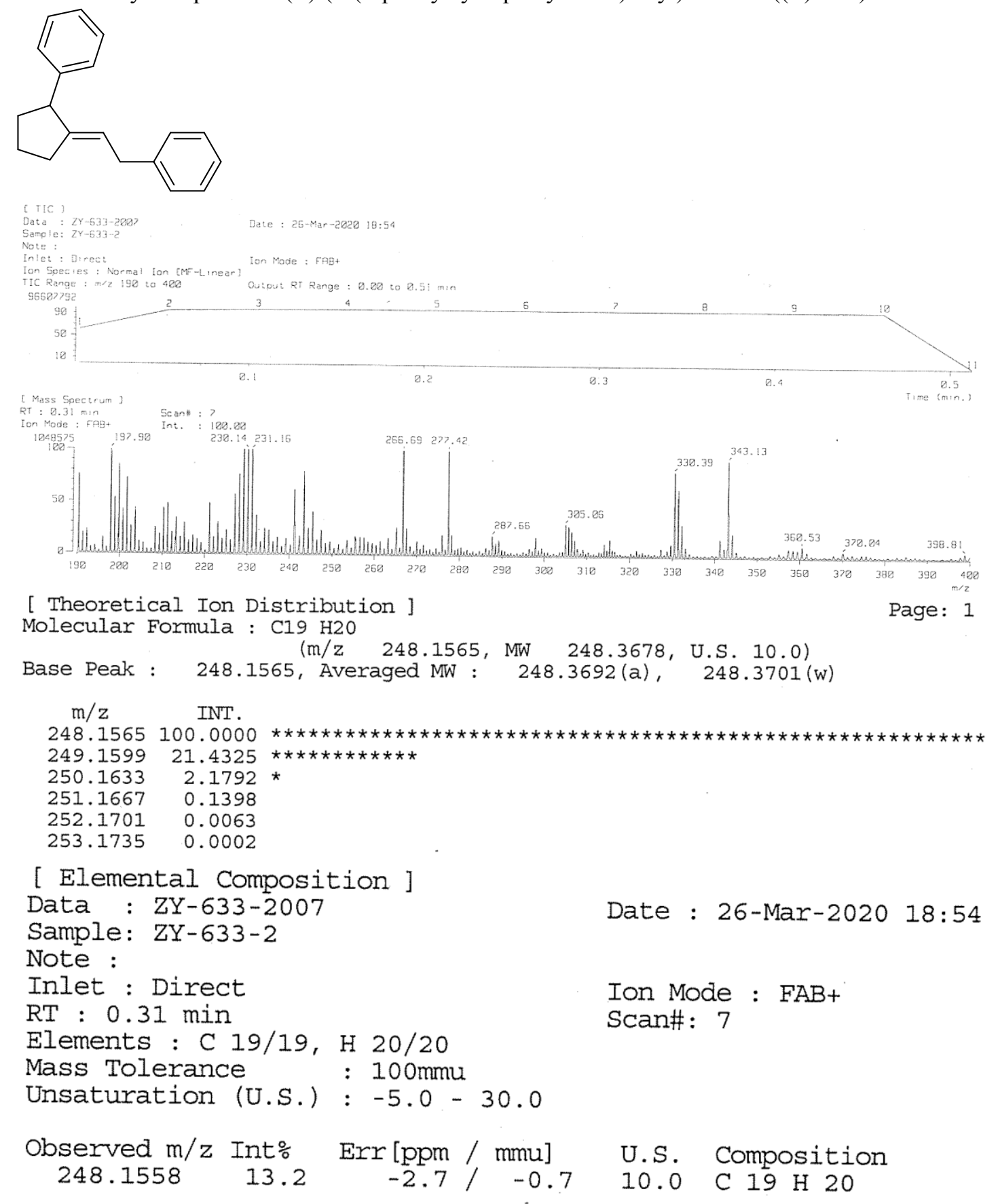


HRMS analysis reports for (Z)-(2-(2-phenylcyclopentylidene)ethyl)benzene ((Z)-3da)

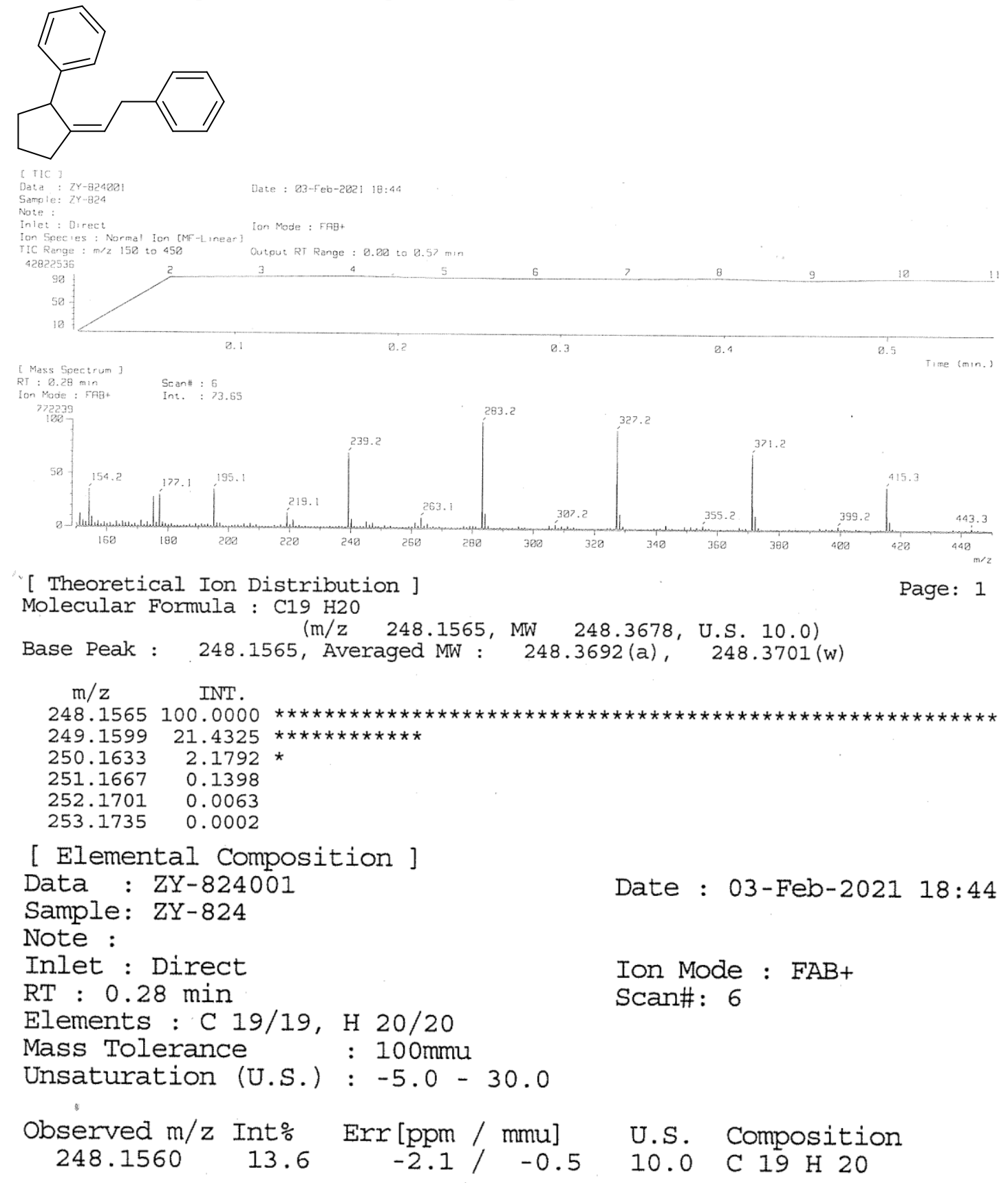


HRMS analysis reports for a mixture of (E)-(2-(2-ethylcyclopentylidene)ethyl)benzene ((E)-3ea) $\&(Z)-3$ ea

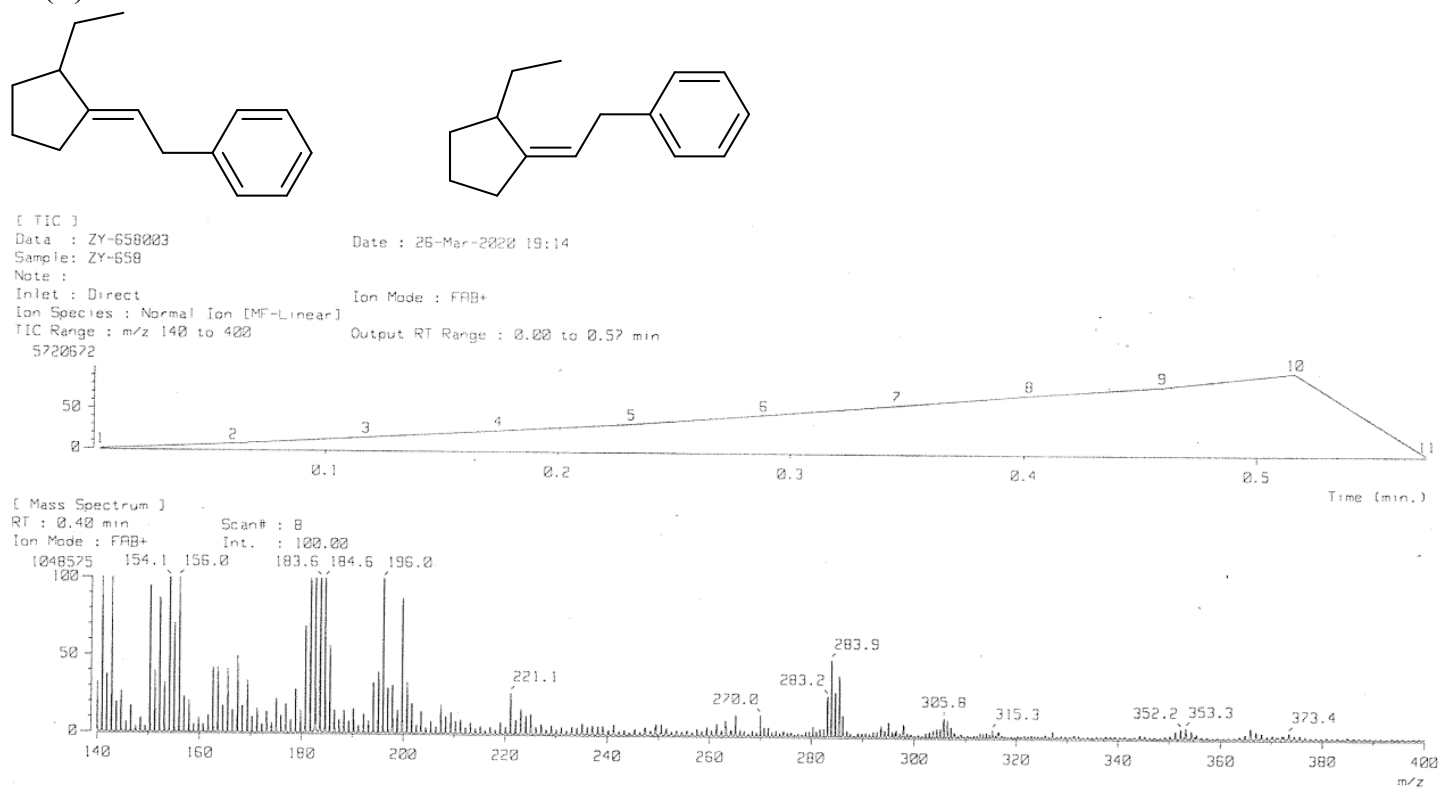

[ Theoretical Ion Distribution ]

Molecular Formula : C15 $\mathrm{H} 20$

Base Peak : 200.1565 (m/z 200.1565, MW 200.3238, U.S. 6.0)

$\mathrm{m} / \mathrm{z} \quad$ INT.

200.1565100 .0000

$201.159916 .9836 * * * * * * * * * *$

$202.16331 .3494 *$

$203.1667 \quad 0.0666$

$204.1702 \quad 0.0023$

[ Elemental Composition ]

Data : ZY-658003

Sample: ZY-658

Note :

Inlet : Direct

RT : $0.40 \mathrm{~min}$

Elements : C 15/15, H 20/20

Date : 26-Mar-2020 19:14

Mass Tolerance : 100mmu

Unsaturation (U.S.) : $-5.0-30.0$

$\begin{array}{ccc}\text { Observed m/z Int\% Err [ppm / mmu } \\ 200.1572 & 33.6 & \text { U.S. Composition }\end{array}$ $200.1572 \quad 33.6+3.5 /+0.7 \quad 6.0$ C 15 H 20 
HRMS analysis reports for a mixture of (E)-(2-(2-butylcyclopentylidene)ethyl)benzene ((E)-3fa) $\&(Z)-3 \mathbf{3 a}$

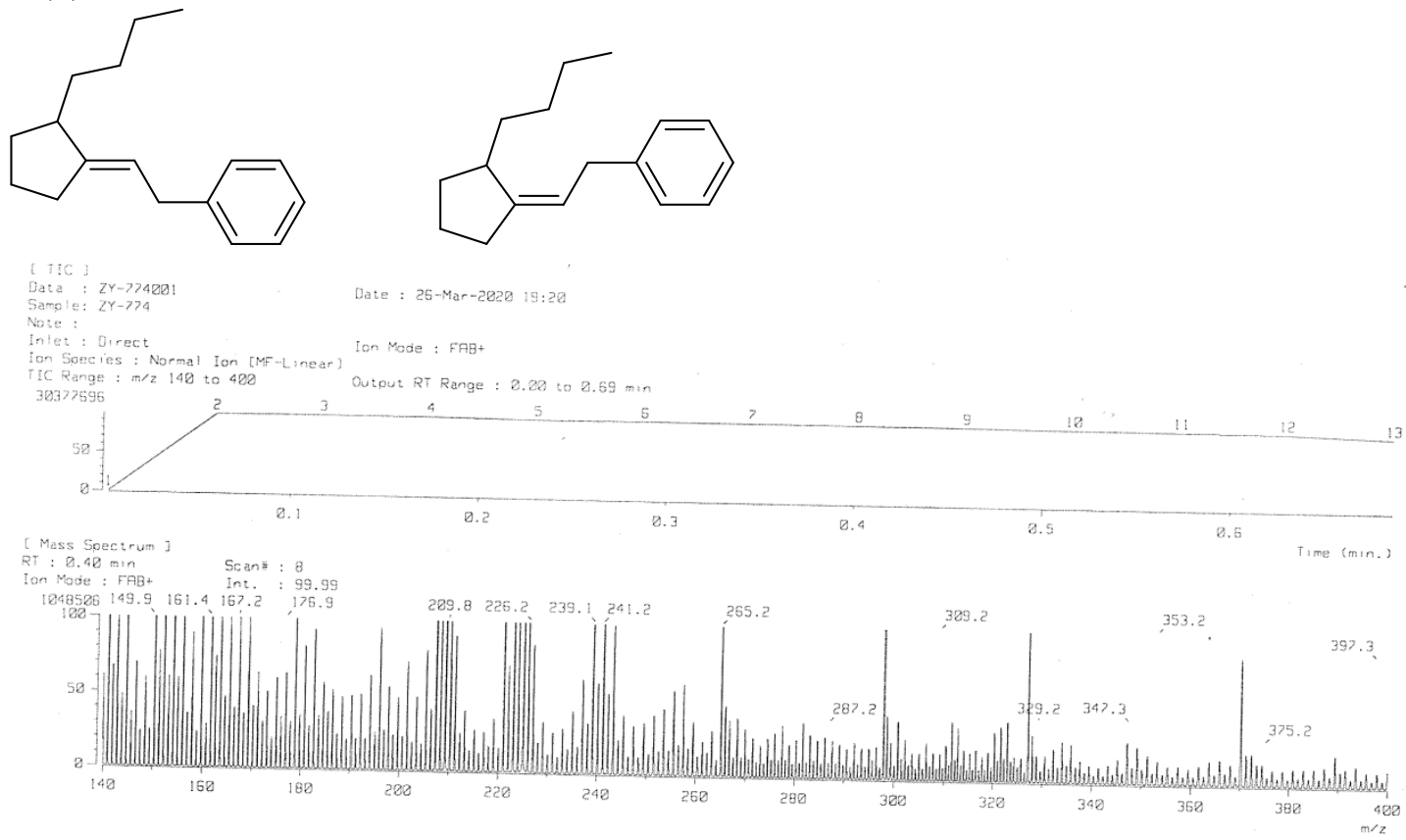

[ Theoretical Ion Distribution ]

Molecular Formula : C17 H24

Page: 1

Base Peak : 228.1878 (m/z 228.1878, MW 228.3776, U.S. 6.0)

$\mathrm{m} / \mathrm{z}$ INT.

228.1878100 .0000

$229.191219 .2680 * * * * * * * * * * *$

$230.1946 \quad 1.7511 *$

$231.1980 \quad 0.0997$

$232.2015 \quad 0.0040$

$233.2049 \quad 0.0001$

[ Elemental Composition]

Data : ZY-774001

Sample: ZY-774

Date : 26-Mar-2020 19:20

Note :

Inlet : Direct

RT : $0.40 \mathrm{~min}$

Elements : C 17/17, H 24/24

Ion Mode : FAB+

Mass Tolerance : 100mmu

Unsaturation (U.S.) : $-5.0-30.0$

Observed m/z Int\% Err [ppm / mmu
228.1882 U.S. Composition $\begin{array}{llllll}228.1882 & 20.1+1.8 / & +0.4 & 6.0 & \text { C } 17 \text { H } 24\end{array}$ 
HRMS analysis reports for a mixture of (E)-(2-(2-heptylcyclopentylidene)ethyl)benzene ((E)-3ga) \& (Z)-3ga

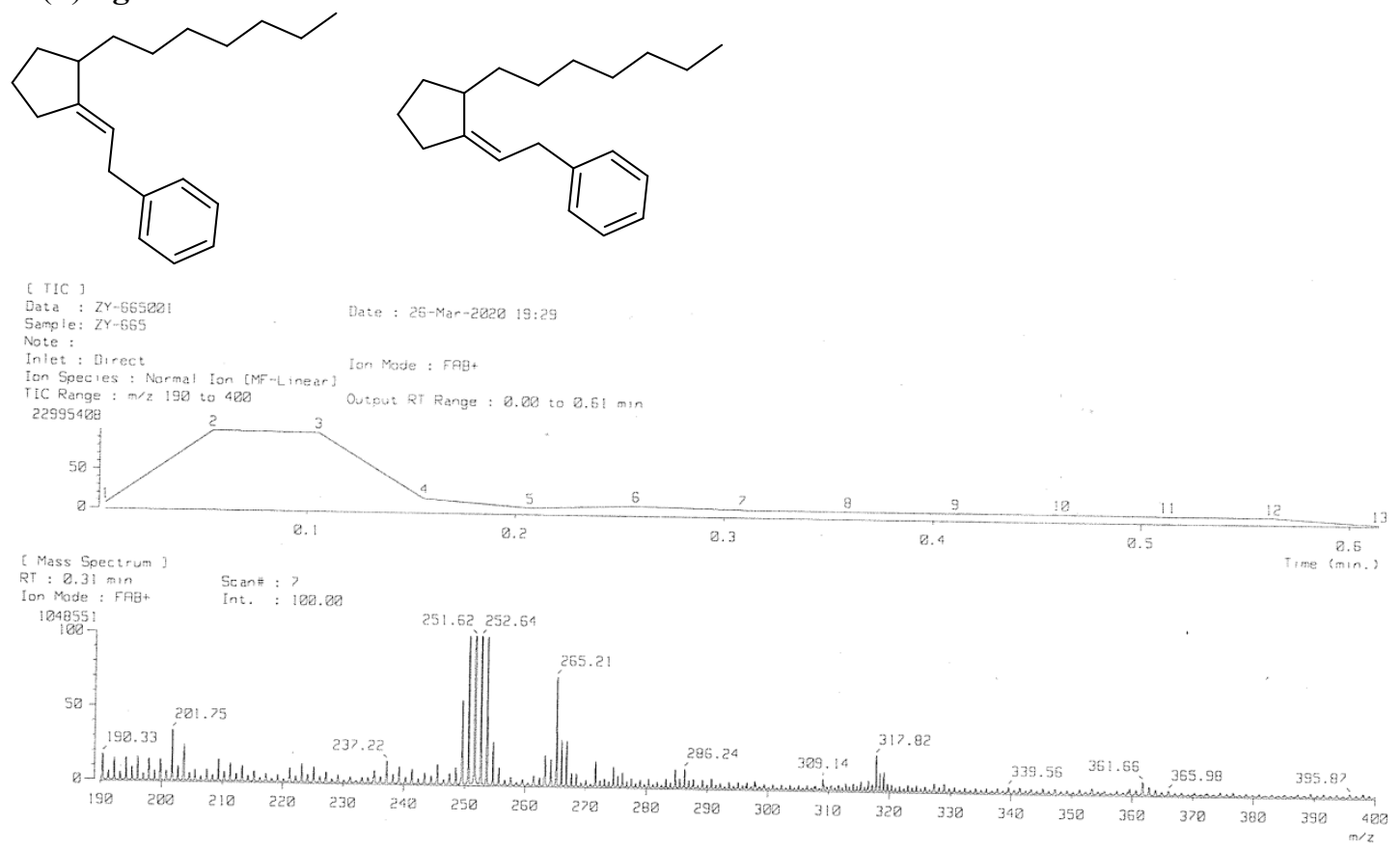

[ Theoretical Ion Distribution ]

Molecular Formula : C20 H30

Page: 1

$(\mathrm{m} / \mathrm{z} 270.2348, \mathrm{MW} 270.4582$, U.S. 6.0)

Base Peak : 270.2348, Averaged MW : $270.4600(\mathrm{a}), 270.4608(\mathrm{w})$

$\mathrm{m} / \mathrm{z}$ INT.

$270.2348100 .0000 *$

271.238222 .6948

272.24162 .4515

$273.2450 \quad 0.1677$

$274.2484 \quad 0.0081$

$275.2519 \quad 0.0003$

[ Elemental Composition ]

Data : ZY-665001

Sample: ZY-665

Note :

Inlet : Direct

$\mathrm{RT}: 0.31 \mathrm{~min}$

Elements : C $20 / 20$, H $30 / 30$

Date : 26-Mar-2020 19:29

Mass Tolerance

: $100 \mathrm{mmu}$

Unsaturation (U.S.) : $-5.0-30.0$

Observed m/z Int\% Err [ppm / mmu] U.S. Composition

$\begin{array}{llll}270.2338 & 30.6 & -3.5 / & -1 .\end{array}$

Ion Mode : $\mathrm{FAB}+$

Scan\#: 7

6.0 C $20 \mathrm{H} 30$ 
HRMS analysis reports for a mixture of $(E)$-(2-(2-cyclohexylcyclopentylidene)ethyl)benzene ((E)-3ha) \& (Z)-3ha
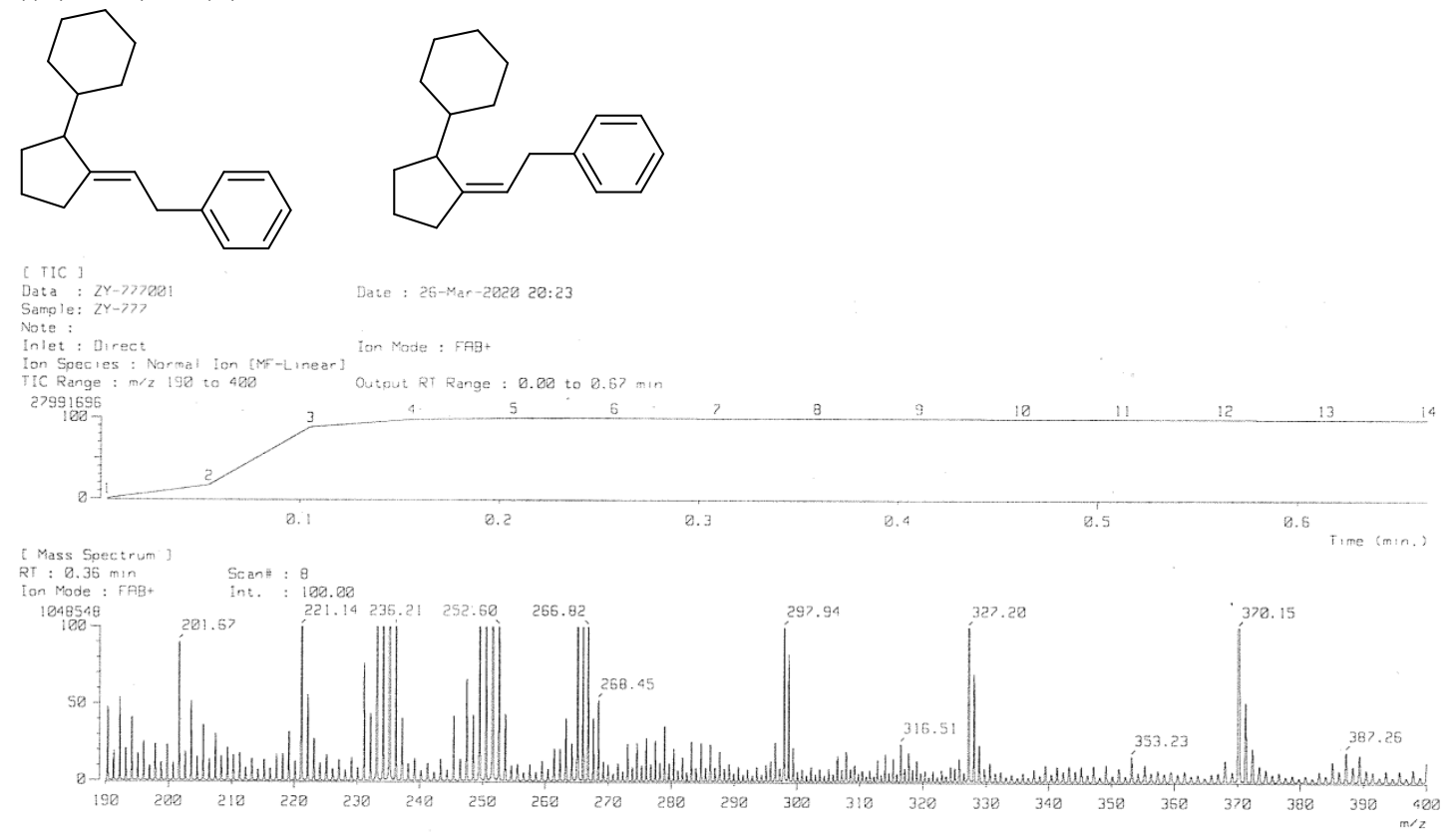

[ Theoretical Ion Distribution ]

Molecular Formula : C19 H26

Page: 1

(m/z 254.2035, MW 254.4154, U.S. 7.0)

Base Peak : 254.2035, Averaged MW : 254.4171(a), 254.4179(w)

$\mathrm{m} / \mathrm{z}$

INT.

$254.2035100 .0000 *$

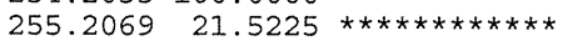

$256.21032 .1985 *$

$257.2137 \quad 0.1417$

258.21710 .0065

$259.2206 \quad 0.0002$

[ Elemental Composition ]

Data : ZY-777001

Sample: ZY-777

Note :

Inlet : Direct

RT : $0.36 \mathrm{~min}$

Elements : C 19/19, H 26/26

Date : 26-Mar-2020 20:23

Mass Tolerance : $100 \mathrm{mmu}$

Unsaturation (U.S.) : $-5.0-30.0$

Observed m/z Int: Err [ppm / mmu] U.S. Composition

$254.2035100 .0+0.3 /+0.1 \quad 7.0$ C 19 H 26


HRMS analysis reports for $(E)-(2-(2,2-$ dimethylcyclopentylidene)ethyl)benzene ((E)-3ia)

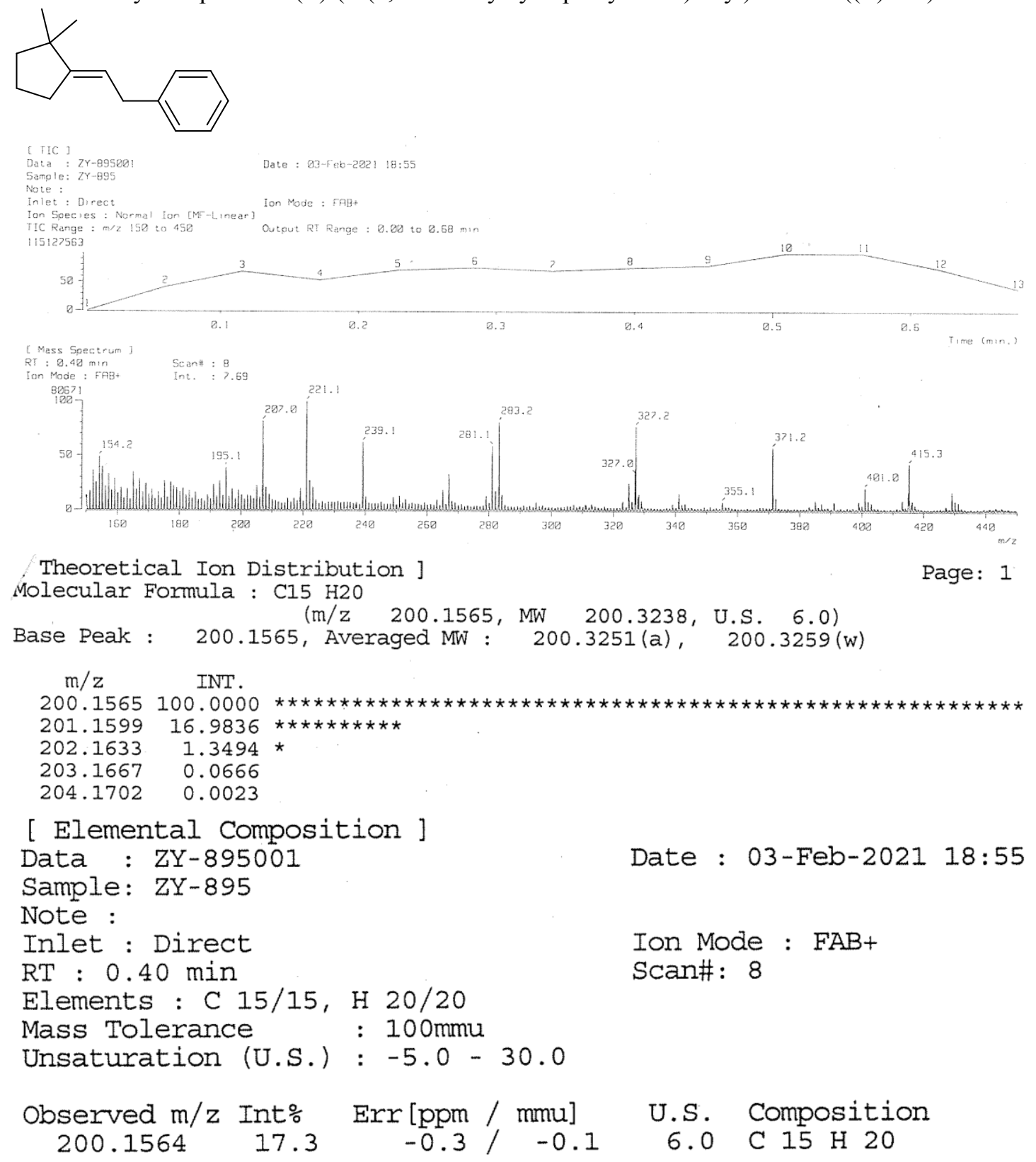


HRMS analysis reports for (E)-1-(2-(2,2-dimethylcyclopentylidene)ethyl)naphthalene ((E)-3ii)

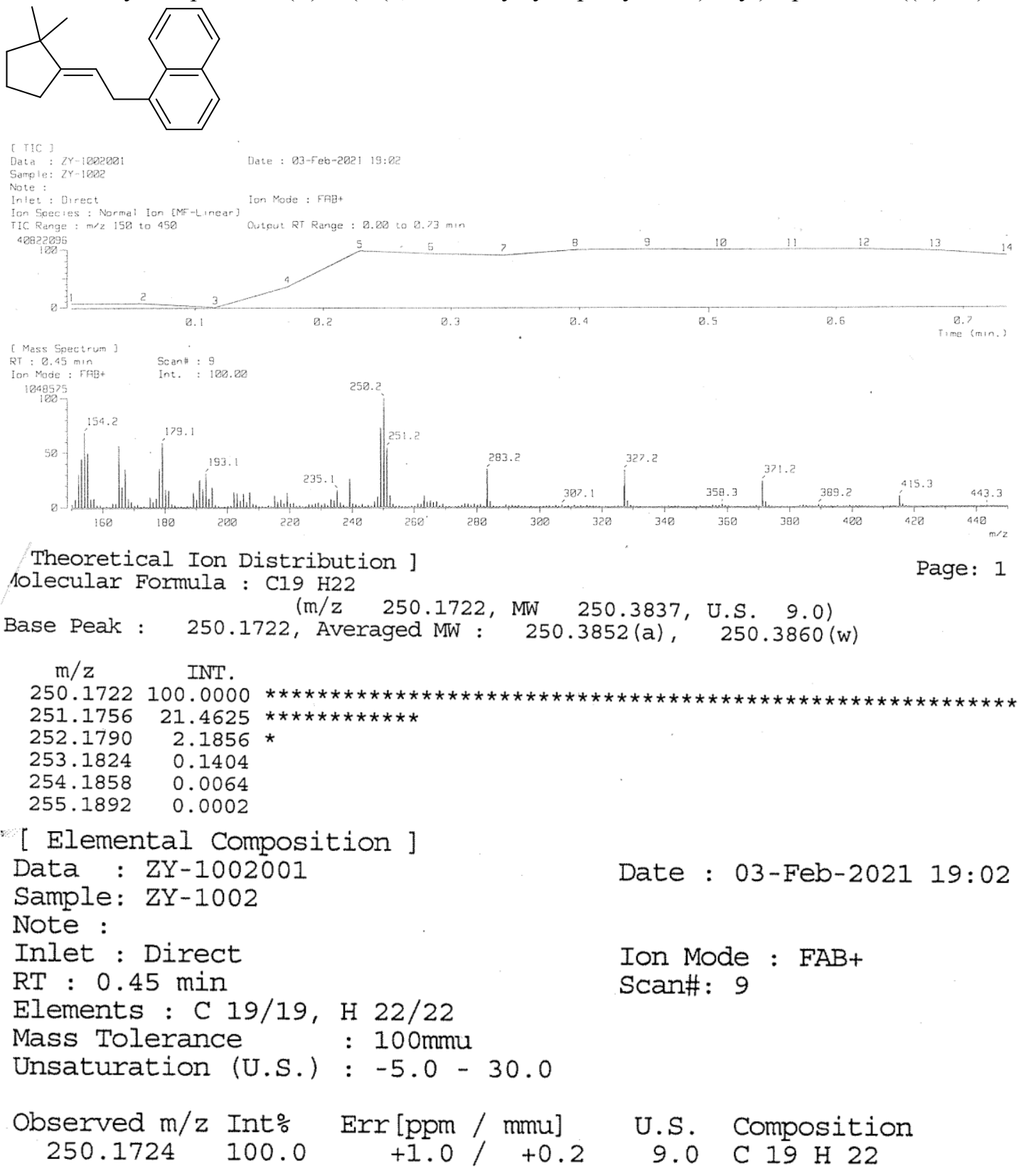


HRMS analysis reports for a mixture of (E)-(2-(2-phenylcyclopentylidene)propyl)benzene $((E)-3 \mathbf{j a}) \&(Z)-3 \mathbf{j a}$

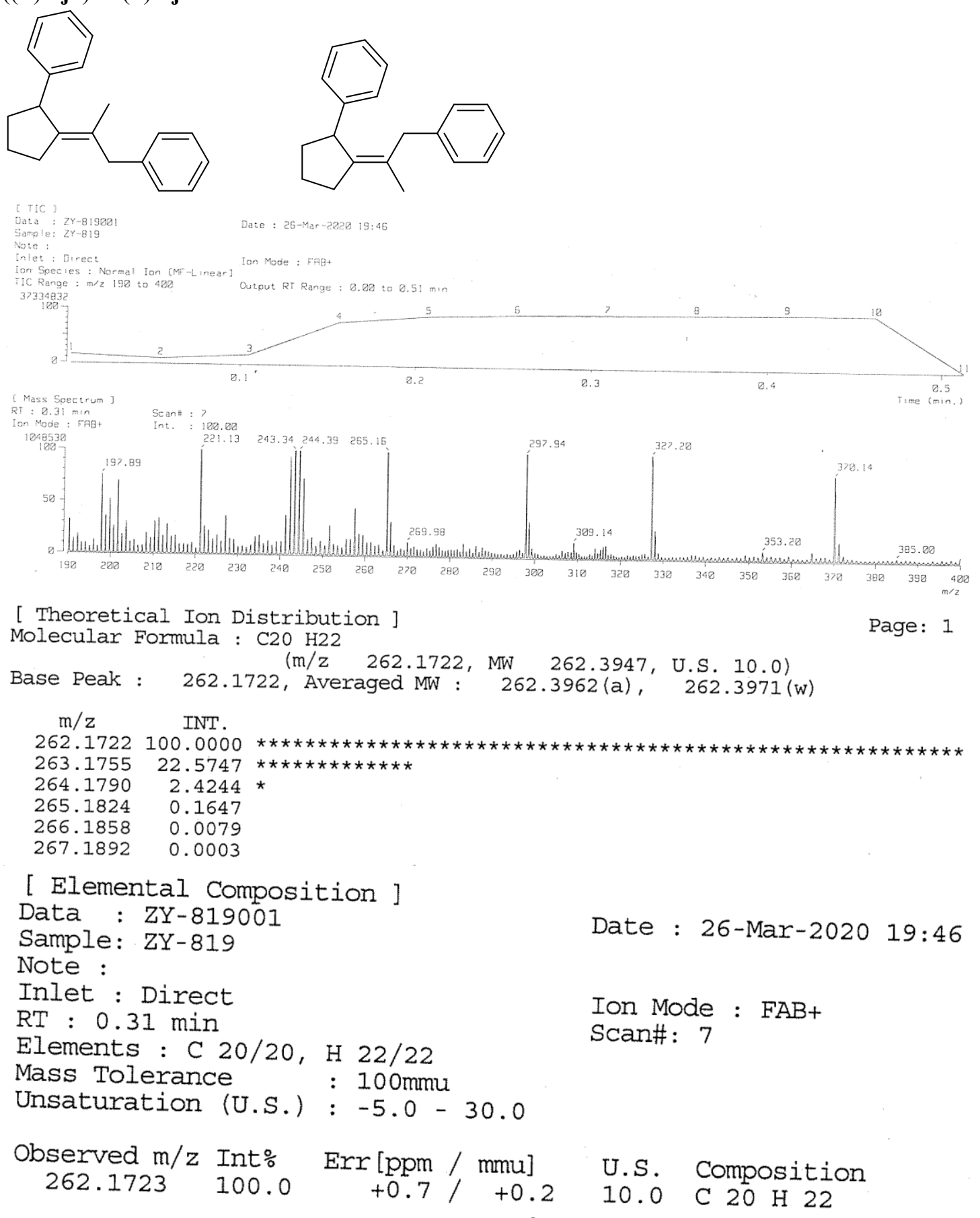


HRMS analysis reports for dimethyl 2-(3-iodopropyl)-2-(prop-2-yn-1-yl)malonate (4b).

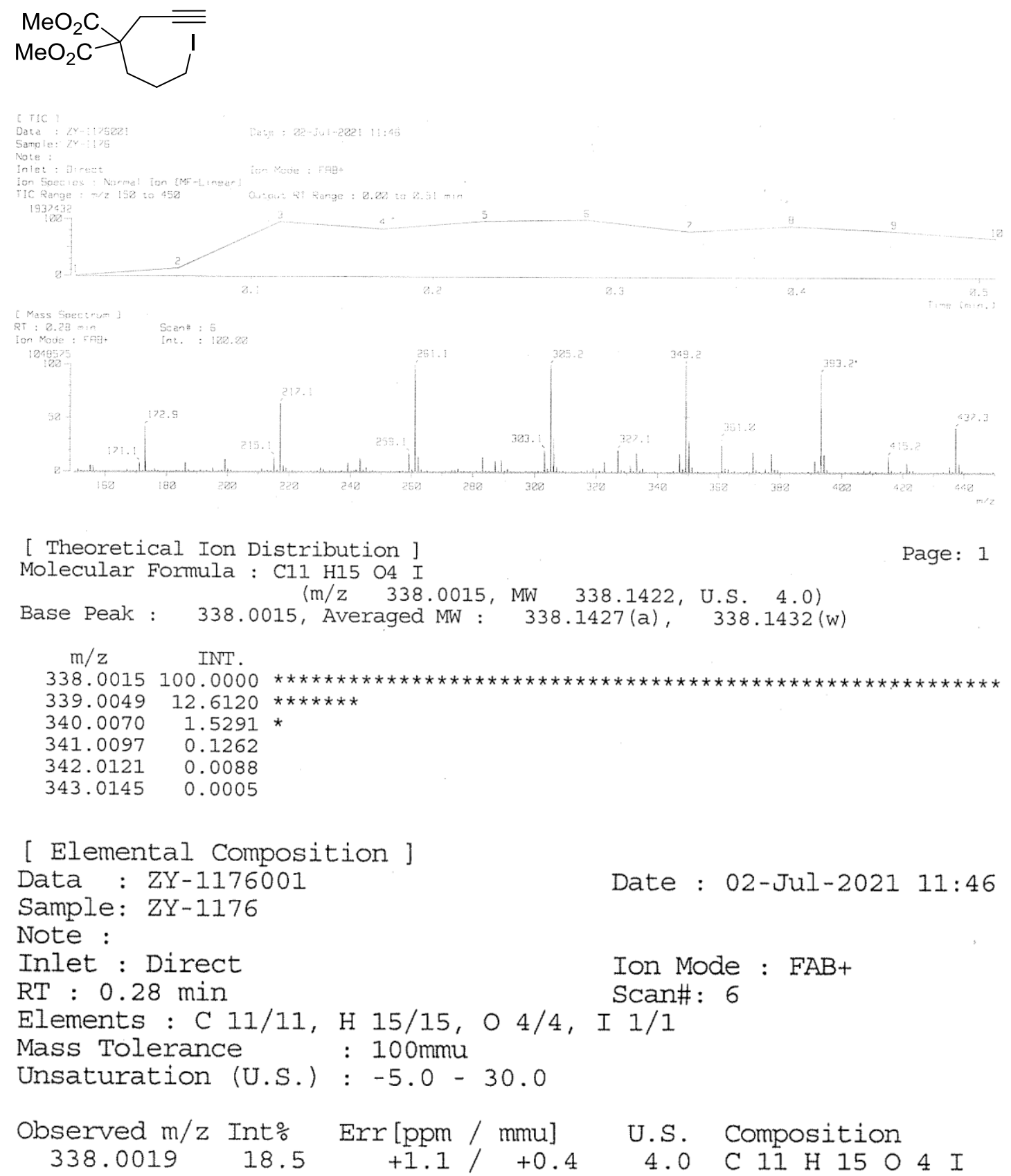


HRMS analysis reports for $(E)$-(2-(iodomethylene)cyclopentyl)benzene ((E)-7d)

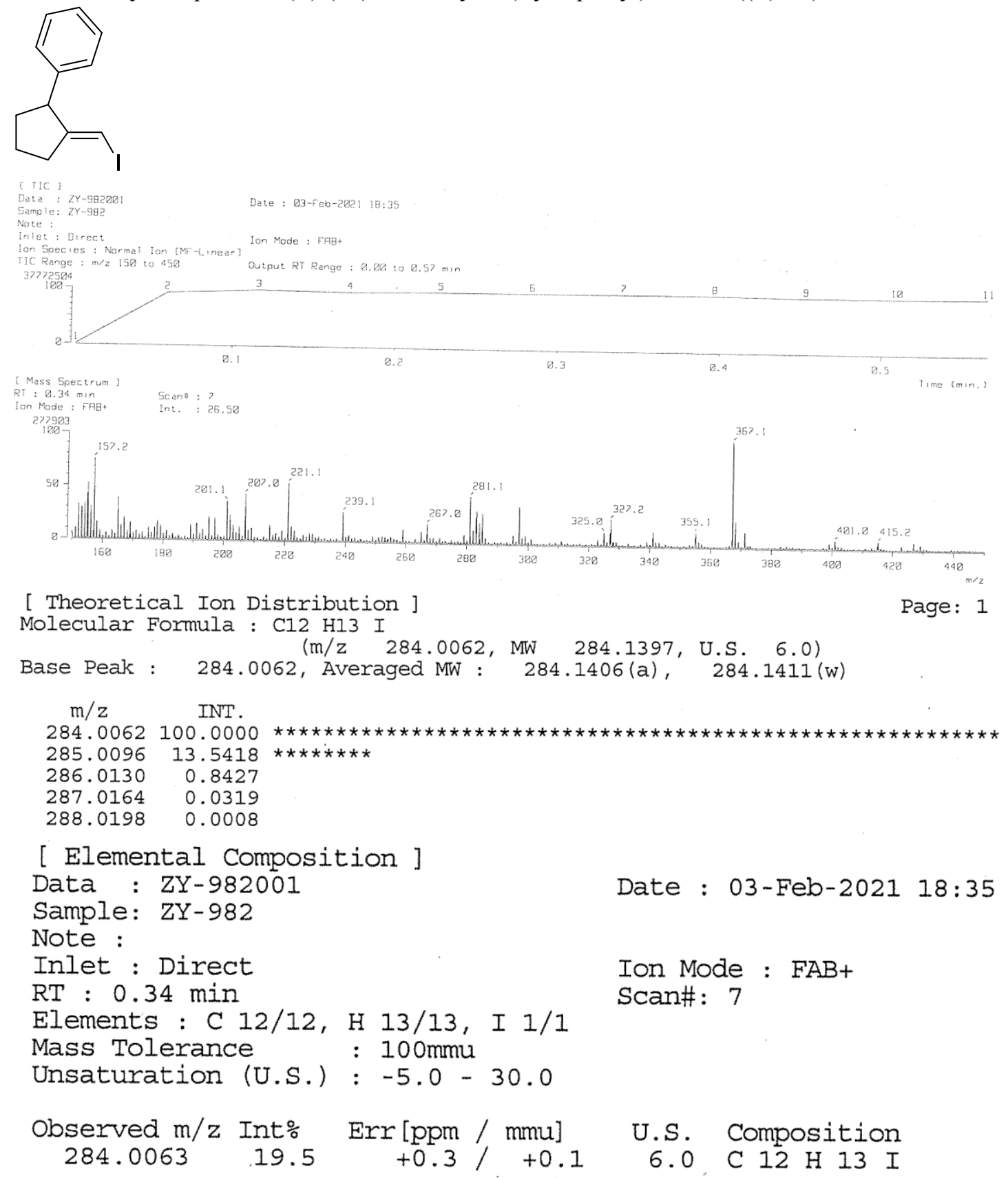

